\title{
Onset, course and comorbidity of bipolar symptoms in population and treatment settings
}

Citation for published version (APA):

van Rossum, I. (2010). Onset, course and comorbidity of bipolar symptoms in population and treatment settings. [Doctoral Thesis, Maastricht University]. Datawyse / Universitaire Pers Maastricht. https://doi.org/10.26481/dis.20100114ir

Document status and date:

Published: 01/01/2010

DOI:

10.26481/dis.20100114ir

Document Version:

Publisher's PDF, also known as Version of record

\section{Please check the document version of this publication:}

- A submitted manuscript is the version of the article upon submission and before peer-review. There can be important differences between the submitted version and the official published version of record.

People interested in the research are advised to contact the author for the final version of the publication, or visit the DOI to the publisher's website.

- The final author version and the galley proof are versions of the publication after peer review.

- The final published version features the final layout of the paper including the volume, issue and page numbers.

Link to publication

\footnotetext{
General rights rights.

- You may freely distribute the URL identifying the publication in the public portal. please follow below link for the End User Agreement:

www.umlib.nl/taverne-license

Take down policy

If you believe that this document breaches copyright please contact us at:

repository@maastrichtuniversity.nl

providing details and we will investigate your claim.
}

Copyright and moral rights for the publications made accessible in the public portal are retained by the authors and/or other copyright owners and it is a condition of accessing publications that users recognise and abide by the legal requirements associated with these

- Users may download and print one copy of any publication from the public portal for the purpose of private study or research.

- You may not further distribute the material or use it for any profit-making activity or commercial gain

If the publication is distributed under the terms of Article $25 \mathrm{fa}$ of the Dutch Copyright Act, indicated by the "Taverne" license above, 
Onset, course and comorbidity of bipolar symptoms in population and treatment settings 
Cover photograph: Bromo volcano, Java, Indonesia

Print:

NPN Drukkers Breda

Universitaire Pers Maastricht

ISBN 9789090249162

(C) Copyright I van Rossum, Maastricht 2009

All rights reserved. No part of this thesis may be reproduced, stored or transmitted in any way or by any means without the prior permission of the author or when appropriate, from the publishers of the publications. 


\title{
Onset, course and comorbidity of bipolar symptoms in population and treatment settings
}

\author{
PROEFSCHRIFT \\ ter verkrijging van de graad van doctor \\ aan de Universiteit Maastricht, \\ op gezag van de Rector Magnificus, \\ prof. mr. G.P.M.F. Mols, \\ volgens het besluit van het College van Decanen, \\ in het openbaar te verdedigen \\ op donderdag 14 januari 2010 om 14:00 uur \\ door \\ Inge van Rossum \\ Geboren op 6 mei 1978 te IJsselstein
}




\section{Promotor}

Prof. dr. J. van Os

\section{Copromotor}

Dr. D.E. Tenback

\section{Beoordelingscommissie}

Prof. dr. M. DeVries, voorzitter

Dr. R.W. Kupka, Altrecht Utrecht

Prof. D.H. Linszen, AMC Amsterdam

Dr. F. Peeters

Emeritus prof. dr. H.M. van Praag

\section{Paranimfen}

Bas Bosma

Leon van Rossum

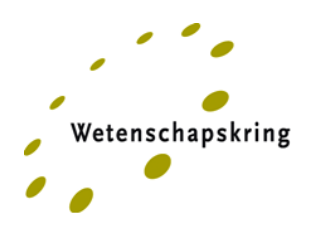

South Limburg Mental Health Research and Teaching Network, PhD Series

The research presented in this thesis was partly conducted at the Max Planck Institute of Psychiatry, Clinical Psychology and Epidemiology Unit, Munich, Germany, and partly conducted by Eli Lilly Health Outcomes, Windlesham, UK

Publication of this thesis was financially supported by Lilly Netherlands BV. 


\section{Table of contents}

Chapter $1 \quad$ Introduction

Chapter 2 Affective dysregulation and reality distortion: a 10-year prospective study of their association and clinical relevance

Chapter 3 The context of the rate of symptom improvement in acute mania

Chapter $4 \quad$ Stability and treatment outcome of distinct classes of 69 mania

Chapter 5 Does cannabis use impact on treatment outcome in bipolar illness? A longitudinal analysis

Chapter 6 Bipolar disorder and dopamine dysfunction: an 109 indirect approach focusing on tardive movement syndromes

Chapter $7 \quad$ Conclusions and interpretation of findings within a dopamine dysfunction model

Chapter 8a/b Summary / Samenvatting 153

Dankwoord 167

Curriculum Vitae 171

Publications and presentations 



\section{1}

Introduction 
Bipolar disorder (BD), also known as manic depressive illness, is a chronic disease, associated with episodic extremes in mood. Prevalence rates vary strongly, with a reported range between $0.8-5 \cdot \%^{1,2}$. This broad range is likely caused by variances in the populations studied, the operationalization of bipolar disorder ${ }^{3}$, and both the course of the illness ${ }^{3}$ and overlap between BD and other psychiatric disorders complicating diagnosis ${ }^{4}$. In a comprehensive review, Bebbington and Ramana $^{3}$ state that it is probably reasonable to suggest a compromise prevalence rate of $1-1.5 \%$, concluding that bipolar disorder is thus a rare albeit debilitating disease.

\section{A disorderly disorder}

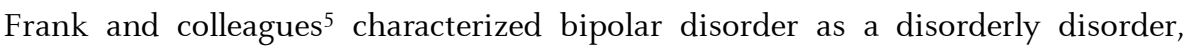
describing the course as typically hectic and variable. Indeed, the term BD covers a spectrum of disorders of diverging severity with a highly variable course. BD type I is usually characterized by an alternation of manic and depressive episodes, although mania and depression can co-occur in a mixed-state. Among other criteria for a diagnosis BD I, at least one manic phase is to be included in a patients' history. Episodes of mania and depression typically recur over the lifespan, and between episodes many patients still experience residual symptoms. When 4 or more episodes occur per year, the course of the illness follows a rapid cycling pattern ${ }^{6}$.

Many patients never develop severe mania but instead experience milder episodes, regarded as hypomania, alternating with depression; a disease state that is classified as BD II. Presence of psychosocial dysfunction is an essential characteristic distinguishing a manic phase from a hypomanic state. Cyclothymia, a milder form of $\mathrm{BD}$, is characterized by alternating hypomanic and dysthymic states, the latter referring to a state of depression of less severity than major depressive disorder. In case a patient clearly suffers from some type of bipolar illness but does not meet the criteria for one of the subtypes above, a diagnosis 'BD Not Otherwise Specified' (BD-NOS) is indicated'.

The impact of BD should not be underestimated, as it may have a devastating effect on many aspects of the patient's life including but not limited to social ${ }^{7}$ and cognitive functioning ${ }^{8}$, work-related performance ${ }^{7-9}$ and quality of life ${ }^{9}$, with high life-time suicide rates of $19.8 \%$, a 27.6 -fold increase compared to the general population ${ }^{10}$. 


\section{The course of the illness}

The illness course of bipolar disorder may follow the 'kindling principle': the natural tendency of the illness is assumed to be toward cycle acceleration and episodes tend to become more autonomous and independent from exogenous precipitants. It is now apparent that, with extensive and consistent treatment, the illness can be decelerated for most individuals ${ }^{11}$. The course of the illness, however, is influenced by a large range of internal and external factors, including but not limited to demographic and illness characteristics, social circumstances, comorbid somatic or psychiatric disorders, genetic vulnerability and the patients' illness history ${ }^{12-14}$. For instance, severe episodes of mania or depression can include psychotic symptoms ${ }^{15}$. More than half of patients with bipolar disorder experience psychotic symptoms in their lifetime ${ }^{10,15}$. Even though inconsistent findings on the effect of psychotic symptoms on treatment course in BD have been reported ${ }^{16,17}$, Kendler $^{18}$ concludes his review by stating that this irregularity in reported results may be caused by neglecting to distinguish mood-congruent from mood-incongruent psychosis within research designs. Indeed, moodincongruent psychosis appears to have a more negative effect on illness course compared to mood-congruent psychosis ${ }^{17}$.

Furthermore, the effects of comorbid disorders on both short-term and long-term outcome have been extensively studied, in particular highly prevalent anxiety disorders and alcohol abuse. Anxiety in patients with BD tends to have an adverse effect by intensifying symptoms of BD and other comorbid disorders, which consequently has a negative impact on the patient and on the course of $\mathrm{BD}^{19}$. Prevalence rates of comorbid anxiety are high; the STEP-BD trial reported $51.2 \%$ for a lifetime anxiety disorder and 30.5\% for a current anxiety disorder ${ }^{20}$. Alcohol abuse is also highly frequent in BD patient populations, and has found to exert a negative effect on the course of the illness by increasing symptom severity and cycle acceleration, among other effects ${ }^{21}$. These findings illustrate the potential impact of individual variances on the course of the disease. Obviously, extensive knowledge on the factors influencing the illness course not only provides physicians tools to set realistic treatment goals, but gives both physicians and patients more insight in opportunities to work towards the most optimal treatment outcome. 


\section{The origin of bipolar disorder}

As is common in medical science, substantial research is directed towards the risk factors for developing BD. In the past few years, cohort studies in the general population have reported interesting findings on the prodromal stage of $\mathrm{BD}$, which may consist of subclinical symptoms of depression, mania or psychosis, anxiety, substance abuse and suicidal thoughts, among other characteristics ${ }^{22}$. Many risk factors were investigated, derived from the genetic, historical, clinical and social status of patients who eventually develop a full-blown BD. One difficulty emerging from these studies was the finding that characteristics of the BD prodromal phase are qualitatively non-specific in nature. Discrimination with respect to the prodromal stage of other psychiatric illnesses was found to be intricate, particularly the differentiation from schizophrenia but also attentiondeficit hyperactivity disorder and borderline personality ${ }^{22}$. Moreover, risk factors for developing clinically significant psychotic symptoms were quite similar across clinical psychosis-related syndromes such as bipolar disorder, schizoaffective disorder and schizophrenia, albeit the magnitude of these risk factors was found to differ between various syndromes ${ }^{23,24}$.

Of particular interest within this context are the few studies investigating how and to what extent subclinical affective dysregulation (hypomania, mania or depression) and psychotic symptoms transitions into clinical BD. Subclinical (hypo)manic, depressive or psychotic symptoms were found to be a common but usually transitory developmental phenomenon ${ }^{25,26}$ with a high degree of cooccurrence $^{27-31}$. Presence of these individual symptoms as well as certain combinations of symptoms were found to increase the transition risk to BD and clinical psychosis ${ }^{26,27,32,33}$.

The increasing evidence on associations between affective dysregulation and psychotic experiences also includes data from clinical samples: psychotic symptoms are reported within the context of a range of affective clinical disorders $^{34,35}$ and, conversely, high rates of affective symptoms have been demonstrated in patients diagnosed with DSM-IV non-affective psychotic disorders $^{36,37}$ and schizotypy ${ }^{38}$. Insight in the interrelationship between affective dysregulation and psychotic experiences regarding onset, persistence and associated impairment may aid research on transitioning mechanisms to clinical syndromes and might even provide a tool to identify ultra high risk individuals. 


\section{Objectives and outline of this thesis}

The main objective of this thesis was to investigate the nature of BD-related symptoms on two levels; i) on a subclinical level, we wished to investigate the effect of the presence of affective dysregulation on the presence, course and impact of reality distortion; ii) on a clinical level, we wished to investigate illness characteristics and factors influencing the short-term and long-term course of bipolar illness. Two large cohort studies are the foundation of all analyses included in this thesis; the Early Developmental Stages of Psychopathology (EDSP) study and the European Mania in Bipolar Longitudinal Evaluation of Medication (EMBLEM) study. Both designs are described in the following sections.

The second chapter of this thesis focuses solely on subclinical symptoms of depression, (hypo)mania and psychosis from an epidemiological perspective, and potential underlying mechanisms such as dysfunctional cognitive processes and emotional salience misattribution. Using data from the general population (EDSP), associations between affective dysregulation (depression or (hypo)mania symptoms) and psychotic experiences were tested, as well as the impact of affective dysregulation on persistence of psychotic symptoms and the impairment associated with psychotic symptoms over time.

Chapters 3, 4 and 5 describe analyses on factors influencing the course of the illness, using the EMBLEM dataset. More specifically, chapter 3 investigates factors that may moderate the speed of symptom improvement in acutely manic, psychotic and depression symptoms. Although much research has been directed towards clinical and demographic predictors at baseline for treatment outcome after 3 months ${ }^{12,39}$, these studies did not take into account the fact that symptom improvement takes place over time. This is valuable information in setting realistic treatment expectations, as qualitative response patterns may be apparent over time that cannot be derived from final treatment outcomes. Multiple variables derived from the social and psychopathological context were investigated as potential moderators of the rate of response for mania, psychotic and depression symptoms.

Chapter 4 describes analyses directed towards the stability over time and treatment outcomes of 3 distinct classes of mania. In a preceding paper on the same patient sample, factor analysis was conducted to extract distinctive classes of patients using baseline data ${ }^{40}$. Three classes were distinguished; 'Typical Mania', 'Psychotic Mania' and 'Dual Mania', constituting 59\%, 28\% and $13 \%$ of 
the sample, respectively. A worrisome finding, as eligibility criteria applied in randomized controlled trials excludes patients from the Dual Mania class (referring to misuse of substances), which may create a gap in our knowledge on treatment effectiveness ${ }^{40}$. For this reason, it was important to test whether the distinction found by Haro and colleagues would persist over time, validating their finding. Additionally, it was of practical relevance to examine whether these 3 classes would demonstrate differential treatment response, in both the psychopathological and the social domain.

The effect of cannabis use on treatment outcome has been extensively studied in schizophrenia, providing evidence of a deleterious effect ${ }^{41,42}$. Given reports of high rates of cannabis use in patients with $\mathrm{BD}^{43}$, surprisingly little research has been conducted on this topic. Additionally, the psychotic symptomatology frequently associated with BD may complicate or worsen the clinical effects of cannabis use, and vice versa. Chapter 5 presents the results of research on the effect of cannabis exposure during one year of treatment on psychopathological outcome and social functioning in a BD population.

The sixth chapter examines movement disorders within the context of bipolar illness, using the EMBLEM dataset. Movement disorders, in particular tardive dyskinesia, have been elaborately studied within the context of schizophrenia. Even though literature suggests that patients with bipolar illness may be more vulnerable for movement disorders ${ }^{44}$, this concept is rarely investigated within a $\mathrm{BD}$ population. Next to incidence rates of tardive movement disorders (i.e., tardive dyskinesia and tardive dystonia), associations between these movement disorders on the one hand and other illness characteristics on the other (i.e. symptomatology as well as side effects) are examined.

\section{Introducing the EDSP study}

The Early Developmental Stages of Psychopathology study is a prospectivelongitudinal cohort study. Data were collected in a representative population sample of adolescents and young adults living in the Munich area (Germany), aged 14-24 years at baseline. The study sample was randomly drawn from the 1994 government population registers. Fourteen to 15-year-olds were sampled at twice the rate of 16- to 21-year-olds, and 22- to 24-year-olds were sampled at half this rate. Ethics Review Board approvals and patient consent followed country regulations. Detailed information about design, sample, instruments, procedures, and statistical methods of the EDSP is presented elsewhere $\mathrm{e}^{45,46}$. 


\section{Longitudinal study design}

The study consists of a baseline survey (To, $n=3021$ ) and 3 follow-up investigations ( $\left.\mathrm{T}_{1}, \mathrm{~T}_{2}, \mathrm{~T}_{3}\right)$, covering a time period of approximately 1.6 years (To$\mathrm{T} 1, \mathrm{SD}=0.2$ ), 3.4 years (To-T2, $\mathrm{SD}=0.3$ ) and 8.3 years (To-T3, range 7.4-10.6 years, $\mathrm{SD}=0.7)$ respectively. The response rate was $84 \%$ at $\mathrm{T} 2(\mathrm{n}=2548)$ and $73 \%$ at $\mathrm{T}_{3}$ $(n=2210)$. With this exceptional sample of adolescents and young adults drawn from the general population, the EDSP study provides a rare opportunity to gain insight into the prodromal phase of various psychiatric illnesses and the mechanisms that either protect from or facilitate transition to clinical syndromes.

\section{Measures}

Interviews were conducted using the Computer-Assisted Personal Interview (CAPI) version of the Munich-Composite International Diagnostic Interview (DIA$\mathrm{X} / \mathrm{M}-\mathrm{CIDI}^{47}$ ), an updated version of the World Health Organization's CIDI version $1.2^{48}$. The DIA-X/M-CIDI is a comprehensive, fully standardized diagnostic interview and assesses symptoms, syndromes and diagnoses of various mental disorders in accordance with the definitions and criteria of DSM-IV and ICD-10. High validity ${ }^{49}$ as well as high interrater and test-retest reliability of the CIDI have been established ${ }^{50,51}$. In order to ensure reliability of the assessments, fully trained and experienced clinical psychologists who were allowed to probe with follow-up questions conducted the interviews. At baseline, the lifetime version of the DIA$\mathrm{X} / \mathrm{M}$-CIDI was used; for the follow-up interviews, the DIA-X/M-CIDI interval version was used, covering the respective time periods between interviews.

\section{Limitations}

Several limitations should be taken into account when interpreting results from this sample. First, the EDSP is an epidemiological study, and no direct measures of affective and cognitive processes were available, making it difficult to gain insight into underlying mechanisms. Second, the measurements were too far apart for dynamic models of the onset of impairment as a function of affective dysregulation. Third, although interviews were conducted by experienced clinical psychologists, the assessment of psychotic experiences will likely contain false positive answers. The impact of these and other limitations is discussed in Chapter 2 . 


\section{Introducing the EMBLEM study}

The European Mania in Bipolar Longitudinal Evaluation of Medication (EMBLEM) is a 2-year prospective observational study on the outcome of pharmacological treatment for mania in the context of bipolar disorder. Psychiatrists across 14 European countries (Belgium, Germany, Denmark, Finland, Norway, France, UK, Ireland, Switzerland, Portugal, Spain, Italy, Greece, and the Netherlands) included 3692 patients between 2001 and 2004. The primary objective of the study is to compare changes in symptoms of mania treated with olanzapine versus other medication (antipsychotics, lithium and anticonvulsants). Secondary objectives include evaluation of symptomatic recovery and relapse as well as functional status. The study also attempted to investigate associations among treatment patterns, patient as well as disease characteristics and outcome. Ethics Review Board approvals and patient consent followed country regulations.

\section{Longitudinal study design}

Enrolled patients were followed up as part of normal clinical care, i.e. no specific study visits were scheduled. A maximum of 10 observations covered a 2 year period. A time range was specified for each assessment in which study data could be collected if the patient attended an appointment as part of normal clinical care. The study can be divided into an Acute Phase, with assessments at baseline and after 1, 2, 3, 6 and 12 weeks, and a Maintenance Phase, including measurements at $6,12,18$ and 24 months post-baseline. Baseline data was to be collected within 24 hours after initiating or changing medication.

\section{Patient sample}

Adult in- and outpatients from rural and urban facilities were included when oral medication for the treatment of a manic or mixed episode was initiated or changed within the standard course of care (excluding simple dose adjustments). The treating physician determined on the presence of a manic or mixed episode through standard diagnostic criteria (DSM-V, ICD and/or clinical judgement). To be considered eligible for participation, the score on the Clinical Global Impression for mania (severity of mania rated on a seven-point scale, higher is worse $\mathrm{5}^{2}$ ) should be at least 3 at baseline. The decision to initiate or change medication, as well as the type of medication that was selected, was at the discretion of the physician and independent of participation in the study. Eligibility for the study was unconditional with regards to the prescribed 
medication for mania or a mixed episode. Investigators were asked but not required to enroll approximately a similar number of patients starting with olanzapine as with other medication (that is, other antipsychotic, lithium or anticonvulsant). In line with the naturalistic design of the study, patients were not required to continue the medication regimen that was initiated at baseline. Throughout the study, medication and/or dosages could be adjusted according to clinical necessity, as judged by the investigator. Simultaneous participation in another study was not allowed when this involved treatment intervention or an investigational drug.

Of the included 3692 patients, 3459 fulfilled the inclusion criteria and formed the basic sample for all analyses. The specific risk set of patients included in the individual analyses varies somewhat due to the conditions set for each analysis. Additionally, the period of follow-up and the variables used differs between the individual analyses, which consequently impacts the patient sample studied. Therefore, demographic information and patient characteristics are specified per analysis and presented in subsequent chapters. Not all countries continued participation into the Maintenance Phase of the EMBLEM study: Switzerland, Germany, Denmark and Spain only participated in the Acute Phase of the study. However, with a study population at baseline of 3459 eligible patients, the EMBLEM represents the largest prospective observational study in her field. This unique sample size makes the EMBLEM an invaluable source to gain insight into the long term course of $\mathrm{BD}$, factors affecting it, and associations among illness characteristics. Additionally, the sample size enables powerful statistical techniques to control for confounding factors.

\section{Measures}

Ease of use and simplicity of assessments were important considerations in the choice of scales and measurements. Psychiatric history (e.g. age of first contact due to bipolar symptoms, suicide attempts, number of episodes in the past year) and clinical status (e.g. hospitalization) were assessed, as well as basic demographic information (e.g. age, gender, social economic status), various symptom severity measures (Clinical Global Impression, Young Mania Rating Scale, Hamilton Depression scale), substance use (previous or current use of alcohol, cannabis and other substances such as heroin), social functioning (e.g. independent living, work impairment, number of dependents to care for), Life 
Chart Methodology, satisfaction with life, compliance with medication, side effects and treatment regimens (for a detailed overview ${ }^{40,53}$ ).

\section{Limitations}

Certain limitations are important to consider. First, a large number of countries and investigators participated in the EMBLEM study. Although this enabled inclusion of a large sample size, the combination of countries with different health care systems may have prevented the compilation of an entirely representative patient sample. Similarly, the participation of a large number of investigators may have introduced error by reducing the reliability of the assessments. Nevertheless, this prospective observational study provides clinically relevant information about the status of manic patients and their treatment across Europe. Second, an elaborate structured diagnostic interview was not administered in this study. Diagnoses were based on standard diagnostic criteria and clinical judgement of investigators, in line with daily practice in Europe. Therefore, the patients enrolled cannot be considered representative of all bipolar patients as they reflect those patients who are treated by psychiatrists practicing in Europe. A final limitation concerns patient selection as the sample was composed of patients experiencing a manic or mixed episode, which may have reduced the generalisability to some extent and maybe even biased the results related to depressive symptoms in the applicable analyses. Additionally, for the individual analyses specific considerations may need to be taken into account, which are described in the respective chapters.

\section{General considerations}

Randomized Clinical Trials (RCTs) are often regarded as the golden standard for investigating treatment efficacy, as the study designs facilitate the attribution of observed effects to the treatment(s) under investigation. Even though high internal validity is aspired through randomization, placebo conditions and standardized treatment protocols, external validity is compromised by employing strict enrollment criteria in controlled settings. These characteristics hamper translation of RCT results to community patient samples.

In contrast, observational cohort studies such as the EDSP and EMBLEM examine naturalistic variations in exposure to a large range of factors and intend to maximize external validity. Large cohort studies in the general population may provide insight into the prodromal phase of psychiatric illnesses and the 
mechanisms that either protect an individual from or facilitate transition to clinical syndromes. Cohort studies in patient populations are generally conducted with heterogeneous samples within naturalistic settings studying real-life outcome measures such as relapse, (re)hospitalization, social functioning and quality of life. This approach enables a translation of findings to clinical practice. Although one may rely on statistical methods to adjust for the effect of possible baseline differences between patients on the outcome measure in this type of research design, influence of unknown confounders may introduce bias.

The concepts of generalisability and internal validity are related, as generalisability is reduced in the face of poor internal validity, and high internal validity is irrelevant if the results cannot be applied ${ }^{54}$. Unfortunately, both internal and external validity can rarely be optimized within one study design. Therefore, observational studies and RCTs should be regarded as necessary complementary approaches to evaluate efficacy and effectiveness thoroughly. 


\section{References}

1. Robins LN, Regier DA. Psychiatric disorders in America: the Epidemiologic Catchment Area Study. New York: The Free Press, 1991

2. Angst J (1998). The emerging epidemiology of hypomania and bipolar II disorder. J Aff Disord, 50:143-51

3. Bebbington P, Ramana R (1995). The epidemiology of bipolar affective disorder. Soc Psychiatry Psychiatric Epidemiol, 30(6):279-92

Krishinan KRR (2005). Psychiatric and medical comorbidities of bipolar disorder. Psychosomatic Medicine, 67:1-8

Frank E, Swartz HA, Kupfer DJ (2000). Interpersonal and social rhythm therapy: managing the chaos of bipolar disorder. Biol Psychiatry, 48:593-604

6. Diagnostic and Statistical Manual of Mental Disorders, fourth edition, Text Revision. American Psychiatric Association, 2000

7. Calabrese JR, Hirschfeld RM, Reed M, Davies MA, Frye MA, Keck PE, Lewis L, McElroy SL, McNulty JP, Wagner KD (2003). Impact of bipolar disorder on a US community sample. J Clin Psychiatry, 64:425-32

8. Keck PE (2006). Long-term management strategies to achieve optimal function in patients with bipolar disorder. J Clin Psychiatry, 67(Suppl 9):19-24

9. Dean BB, Gerner D, Gerner RH (2004). A systematic review evaluating health-related quality of life, work impairment, and healthcare costs and utilization in bipolar disorder. Curr Med Res Opin, 20:139-54

10. Goodwin FK, Jamison KR. Manic-depressive illness. New York: Oxford University Press, $157^{-185}, 1990$

11. Post RM (2007). Kindling and sensitization as models for affective episode recurrence, cyclicity and tolerance phenomena. Neurosci biobehav Rev, 31:858-73

12. Feske U, Frank E, Mallinger AG, Houck PR, Fagiolini A, Shear MK, Grochocinski VJ, Kupfer DJ (2000). Anxiety as a correlate of response to the acute treatment of bipolar I disorder. Am J Psychiatry, 157:956-62

13. Miklowitz DJ, Johnson SL (2006). The psychopathology and treatment of bipolar disorder. Ann Rev Clin Psychology, 2:199-235

14. Zarate CA, Narendran R, Tohen M, Greaney JJ, Berman A, Pike S, Madrid A (1998). Clinical predictors of acute response with olanzapine in psychotic mood disorders. J Clin Psychiatry, 59:24-8

15. National Institute of Mental Health. Bipolar disorder. Bethesda (MD): National Institute of Mental Health, National Institutes of Health, US Department of Health and Human Services; 2001/updated 2007. Available at http://www.nimh.nih.gov/health/publications/bipolar-disorder/complete-publication.shtml

16. Coryell W, Leon AC, Turvey C, Akiskal HS, Mueller T, Endicott J (2001). The significance of psychotic features in mania episodes: a report from the NIMH collaborative study. J Aff Disord, 67:79-88

17. Keck PE, McElroy SL, Rochussen-Havens J, Altshuler LL, Nolen WA, Frye MA, Suppes T, Denicoff KD, Kupka R, Leverich GS, Rush AJ, Post RM (2003). Psychosis in bipolar disorder: phenomenology and impact on morbidity and course of illness. Compr Psychiatry, 44(4) :263-9 
18. Kendler KS (1991). Mood-incongruent psychotic affective illness. Arch Gen Psychiatry, 48:362-9

19. Keller MB (2006). Prevalence and impact of comorbid anxiety and bipolar disorder. J Clin Psychiatry, 67 (suppl 1):5-7

20. Simon NM, Otto MW, Wisniewski SR (2004). Anxiety disorder comorbidity in bipolar disorder patients: data from the first 500 participants of the Systematic Treatment Enhancement Program for Bipolar Disorder (STEP-BD). Am J Psychiatry, 161:2222-9

21. Strakowski SM, DelBello MP, Fleck DE, Adler CM, Anthenelli RM, Keck PE, Arnold LM, Amicone J (2007). Effects of co-occuring cannabis use disorders on the course of bipolar disorder after a first hospitalisation for mania. Arch Gen Psychiatry, 64:57-64

22. Berk M, Conus P, Lucas N, Hallam K, Malhi GS, Dodd S, Yatham LN, Yung A, McGorry P (2007). Setting the stage: from prodrome to treatment resistance in bipolar disorder. Bipolar Disord, 9:671-8

23. Laursen TM, Munk-Olsen T, Nordentoft M, Mortensen PB (2007). A comparison of selected risk factors for unipolar depressive disorder, bipolar affective disorder, schizoaffective disorder and schizophrenia from a Danish population cohort. J Clin Psychiatry, 68:1673-81

24. Van Os J, Jones P, Sham P, Bebbington P, Murray RM (1998). Risk factors for the onset and persistence of psychosis. Soc Psychiatry Psychiatric Epidemiol, 33(12):596-605

25. Cougnard A, Marcelis M, Myin-Germeys I, de Graaf R, Vollebergh W, Krabbendam L, Lieb R, Wittchen HU, Henquet C, Spauwen J, van Os J (2007). Does normal developmental expression of psychosis combine with environmental risk to cause persistence of psychosis? A psychosis proneness-persistence model. Psychol Med, 37:513-27

26. Tijssen MJA, van Os J, Wittchen HU, Lieb R, Beesdo K, Mengelers R, Wichers M (2009). Prediction of transition from common adolescent bipolar experiences to bipolar disorder. In press

27. Kaymaz N, van Os J, de Graaf R, ten Have M, Nolen W, Krabbendam L (2007). The impact of subclinical psychosis on the transition from subclinical mania to bipolar disorder. J Aff Disord, 98:55-64

28. Krabbendam L, Myin-Germeys I, Bak M, van Os J (2005). Explaining transitions over de hypothesized psychosis continuum. Aust NZ J Psychiatry, 39(3):180-6

29. Krabbendam L, Myin-Germeys I, Hanssen M, de Graaf R, Vollebergh W, Bak M, van Os J (2005). Development of depressed mood predicts onset of psychotic disorder in individuals who report hallucinatory experiences. Br J Clin Psychol, 44:113-25

30. Krabbendam L, van Os J (2005). Affective processes in the onset and persistence of psychosis. Eur Arch Psychiatry Clin Neurosci, 255:185-9

31. Stefanis NC, Hanssen M, Smirnis NK, Avramopoulos DA, Evdokimidis IK, Stefanis CN, Verdoux H, Van Os J (2002). Evidence that three dimensions of psychosis have a distribution in the general population. Psychol Med, 32:347-58

32. Tijssen MJA, van Os J, Wittchen HU, Lieb R, Beesdo K, Mengelers R, Krabbendam L, Wichers M (2009). Evidence that bipolar disorder is the poor outcome fraction of a common developmental phenotype: An 8-year cohort study in young people. Psychol Med, in press Dominguez M, Wichers M, Lieb R, Wittchen HU, van Os J (2009). Evidence that onset of clinical psychosis is the outcome of progressively more persistent subclinical psychotic experiences: an 8-year cohort study. Schiz Bull, epub ahead of print PUBMED publication:doi:10.1093/schbul/sbpo22 
Dunayevich E, Keck PE (2000). Prevalence and description of psychotic features in bipolar mania. Curr Psychiatr Reports, 2(4):286-90

Sareen J, Cox BJ, Goodwin RD, Asmundson GJG (2005). Co-occurrence of post-traumatic stress disorder with positive psychotic symptoms in a nationally representative sample. J Traumatic Stress, 18(4):313-22

Peralta V, Cuesta MJ (2009). Characterization of affective domains within the nonaffective psychotic disorders. Schiz Res, 111 (1-3):61-9

Zisook S, McAdams LA, Kuck J, Harris MJ, Bailey A, Patterson TL, Judd LL, Jeste DV (1999). Depression symptoms in schizophrenia. Am J Psychiatry, 156:1736-43

8. Debbane M, Van der Linden M, Gex-Fabry M, Eliez S (2009). Cognitive and emotional associations to positive schizotypy during adolescence. J Child Psychol Psychiatry 50, 32634

Black DW, Winokur G, Hulbert J, Nasrallah A (1988). Predictors of immediate response in the treatment of mania: the importance of comorbidity. Biol Psychiatry, 24:191-98

Haro JM, Van Os J, Vieta E, Reed C, Lorenzo M, Goetz I, the EMBLEM Advisory Board (2006). Evidence for three distinct classes of 'Typical', 'Psychotic' and 'Dual' mania: results from the EMBLEM study. Acta Psychiatr Scand, 113, 112-20

Grech A, Van Os J, Jones PB, Lewis SW, Murray RM (2005). Cannabis use and outcome of recent onset psychosis. Eur Psychiatry, 20:349-53

2. Verdoux H, Liraud F, Gonzales B, Assens F, Abalan F, Van Os J (2001). Predictors and outcome characteristics associated with suicidal behaviour in early psychosis: a two-year follow-up of first-admitted subjects. Acta Psychiatr Scand, 103:347-54

Brown ES, Suppes T, Adinoff B, Rajan Thomas N (2001). Drug abuse and bipolar disorder: comorbidity or misdiagnosis? J Affect Disord, 65:105-15

4. Cavazonni PA, Berg PH, Kryzhanovskaya LA, Briggs SD, Roddy TE, Tohen M, Kane JM (2006). Comparison of treatment-emergent extrapyramidal symptoms in patients with bipolar mania or schizophrenia during olanzapine clinical trials. J Clin Psychiatry, 67:107-13 Wittchen HU, Perkonigg A, Lachner G, Nelson CB (1998). Early developmental stages of psychopathology study (EDSP): objectives and design. Eur Addict Res, 4(1-2):18-27

Lieb R, Isensee B, von Sydow K, Wittchen HU (2000). The Early Developmental Stages of Psychopathology Study (EDSP): a methodological update. Eur Addict Res, 6(4):170-82

Wittchen HU, Pfister H. DIA-X-Interviews: Manual für screening-Verfahren und Interview; Interviewheft Längsschnittuntersuchung (DIA-X-Lifetime); Ergänzungsheft (DIA-XLifetime); Interviewheft Querschnittsuntersuchung (DIA-X-12 Monatsversion); Ergänzungsheft (DIA-X-12 Monatsversion); PC-Programm zur Durchführung der Interviews (Längsund Querschnittsuntersuchung). Auswertungsprogramm. In: Swets \& Zeitlinger, Frankfurt, Germany

World Health Organization. Composite International Diagnostic Interview (CIDI), Version 1.o. Geneva: WHO, 1990

9. Reed V, Gander F, Pfister H, Steiger A, Sontagg H, Trenkwalder C, Hundt W, Wittchen HU (1998). To what degree does the Composite International Diagnostic Interview (CIDI) correctly identify DSM-IV disorders? Testing validity issues in a clinical sample. Int J Methods Psychiatr Res, 7:142-55 Wittchen HU, Robins LN, Cottler LB, Sartorius N, Burke JD, Regier D (1991). Cross-cultural feasibility, reliability and sources of variance of the Composite International Diagnostic Interview (CIDI). The multicentre WHO/ADAMHA Field trials. Br J Psychiatry, 159:645-53 
51. Wittchen HU (1994). Reliability and validity studies of the WHO-Composite International Diagnostic Interview (CIDI): a critical review. J Psychiatr Res, 28(1):57-84

52. Spearing MK, Post RM, Leverich GS (1997). Modification of the Clinical Global Impressions (CGI) Scale for Use in Bipolar Illness (BP): the CGI-BP. Psychiatry Res, 73:159-71

53. Goetz I, Tohen M, Reed C, Lorenzo M, Vieta E and the EMBLEM Advisory Board (2007). Functional Impairment in Patients with Mania: Baseline Results of the EMBLEM Study. Bipolar Disord, 9(1-2):45-52

54. Mant J, Dawes M, Graham-Jones S (1996). Internal validity of trials is more important than generalisibility. Br J Medicine, 312: 779 


\section{2}

\section{Affective dysregulation and reality distortion:}

\section{A 10-year prospective study of their association and clinical relevance}

Published:

Inge van Rossum, Maria-de-Gracia Dominguez, Roselind Lieb, Hans-Ulrich Wittchen, Jim van Os (2009). Schizophrenia Bulletin, epub ahead of print 


\section{Abstract}

Introduction. Evidence from clinical patient populations indicates that affective dysregulation is strongly associated with reality distortion, suggesting that a process of misassignment of emotional salience may underlie this connection. To examine this in more detail without clinical confounds, affective regulationreality distortion relationships, and their clinical relevance, were examined in a German prospective cohort community study.

Methods. A cohort of 2524 adolescents and young adults aged 14-24 years at baseline, drawn from the Early Developmental Stages of Psychopathology (EDSP) study, was examined by experienced psychologists. Presence of psychotic experiences and (hypo)manic and depressive symptoms was assessed at two time points (3.5 and up to 10 years after baseline) using the Munich-Composite International Diagnostic Interview. Associations were tested between level of affective dysregulation on the one hand and incidence of psychotic experiences, persistence of these experiences and psychotic impairment on the other.

Results. Most psychotic experiences occurred in a context of affective dysregulation, and bi-directional dose-response was apparent with greater level of both affective dysregulation and psychotic experiences. Persistence of psychotic experiences over time was progressively more likely to occur with greater level of (hypo)manic symptoms and depressive symptoms. Similarly, psychotic experiences of clinical relevance were progressively more likely to occur with greater level of affective dysregulation.

Conclusion. The findings suggest that correlated genetic liabilities underlying affective and non-affective psychotic syndromes may be expressed as correlated dimensions in the general population. Also, affective dysregulation may contribute causally to the persistence and clinical relevance of reality distortion, possibly by facilitating a mechanism of aberrant salience attribution. 


\section{Introduction}

Evidence from multiple domains indicates that affective dysregulation is strongly associated with reality distortion ${ }^{1,2}$. Genetic epidemiological research has demonstrated that the liabilities for bipolar disorder and schizophrenia are correlated $^{3-5}$. Psychopathological studies have demonstrated that psychotic experiences are reported within the context of a range of affective clinical disorders $^{6,7}$ and, conversely, high rates of affective symptoms have been demonstrated in patients diagnosed with DSM-IV non-affective psychotic disorders $^{8,9}$ and schizotypy ${ }^{10}$. Specific aspects of delusional content and severity of psychotic experiences are associated with dysfunctional emotional processes ${ }^{11-13}$. Most of the work in this area is cross-sectional and conducted in clinical samples, making it difficult to disentangle the direction of effects between affective and cognitive processes, and to distinguish between illness cause and illness consequence. Despite these limitations, the strong and consistent associations between affective states and reality distortion may imply causality.

Experimental work by Holt and colleagues ${ }^{14}$ indicated that patients with a diagnosis of schizophrenia who had delusions were more likely to assign (negative) affective meanings to neutral stimuli compared to those without delusional ideation. The magnitude of this response bias correlated with the severity of delusions. The findings were interpreted as consistent with an inappropriate activation of a stimulus-independent internal 'salience detector', leading to misassignment of emotional salience to neutral, ambiguous stimuli and ultimately to the formation of delusions ${ }^{14}$. Thus, affective dysregulation may result in maladaptive appraisal patterns of events, triggering a search for an explanation of their meaning that in turn increases the risk for positive psychotic experiences in vulnerable individuals ${ }^{15}$. Dysregulation in dopamine transmission, facilitating stimulus-independent release of dopamine, causing aberrant assignment of salience and motivational significance to external objects (leading to delusions) and internal representations of percepts and memories (leading to hallucinations), may represent the underlying neurobiological vulnerability mediating the process of reality distortion ${ }^{16}$.

Research on associations between variable clinical characteristics such as affective symptoms and psychotic experiences in clinical samples cannot examine to what degree such associations may arise as a result of the illness itself, and how interacting affective and cognitive processes, from a perspective of risk, may contribute to the onset of need for care and patient status. Finally, to the degree 
that the affective and cognitive processes in patients with psychotic disorder are universal, that is, these processes are quantitative variations of normal human mentation ${ }^{17}$, more fundamental knowledge is needed on their association in the general population, as otherwise a correct interpretation of their role in pathological states, such as psychotic disorder, is not possible.

It has long been recognized that schizophrenia-related pathology is also expressed, at attenuated levels, in individuals with 'schizotypal' or 'schizoid' personality traits. Systematic review of general population surveys indicates that the experiences associated with schizophrenia and related categories, such as paranoid delusional thinking and auditory hallucinations, are observed, in an attenuated form, in $5-8 \%$ of healthy people ${ }^{18}$. These attenuated expressions may be conceived as the behavioural expression of the underlying distributed liability for schizophrenia and related disorders, just as higher levels of blood pressure express higher liability for cardiovascular disease in a dose-response fashion. This interpretation is validated by longitudinal research showing a link between psychotic experiences in the general population and later outcomes of psychotic disorder. Since the seminal study by Chapman and colleagues $^{19}$, there is replicatory evidence from 2 birth cohorts $^{20,21}$ and 3 representative general population cohorts $^{22-24}$ that low grade psychotic experiences such as delusional thinking and mild hallucinatory experiences may precede the diagnosis of psychotic disorder, including clinical diagnosis of schizophrenia requiring hospital admission by many years. It has been shown that particularly persistence of subclinical psychotic experiences over time is associated with increased risk of later transition to clinically relevant psychosis ${ }^{22,25}$. Additional evidence is provided by a body of work on help-seeking individuals with low-grade psychotic experiences who, when followed over time, display high conversion rates to clinical psychotic disorder ${ }^{26}$.

Therefore, epidemiological research in the general population can be useful in complementing clinical research on the link between affective dysregulation, emotional salience misattribution and psychosis, particularly when a longitudinal perspective can be added in order to clarify the direction of effects and to study the relationship with onset of impairment. Earlier general population surveys in Greece and the Netherlands have shown a high degree of overlap between psychotic experiences and affective symptoms below the threshold for clinical disorder ${ }^{27-31}$. For the current study, it was hypothesized that (i) level of affective dysregulation, in the form of depression or (hypo)mania symptoms 
(regardless of the presence of formal mood disorder) in the general population, would be strongly and linearly associated with experience of reality distortion, expressed as psychotic experiences (ii) presence of affective dysregulation would be associated with persistence of reality distortion over time and (iii) affective dysregulation would be associated with psychotic impairment in the context of reality distortion.

\section{Methods}

Study design and population

The Early Developmental Stages of Psychopathology (EDSP) study is a prospective-longitudinal cohort community study, which collected data on the prevalence, incidence, risk factors, comorbidity and course of mental disorders. Following ethics committee approval, a representative population sample was randomly drawn from the 1994 German government population registers. The sample consisted of adolescents and young adults living in the Munich area aged 14-24 years at baseline. Because the primary goal of the study was to examine the incidence and developmental risk factors for psychopathology, stratification of the sample was performed by sampling 14 and 15-year olds, presumed to have the highest incidence density, at twice the rate of 16 to 21 -year olds, and by sampling 22 to 24 -year olds at half this rate. The 4809 sampled individuals were approached through letter and phone. Of these, 4263 individuals were located and determined to be eligible for the study. Most interviews took place at the participant's home. The study consists of a baseline survey (To, $n=3021$ ) and 3 follow-up investigations ( $\mathrm{T}_{1}, \mathrm{~T}_{2}$ and $\mathrm{T}_{3}$ ), covering a time period of approximately 1.6 years (To-T1, SD = 0.2), 3.5 years (To-T2, $\mathrm{SD}=0.3$ ) and 8.6 years (To-T3, range 7.4-10.6 years, $\mathrm{SD}=0.7$ ), respectively. Written informed consent was obtained from all participants. The study design and sample has been described in detail in previous reports ${ }^{27,28}$.

\section{Measures}

Interviews were conducted using the Computer-Assisted Personal Interview (CAPI) version of the Munich-Composite International Diagnostic Interview (DIA$\mathrm{X} / \mathrm{M}-\mathrm{CIDI}^{29}$ ), an updated version of the World Health Organization's CIDI version 1.2. The DIA-X/M-CIDI is a comprehensive, fully standardized diagnostic interview and assesses symptoms, syndromes and diagnoses of various mental disorders in accordance with the definitions and criteria of DSM-IV, along with 
information about onset, duration, severity and psychosocial impairment. The CIDI is divided into 16 sections: a socio-demographic section, 12 sections consisting of 288 symptom questions regarding groups of mental disorders and three final sections containing concluding questions, interviewer observations and interviewer ratings. High validity ${ }^{30}$ as well as high interrater and test-retest reliability of the CIDI have been established ${ }^{31,32}$. In order to ensure reliability of the assessments, fully trained and experienced clinical psychologists conducted the interviews. These interviewers were allowed to probe with clinical follow-up questions. At baseline, the lifetime version of the DIA-X/M-CIDI was used; for the follow-up interviews, the DIA-X/M-CIDI interval version was used, covering the respective time periods between interviews. As data on the DIA-X/M-CIDI Gsection concerning psychosis and its clinical relevance were only collected at $\mathrm{T}_{2}$ (lifetime version, assessing lifetime cumulative incidence up to T2) and $\mathrm{T}_{3}$ (interval version, assessing onset of new, incident, symptoms or interval rate of any symptom between $\mathrm{T}_{2}$ and $\mathrm{T}_{3}$ ), the current analyses are limited to T2 and $\mathrm{T}_{3}$. The response rate was $84 \%$ at $\mathrm{T}_{2}(\mathrm{n}=2548)$ and $73 \%$ at $\mathrm{T}_{3}(\mathrm{n}=\mathbf{2 2 1 0})$, covering an interval period of 4.9 years on average $(\mathrm{SD}=0.6)$.

\section{Measures: assessment of reality distortion}

Information from the CIDI psychosis section and the clinical interview rating section with its embedded Brief Psychiatric Rating scale ${ }^{33}$ were used to derive measures of the psychosis dimensions. In order to calculate measures of frequency of psychopathological experiences, such as lifetime cumulative incidence and interval incidence rates, as well as persistence estimates, discrete variables indicating their presence or absence across interview waves were, per definition, necessary.

Reality distortion, expressed as psychotic experiences, was the focus of the current analyses. All expressions of psychotic experiences, regardless of the presence of a formal psychotic disorder, were included. Psychotic experiences were assessed at $\mathrm{T}_{2}$ and $\mathrm{T}_{3}$ using the DIA-X/M-CIDI core psychosis section on delusions (14 items), hallucinations (5 items) and passivity (1 item). Specifically, items used were G1, G2a, G3-5, G7-G13, G13b, G14, G17, G18, G20, G20c, G21 and G22a. These items concern classic psychotic symptoms including but not limited to persecution, thought interference and passivity phenomena. Participants were first asked to read a list of all the psychotic experiences and then asked by the psychologist whether they ever experienced such symptoms (list and phrasing 
available upon request). All of these psychosis items can be rated in two ways: 1 (absent) and 5 (present), without intermediate levels. The presence of positive psychotic experiences was defined as any rating of " 5 " on any of the 20 DIA-X/MCIDI core psychosis items ${ }^{22}$. In order to examine dose-response as a function of level of psychotic experiences, an additional variable was constructed reflecting the presence of $0,1,2$ or 3 or more psychotic experiences (hereafter: Psychosis Load).

\section{Measures: assessment of Psychotic Impairment}

In order to assess functional impact of psychotic experiences, secondary dysfunction and help-seeking behavior were examined in individuals with evidence of DIA-X/M-CIDI psychotic experiences at T2 and T3; the following procedures were followed as described in an earlier report ${ }^{22}$. First, two DIA-X/MCIDI psychosis section items for help-seeking were used: G16 (delusions) and G23 (hallucinations). These items were phrased as follows: "Did you tell a doctor about ... (insert the psychosis section beliefs/experiences previously acknowledged by the participant along with a visual representation from the response booklet) you have had?" These items were rated in a dichotomous manner ( $\mathrm{o}=\mathrm{no}, 1=\mathrm{yes}$ ). In addition, participants were shown a list on which several types of outpatient or inpatient institutions for mental health problems were mentioned, ranging from general practitioner or school psychologist to psychiatric sheltered housing, and asked whether they had ever sought help at any of these institutions because of psychotic symptoms as elicited in the DIA-X/M-CIDI G-section. This item was rated in a dichotomous manner ( $\mathrm{O}=$ no, $1=y e s)$. Using these three help-seeking items, a dichotomous variable "Help-seeking" was constructed, indicating whether help-seeking behavior had been present (1) or absent (0).

Second, the level of dysfunction related to psychotic experiences was assessed using the DIA-X/M-CIDI items G28, G29, G29a and G36. The dysfunction score assessed the effect of the psychotic experiences on: (i) feeling upset, unable to work, go places, or enjoy oneself, at the time of having these experiences (item G28); (ii) being less able to work since these experiences began (item G29); (iii) being less able to make friends or enjoy social relationships since these experiences began (item G29a); (iv) how much their life and everyday activities were impaired when these experiences were at their worst (item G36). These four psychosis section items were rated in a dichotomous manner ( $\mathrm{o}=$ no, $1=y e s$ ). A dichotomous variable 'Dysfunction' was constructed, representing a positive 
answer on any of the four questions (value label 1) versus negative answers on all four questions (value label o).

Based on these two assessments, a combined outcome was created (hereafter 'Psychotic impairment'). Psychotic impairment was absent and scored as 'o' for subjects scoring 'o' on both help seeking behavior and dysfunction. Subjects scoring ' 1 ' on either or both help seeking behavior and dysfunction scored ' 1 ' on Psychotic Impairment.

Validation of this variable using third variables was presented previously ${ }^{22}$, using two variables: Caseness and Antipsychotic Treatment. Briefly, the X16 DIA-X/M-CIDI item rated the interviewer's opinion regarding clinical evidence of psychological ill-health in 4 levels: essentially not noticeable (o), not very noticeable (1), clearly ill (2), and very ill (3). The dichotomous variable 'Caseness' indicated individuals with a noticeable level of psychiatric caseness (any score above " 1 "). As part of the CIDI treatment module, participants were shown a list of different types of medication, rating their use because of any psychopathological or psychosomatic problem. The acknowledgement of any antipsychotic medication (Q1EA4) reported at $\mathrm{T}_{2}$ and $\mathrm{T}_{3}$ was used to derive treatment ('Antipsychotic Treatment': o=no, $1=y e s$ ). Validation analyses revealed that Psychotic Impairment was strongly associated with both the Caseness $(\mathrm{OR}=10.3, \quad 95 \% \mathrm{CI}=7.0-15.2)$ and the Antipsychotic Treatment (OR=15.3, $95 \% \mathrm{CI}=6.1-38.4)$ variable.

\section{Measures: assessment of affective dysregulation}

Affective dysregulation was assessed at T2 and T3 using the 28 symptom items (DSM-IV and ICD-10) of the DIA-X/M-CIDI depression and dysthymia section (items regarding feeling depressed, loss of interest, loss of energy, hopelessness, decreased concentration, loss of appetite, weight loss, sleep disturbances, feelings of worthlessness or guilt, decreased self-esteem and suicidal ideation/attempt) and the 11 symptom items of the DIA-X/M-CIDI mania section (items regarding increase in goal directed-activity, psychomotor agitation, spending sprees, sexual indiscretions, increased talkativeness, flight of ideas, increased self-esteem or grandiosity, decreased need for sleep and distractibility). Symptom items were rated either yes or no. Depression symptoms were only rated if present for at least two weeks; (hypo)mania symptoms if present for at least 4 successive days. In case the participant endorsed the presence of a particular symptom, additional probes ascertained whether the symptom was the direct result of alcohol or drug 
use or of physical diseases or conditions. If this were the case, the CIDI codes for substance use or somatically induced symptoms were used, and the item was not counted towards the diagnosis of a primary mood disorder. Furthermore, symptoms were only assessed and rated if at least one of the DIA-X/M-CIDI core depressive (depressed mood or loss of interest / pleasure) or core (hypo)mania symptoms (unusual happiness or excitement or unusual irritability) was present. Only participants having core (hypo) mania symptoms that were either noticed by others or because of which participants experienced problems were included.

\section{Binary and continuous affective variables}

Both binary and continuous affective variables were constructed as described previously ${ }^{34-36}$ :

i) 'Binary (hypo)mania' and 'binary depression': An a priori binary (hypo)mania variable was defined as at least two DIA-X/M-CIDI mania symptoms and a binary depression variable as at least three DIA-X/MCIDI depression symptoms.

ii) In addition, guided by previous work ${ }^{34-36}$, the continuous variables '(hypo)mania score' and 'depression score' were constructed. These variables represented two continuous sum scores of symptom ratings: a sum score of (hypo)mania symptoms with a minimum of $\mathrm{o}$, and a maximum score of 11 endorsements (hereafter: "(Hypo)mania Score"), and a sum score of depression symptoms with a minimum of $\mathrm{o}$, and a maximum score of 28 endorsements (hereafter: "Depression Score").

iii) Subsequent to ii), we created, for both symptom groups, progressively stricter and overlapping subcategories of these sum scores, indicating the degree of symptom loading. For depression, 6 categories were created of no symptoms (o), at least 1 symptom (1), at least 3 symptoms (2) at least 5 symptoms (3), at least 7 symptoms (4) and at least 9 symptoms (5). For (hypo)mania, the categories were similar except that the highest category consisted of at least 5 symptoms due to the very small number of subjects with 6 or more symptoms.

Analysis

Analyses were conducted in STATA, version $10^{37}$. Associations were expressed as odds ratios (OR) and 95\% confidence intervals (95\%CI) derived from logistic regression. 
Associations between affective dysregulation and psychotic experiences

Cumulative incidence measures of affective dysregulation and psychotic experiences up until T2 were tested for association in order to establish their lifetime comorbidity (risk set $n=2524$ ). Similarly, interval incidence of psychotic experiences at $T_{3}$ (i.e. individuals with psychotic experiences at $T_{3}$ free from psychotic experiences at T2) was modeled as a function of measures for level of affective dysregulation at $T_{3}$ (risk set $n=1564$ ). This latter analysis provided a temporally more precise test of the hypothesis that affective dysregulation accompanies the onset of psychotic experiences. Finally, T2 and T3 associations between individual psychotic experiences on the one hand and the level of depressive and (hypo)mania symptoms on the other hand were tested in order to gain insight in possible patterns of association between specific psychotic experiences and affective dysregulation.

\section{Psychosis Persistence}

In order to assess the association between level of affective dysregulation and persistence of psychotic experiences over the period $\mathrm{T}_{2}-\mathrm{T}_{3}$, associations between $\mathrm{T}_{3}$ level of affective dysregulation and $\mathrm{T}_{3}$ psychotic experiences were assessed in individuals with evidence for psychotic experiences at T2 (risk set $n=464$ ).

\section{Psychotic impairment}

In order to assess the relationship between level of affective dysregulation and incident Psychotic Impairment, associations between T3 Psychotic Impairment and $T_{3}$ level of affective dysregulation were assessed in individuals with evidence of psychotic experiences at $T_{3}$ but free from Psychotic Impairment at T2 (risk set $\mathrm{n}=191)$.

\section{Results}

At T2, over half $(51 \%)$ of the sample was male and the mean age was 21.7 years (SD 3.4). At T2, 574 (23\%) of all subjects presented with one or more lifetime psychotic experiences, with a stronger representation of delusions $(21 \%)$ compared to hallucinations ( $5 \%)$. At $\mathrm{T}_{3}$, the rates were lower, representing only the occurrence of psychotic experiences over the interval from T2 to T3 (Table 1). At T2, 978 subjects (32\%) had experienced two or more (hypo)mania or three or more depression symptoms; at $\mathrm{T}_{3}$, this was the case for 925 subjects $(31 \%)$. Within the subgroup of subjects with two or more (hypo)mania or three or more 
depression symptoms at $\mathrm{T} 2 \quad(\mathrm{n}=978), 57 \%$ did not report similarly defined (hypo)mania or depression symptoms at T3. Conversely, within the subgroup of subjects that did not experience two more (hypo)mania or three or more depression symptoms at T2, 25\% did present similarly defined (hypo)mania or depression symptoms at $\mathrm{T}_{3}$. The lifetime cumulative incidence up until $\mathrm{T}_{2}$ and the $\mathrm{T}_{2}-\mathrm{T}_{3}$ interval rates, assessed at $\mathrm{T}_{3}$, of hallucinations, delusions, (hypo)mania and depression symptoms are provided in Table 1.

Table 1. Lifetime cumulative incidence $\left(\mathrm{T}_{2}\right)$ and interval rates $\left(\mathrm{T}_{3}\right)$ of various symptoms.

\begin{tabular}{cccc}
\hline & $\begin{array}{c}\mathrm{T} 2 \\
\text { (n, total n; \%) }\end{array}$ & $\begin{array}{c}\mathrm{T} 3 \\
(\mathrm{n}, \text { total n; \% })^{\mathrm{a}}\end{array}$ & $\begin{array}{c}\mathrm{T}_{3} \\
\text { (n, total n; \% })^{\mathrm{b}}\end{array}$ \\
\hline Ever experienced hallucinations & 117 & 69 & 51 \\
(at least 1) & $(2524 ; 4.6 \%)$ & $(2210 ; 3.1 \%)$ & $(1937 ; 2.6 \%)$ \\
Ever experienced delusions & 529 & 248 & 121 \\
(at least 1) & $(2524 ; 21.0 \%)$ & $(2210 ; 11.2 \%)$ & $(1598 ; 7.6 \%)$ \\
Ever experienced hallucinations or & 574 & 274 & 128 \\
delusions (at least 1 symptom) & $(2524 ; 22.7 \%)$ & $(2210 ; 12.4 \%)$ & $(1564 ; 8.2 \%)$ \\
(Hypo)mania symptoms & 495 & 285 & 121 \\
(at least 2 symptoms) & $(2525 ; 19.6 \%)$ & $(2210 ; 12.9 \%)$ & $(1598 ; 7.6 \%)$ \\
Depressive symptoms & 695 & 780 & 392 \\
(at least 3 symptoms) & $(2529 ; 27.5 \%)$ & $(2210 ; 35.3 \%)$ & $(1391 ; 28.2 \%)$ \\
\hline
\end{tabular}

For each clinical characteristic, the size of the sample varies due to missing data on individual variables. ${ }^{a}$ Analyses were performed in the complete sample at $T_{3}$, regardless of presence of psychotic experiences at T2. ${ }^{b}$ Analyses were performed in the $T_{3}$ sample free of the specific type of symptom at T2, thus representing interval incidence of symptoms (e.g. the interval incidence of (hypo)mania symptoms at $T_{3}$ in subjects without (hypo)mania symptoms at T2 was $7.6 \%)$.

\section{Affective dysregulation and reality distortion co-occurrence}

Of the 574 subjects with psychotic experiences at T2, 35\% also presented with at least 2 (hypo)mania symptoms at T2, compared to $15 \%$ of subjects without lifetime psychotic experiences at T2. At $\mathrm{T}_{3}$, these figures were $27 \%$ and $11 \%$, respectively. Similarly, $43 \%$ of the 574 subjects with psychotic experiences presented with at least 3 depression symptoms at T2, compared to $23 \%$ of subjects without psychotic experiences. At $\mathrm{T}_{3}$, these figures were $46 \%$ and $31 \%$, respectively. At both $\mathrm{T}_{2}$ and $\mathrm{T}_{3}$, the majority of psychotic experiences occurred in the context of affective dysregulation (at least 2 (hypo)mania symptoms or at least 3 depression symptoms; Table 2). 
Bi-directional dose-response associations between affective symptoms and reality distortion

The probability of lifetime psychotic experiences at T2 was progressively higher with greater level of co-occurrent affective dysregulation in a dose-response fashion ((Hypo)mania Score OR linear trend over 4 levels=1.70, 95\%CI: 1.55, 1.87; p<.001; Depression Score OR linear trend over 6 levels: OR=1.31, 95\%CI: 1.24, 1.38; $\mathrm{p}<.001$; Table 3). Incident psychotic experiences at $\mathrm{T}_{3}$ (i.e., psychotic experiences at $\mathrm{T}_{3}$ in subjects free from psychotic experiences at $\mathrm{T}_{2}$ ) were similarly associated with (Hypo)mania Score and Depression Score in a doseresponse fashion (Table 3).

Similarly, the above OR linear trends expressing the association between psychotic experiences and affective dysregulation became progressively greater at higher level of Psychosis Load, both for mania and depression, and both at T2 (Table 4) and at T3 (Table 5).

\section{Psychosis Persistence}

(Hypo)mania Score and Depression Score were associated with persistence of psychotic experiences over the period T2-T3. Thus, within the sample of subjects with psychotic experiences at $T_{2}$ and interviewed again at $T_{3}$ (risk set $n=464$ ), the probability of persistence of psychotic experiences was progressively greater with higher (Hypo)mania Score (OR linear trend 4 categories=1.51; 95\%CI: 1.22, 1.88; $\mathrm{p}<0.001$ ) and higher Depression Score (OR linear trend 6 categories $=1.15$; $95 \% \mathrm{CI}=1.03,1.28 ; \mathrm{p}=0.012$ ).

\section{Psychotic impairment}

Two-hundred and twenty-eight subjects (9\%) presented at T2 with Psychotic Impairment. At T3, the number with Psychotic Impairment was 118 (5\%). Of these 118,70 subjects had not presented previously with Psychotic Impairment at T2, representing incident Psychotic Impairment. 
Table 2. Frequency of affective dysregulation as a function of presence of psychotic experiences at $\mathrm{T}_{2}$ and $\mathrm{T} 3$.

\begin{tabular}{|c|c|c|c|c|}
\hline & & $\begin{array}{l}\text { At least } 2 \text { (hypo)mania } \\
\text { symptoms present }\end{array}$ & $\begin{array}{c}\text { At least } 3 \text { depression symptoms } \\
\text { present }\end{array}$ & $\begin{array}{c}\text { At least } 2 \text { (hypo)mania } \\
\text { symptoms and/or at least } 3 \\
\text { depression symptoms present }\end{array}$ \\
\hline \multirow[t]{2}{*}{ T2 } & $\begin{array}{l}\text { Psychotic experience } \\
\text { absent (n, n total; \%) }\end{array}$ & 295 (1950; 15.1\%) & 446 (1950; $22.8 \%)$ & 630 (1950; $32.3 \%)$ \\
\hline & $\begin{array}{l}\text { Psychotic experience } \\
\quad \text { present (n, n total; \%) }\end{array}$ & $200(574 ; 34.8 \%)$ & $247(574 ; 43.0 \%)$ & $346(574 ; 60.3 \%)$ \\
\hline \multirow[t]{2}{*}{$\mathrm{T} 3^{\mathrm{a}}$} & $\begin{array}{l}\text { Psychotic experience } \\
\text { absent (n, n total; \%) }\end{array}$ & $212(1936 ; 11.0 \%)$ & $636(1936 ; 32.9 \%)$ & 756 (1936; $39.1 \%)$ \\
\hline & $\begin{array}{l}\text { Psychotic experience } \\
\text { present (n, n total; \%) }\end{array}$ & $73(274 ; 26.6 \%)$ & $144(274 ; 52.6 \%)$ & $169(274 ; 61.7 \%)$ \\
\hline \multirow[t]{2}{*}{$\mathrm{T} 3^{\mathrm{b}}$} & $\begin{array}{l}\text { Psychotic experience } \\
\text { absent (n, n total; \%) }\end{array}$ & $147(1436 ; 10.2 \%)$ & $420(1436 ; 29.3 \%)$ & $506(1436 ; 35.2 \%)$ \\
\hline & $\begin{array}{l}\text { Psychotic experience } \\
\text { present (n, n total; \%) }\end{array}$ & $33(128 ; 25.8 \%)$ & $60(128 ; 46.9 \%)$ & $70(128 ; 54.7 \%)$ \\
\hline
\end{tabular}

For each clinical characteristic, the size of the sample varies due to missing data on individual variables. ${ }^{a}$ Analyses were performed in the complete sample, regardless of presence of psychotic experiences at T2. ${ }^{b}$ Analyses were performed in the sample free of the specific type of symptom at T2. For example, first column, last row: the proportion of people with at least 2 (hypo)mania symptoms present in those with psychotic experiences at $T_{3}$ and no hypomania symptoms at T2 was $25.8 \%$. 
Table 3. Odds ratios of psychotic experiences with increasing load of affective dysregulation at $\mathrm{T} 2$ (risk set $\mathrm{n}=2524)$ and $\mathrm{T}_{3}$ (risk set $\mathrm{n}=1564$ ).

\begin{tabular}{|c|c|c|c|c|c|c|}
\hline & \multicolumn{3}{|c|}{ T2: Lifetime psychotic experiences (up to T2) } & \multicolumn{3}{|c|}{$\mathrm{T}_{3}: \mathrm{T}_{2}$-T3 Interval incident psychotic experiences } \\
\hline & $\begin{array}{l}\mathrm{n} \text { total } \\
\text { at } \mathrm{T} 2\end{array}$ & $\begin{array}{c}\mathrm{n}(\%) \text { with psychotic } \\
\text { experiences }\end{array}$ & OR $(95 \% \mathrm{CI})$ & $\begin{array}{c}\text { n total at } \\
\mathrm{T}_{3}\end{array}$ & $\begin{array}{c}\text { n (\%) with psychotic } \\
\text { experiences }\end{array}$ & OR $(95 \% \mathrm{CI})$ \\
\hline (Hypo)mania score o & 1966 & $360(18.3 \%)$ & a & 1338 & $90(6,7 \%)$ & $\mathrm{a}$ \\
\hline (Нypo)mania score 1 & 169 & $4^{2}(24.9 \%)$ & $1.48(1.02,2.13) \dagger$ & 113 & $11(9.7 \%)$ & $1.50(0.77,2.89)$ \\
\hline (Нypo)mania score 2 & 229 & $83(36.2 \%)$ & $2.54(1.89,3.40)^{*}$ & 79 & $16(20.3 \%)$ & $3.5^{2}(1.95,6.35)^{*}$ \\
\hline (Hypo)mania score 3 & 160 & $89(55.6 \%)$ & $5.59(4.01,7.80)^{*}$ & 34 & $11(32.4 \%)$ & $6.63(3.13,14.04)^{*}$ \\
\hline OR linear trend\# & \multicolumn{3}{|c|}{$\mathrm{OR}=1.70, \mathrm{CI}: 1.55,1.87^{*}$} & \multicolumn{3}{|c|}{$\mathrm{OR}=1.86, \mathrm{CI}: 1.52,2.26^{*}$} \\
\hline Depression score o & 1710 & $303(17 \cdot 7 \%)$ & a & 858 & $49(5 \cdot 7 \%)$ & a \\
\hline Depression score 1 & 121 & $24(19.8 \%)$ & $1.15(0.72,1.83)$ & 226 & $19(8.4 \%)$ & $1.52(0.87,2.63)$ \\
\hline Depression score 2 & 187 & $56(30.0 \%)$ & $1.99(1.42,2.78)^{*}$ & 129 & $11(8.5 \%)$ & $1.54(0.78,3.04)$ \\
\hline Depression score 3 & 170 & $48(28.2 \%)$ & $1.83(1.28,2.61)^{*}$ & 128 & $13(10.2 \%)$ & $1.87(0.98,3.55)$ \\
\hline Depression score 4 & 126 & $38(30.2 \%)$ & $2.01(1.34,2.99)^{*}$ & 97 & $13(13.4 \%)$ & $2.56(1.33,4.90) \dagger$ \\
\hline Depression score 5 & 210 & $105(50.5 \%)$ & $4.64(3.45,6.25)^{*}$ & 126 & $23(18.3 \%)$ & $3.69(2.16,6.30)^{*}$ \\
\hline OR linear trend\# & \multicolumn{3}{|c|}{$\mathrm{OR}=1.31, \mathrm{CI}: 1.24,1.38^{*}$} & \multicolumn{3}{|c|}{$\mathrm{OR}=1.28, \mathrm{CI}: 1.16,1.40^{*}$} \\
\hline
\end{tabular}

OR=Odds Ratio; CI=Confidence Interval. (Hypo)mania Score and Depression Score variables were constructed as described in text. Higher scores indicate more affective symptoms. ${ }^{a}$ Reference category: reference category is group without (hypo)mania symptoms and group without depressive symptoms. ${ }^{*} \leq \leq .001 ; \dagger p \leq 0.01$. \# OR linear trend is in the summary increase in risk with one unit change in affective score variable. 
Table 4. Linear associations between T2 lifetime experiences of affective dysregulation and psychotic experiences at different levels of psychosis severity (Psychosis Load).

\begin{tabular}{|c|c|c|c|c|}
\hline & $\begin{array}{c}\text { No psychotic } \\
\text { experiences (n,\%) }\end{array}$ & $\begin{array}{c}1 \text { psychotic experience } \\
(\mathrm{n}, \%)\end{array}$ & $\begin{array}{l}2 \text { psychotic experiences } \\
(\mathrm{n}, \%)\end{array}$ & $\begin{array}{l}\geq 3 \text { psychotic experiences } \\
(\mathrm{n}, \%)\end{array}$ \\
\hline (Hypo)mania score o $(\mathrm{n}=1966)$ & $1606(81.7 \%)$ & $236(12.0 \%)$ & $62(3.2 \%)$ & $62(3.2 \%)$ \\
\hline (Hypo)mania score $1(n=169)$ & $127(75.2 \%)$ & $25(14.8 \%)$ & $8(4.7 \%)$ & $9(5 \cdot 3 \%)$ \\
\hline (Hypo)mania score $2(\mathrm{n}=229)$ & $146(63.8 \%)$ & $43(18.8 \%)$ & $17(7 \cdot 4 \%)$ & $23(10.0 \%)$ \\
\hline (Hypo)mania score $3(\mathrm{n}=160)$ & $71(44.4 \%)$ & $28(17.5 \%)$ & $21(13.1 \%)$ & $40(25.0 \%)$ \\
\hline OR linear trend (hypo)mania \# & $1 \#$ & $1.4(1.2,1.6)$ & $1.9(1.6,2.2)$ & $2.4(2.0,2.7)$ \\
\hline Depression score $\circ(\mathrm{n}=1710)$ & $1407(82.3 \%)$ & $192(11.2 \%)$ & $59(3.5 \%)$ & $52(3.0 \%)$ \\
\hline Depression score $1(n=121)$ & $97(80.2 \%)$ & $13(10.7 \%)$ & $6(5.0 \%)$ & $5(4.1 \%)$ \\
\hline Depression score $2(\mathrm{n}=187)$ & $131(70.1 \%)$ & $39(20.9 \%)$ & $7(3.7 \%)$ & $10(5 \cdot 4 \%)$ \\
\hline Depression score $3(\mathrm{n}=170)$ & $122(71.8 \%)$ & $30(17.7 \%)$ & $7(4.1 \%)$ & $11(6.5 \%)$ \\
\hline Depression score $4(\mathrm{n}=126)$ & $88(69.8 \%)$ & $16(12.7 \%)$ & $8(6.4 \%)$ & $14(11.1 \%)$ \\
\hline Depression score $5(\mathrm{n}=210)$ & $105(50.0 \%)$ & $42(20.0 \%)$ & $21(10.0 \%)$ & $42(20.0 \%)$ \\
\hline OR linear trend depression \# & $1 \#$ & $1.2(95 \% \mathrm{CI}: 1.1,1.3)$ & $1.3(95 \% \mathrm{CI}: 1.2,1.4)$ & 1.6 (95\%CI: $1.4,1.7)$ \\
\hline
\end{tabular}

OR=odds ratio, CI=confidence interval. Assessments refer to cumulative incidence of psychopathology up until T2. \# OR linear trend is in the summary increase in risk with one unit change in affective score variable. 
Table 5. Linear associations between $\mathrm{T}_{2}-\mathrm{T}_{3}$ interval incident affective dysregulation and psychotic experiences at different levels of psychosis severity (Psychosis Load).

\begin{tabular}{|c|c|c|c|c|}
\hline & $\begin{array}{l}\text { No psychotic experiences } \\
\qquad(\mathrm{n}, \%)\end{array}$ & $\begin{array}{c}1 \text { psychotic experience } \\
(\mathrm{n}, \%)\end{array}$ & $\begin{array}{c}2 \text { psychotic experiences } \\
(\mathrm{n}, \%)\end{array}$ & $\begin{array}{c}\geq 3 \text { psychotic } \\
\text { experiences }(n, \%)\end{array}$ \\
\hline (Hypo)mania score o $(\mathrm{n}=1338)$ & $1248(93 \cdot 3 \%)$ & $66(4.9 \%)$ & $13(1.0 \%)$ & $11(0.8 \%)$ \\
\hline (Hypo)mania score $1(n=113)$ & $102(90.3 \%)$ & $7(6.2 \%)$ & $1(0.9 \%)$ & $3(2.7 \%)$ \\
\hline (Hypo)mania score $2(\mathrm{n}=79)$ & $63(79.8 \%)$ & $13(16.5 \%)$ & $2(2.5 \%)$ & $1(1.3 \%)$ \\
\hline (Hypo)mania score $3(n=34)$ & $23(67.7 \%)$ & $2(5.9 \%)$ & $5(14.7 \%)$ & $4(11.8 \%)$ \\
\hline OR linear trend\# & $1 \#$ & $1.6(1.2,2.0)$ & $2.5(1.7,3.7)$ & $2.4(1.6,3.6)$ \\
\hline Depression score $\circ(\mathrm{n}=858)$ & $809(94.3 \%)$ & $38(4.4 \%)$ & $8(0.9 \%)$ & $3(0.4 \%)$ \\
\hline Depression score $1(n=226)$ & $207(91.6 \%)$ & $14(6.2 \%)$ & $2(0.9 \%$ & $3(1.3 \%)$ \\
\hline Depression score $2(\mathrm{n}=129)$ & $118(91.5 \%)$ & $8(6.2 \%)$ & $2(1.6 \%)$ & $1(0.8 \%)$ \\
\hline Depression score $3(n=128)$ & $115(89.8 \%)$ & $9(7.0 \%)$ & $3(2.3 \%)$ & $1(0.8 \%)$ \\
\hline Depression score 4 (n=97) & $84(86.6 \%)$ & $6(6.2 \%)$ & $3(3.1 \%)$ & $4(4.1 \%)$ \\
\hline Depression score $5(n=126)$ & $103(81.8 \%)$ & $13(10.3 \%)$ & $3(2.4 \%)$ & $7(5.6 \%)$ \\
\hline OR linear trend\# & $1 \#$ & $1.2(95 \%$ CI: $1.1,1.3)$ & $1.3(95 \%$ CI: $1.0,1.6)$ & 1.7 (95\%CI: $1.4,2.2)$ \\
\hline
\end{tabular}

OR=odds ratio, CI=confidence interval. Assessments refer to psychopathology arising between $T_{2}$ and $T_{3}$; those with psychotic experiences at $T_{2}$ were excluded from the analysis. \# OR linear trend is in the summary increase in risk with one unit change in affective score variable. 
Table 6 (continued on next page). Specific psychotic experiences and associations with binary depressive (at least 3 symptoms) and binary (hypo)mania (at least 2 symptoms) variables at $\mathrm{T} 2$ (risk set $\mathrm{n}=2524$ ) and $\mathrm{T} 3$ (risk set $\mathrm{n}=1564$ ).

\begin{tabular}{|c|c|c|c|c|c|c|}
\hline & \multicolumn{2}{|c|}{$\begin{array}{l}\text { Prevalence of psychotic } \\
\text { experience }(n, \%)\end{array}$} & \multicolumn{2}{|c|}{$\begin{array}{l}\text { At least three depressive symptoms } \\
\qquad \text { OR }(95 \% \mathrm{CI})\end{array}$} & \multicolumn{2}{|c|}{$\begin{array}{c}\text { At least } 2 \text { (hypo)mania symptoms } \\
\text { OR }(95 \% \mathrm{CI})\end{array}$} \\
\hline & $\mathrm{T} 2$ & $\mathrm{~T} 3^{\mathrm{a}}$ & $\mathrm{T} 2$ & $T 3^{\mathrm{a}}$ & $\mathrm{T} 2$ & $\mathrm{~T}_{3}^{\mathrm{a}}$ \\
\hline & & & OR $(95 \% \mathrm{CI})$ & OR $(95 \% \mathrm{CI})$ & OR $(95 \% \mathrm{CI})$ & OR $(95 \% \mathrm{CI})$ \\
\hline Being spied on & $186(7.4)$ & $36(2.3)$ & $2.28(1.69,3.09)^{*}$ & $3.67(1.86,7.24)^{*}$ & $2.38(1.73,3.28)^{*}$ & $3.07(1.46,6.48) \dagger$ \\
\hline Being followed & $107(4.2)$ & $19(1.2)$ & $2.42(1.64,3.58)^{*}$ & $3.15(1.26,7.89) \ddagger$ & $2.26(1.50,3.41)^{*}$ & $4.63(1.80,11.91)^{*}$ \\
\hline Being tested & $125(5.0)$ & $34(2.2)$ & $2.85(1.99,4.10)^{*}$ & $2.04(1.03,4.04) \ddagger$ & $3.50(2.42,5.05)^{*}$ & $5.05(2.48,10.28)^{*}$ \\
\hline Conspiracy & $147(5.8)$ & $29(1.9)$ & $3.24(2.31,4.54)^{*}$ & $6.15(2.71,14.00)^{*}$ & $3.18(2.25,4.48)^{*}$ & $4.94(2.29,10.64)^{*}$ \\
\hline Loved by stranger & $72(2.9)$ & $15(1.0)$ & $1.33(0.81,2.19)$ & $1.99(0.72,5.52)$ & $2.87(1.78,4.65)^{*}$ & $3.93(1.33,11.62) \ddagger$ \\
\hline Can read thoughts & $89(3.5)$ & $12(0.8)$ & $2.69(1.76,4.12)^{*}$ & $2.27(0.73,7.09)$ & $3.22(2.09,4.97)^{*}$ & $3.91(1.17,13.11) \ddagger$ \\
\hline Can hear thoughts & $55(2.2)$ & $7(0.5)$ & $1.93(1.12,3.32) \ddagger$ & $5.69(1.10,29.46) \neq$ & $4.79(2.808 .22)^{*}$ & $5.85(1.30,26.34) \ddagger$ \\
\hline Thoughts being heard & $31(1.2)$ & $3(0.2)$ & $3.73(1.82,7.65)^{*}$ & $1.13(0.10,12.49)$ & $3.93(1.93,8.01)^{*}$ & $3.86(0.35,42.79)$ \\
\hline Controlled by force & $21(0.8)$ & $2(0.1)$ & $1.99(0.84,4.75)$ & b & $3.78(1.60,8.96) \dagger$ & $7.73(0.48,124.06)$ \\
\hline Being given thoughts & $12(0.5)$ & $\circ(0.0)$ & $2.66(0.85,8.26)$ & $\mathrm{b}$ & $4.14(1.33,12.88) \ddagger$ & $\mathrm{b}$ \\
\hline
\end{tabular}

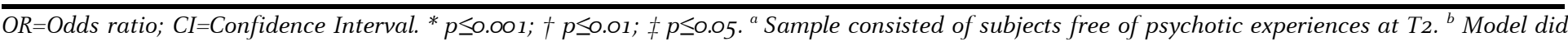
not converge. 
Table 6 (continued from previous page). Specific psychotic experiences and associations with binary depressive (at least 3 symptoms) and binary (hypo)mania (at least 2 symptoms) variables at $\mathrm{T}_{2}$ (risk set $\mathrm{n}=2524$ ) and $\mathrm{T}_{3}$ (risk set $\mathrm{n}=1564$ ).

\begin{tabular}{|c|c|c|c|c|c|c|}
\hline & \multicolumn{2}{|c|}{$\begin{array}{c}\text { Prevalence of psychotic } \\
\text { experience }(n, \%)\end{array}$} & \multicolumn{2}{|c|}{$\begin{array}{l}\text { At least three depressive symptoms } \\
\qquad \text { OR }(95 \% \mathrm{CI})\end{array}$} & \multicolumn{2}{|c|}{$\begin{array}{c}\text { At least } 2 \text { (hypo)mania symptoms } \\
\text { OR }(95 \% \mathrm{CI}) \\
\end{array}$} \\
\hline & $\mathrm{T} 2$ & $T 3^{a}$ & $\mathrm{~T} 2$ & $\mathrm{~T}_{3^{\mathrm{a}}}$ & $\mathrm{T} 2$ & $\mathrm{~T}_{3}^{\mathrm{a}}$ \\
\hline & & & OR $(95 \% \mathrm{CI})$ & OR $(95 \% \mathrm{CI})$ & OR $(95 \% \mathrm{CI})$ & OR $(95 \% \mathrm{CI})$ \\
\hline Thoughts being taken & $6(0.2)$ & $2(0.1)$ & $0.53(0.06,4.53)$ & $\mathrm{b}$ & $4.12(0.83,20.46)$ & $7.73(0.48,124.06)$ \\
\hline Messages & $13(0.5)$ & $7(0.5)$ & $8.92(2.45,32.51)^{*}$ & $5.69(1.10,29.46) \neq$ & $4.84(1.62,14.46) \dagger$ & $10.46(2.32,47.13) \dagger$ \\
\hline $\begin{array}{l}\text { Book or song solely } \\
\text { for person }\end{array}$ & $46(1.8)$ & $5(0.3)$ & $3.53(1.96,6.37)^{*}$ & $1.51(0.25,9.05)$ & $3.55(1.97,6.40)^{*}$ & $5.17(0.86,31.17)$ \\
\hline $\begin{array}{l}\text { Being influenced by } \\
\text { strange force }\end{array}$ & $25(1.0)$ & $5(0.3)$ & $1.77(0.79,3.96)$ & $0.56(0.06,5.06)$ & $3.27(1.48,7.25) \dagger$ & $\mathrm{b}$ \\
\hline Seeing things & $27(1.1)$ & $6(0.4)$ & $2.88(1.35,6.17) \dagger$ & $2.27(0.46,11.27)$ & $3.88(1.81,8.31)^{*}$ & $7.80(1.56,38.95) \ddagger$ \\
\hline Hearing things & $40(1.6)$ & $14(0.9)$ & $3.30(1.76,6.20)^{*}$ & $4.12(1.37,12.37) \neq$ & $4.69(2.50,8.79)^{*}$ & $5.93(2.0317 .29)^{*}$ \\
\hline Smelling things & $26(1.0)$ & $7(0.5)$ & $5.09(2.26,11.48)^{*}$ & $3.03(0.68,13.68)$ & $4.18(1.93,9.08)^{*}$ & $5.85(1.30,26.34) \neq$ \\
\hline Tasting things & $26(1.0)$ & $6(0.4)$ & $4.30(1.94,9.53)^{*}$ & $1.13(0.21,6.19)$ & $3.05(1.39,6.69) \dagger$ & $1.54(0.18,13.26)$ \\
\hline Feeling things & $36(1.4)$ & $7(0.5)$ & $4.26(2.16,8.37)^{*}$ & $1.70(0.38,7.62)$ & $2.66(1.35,5.23) \dagger$ & $3.10(0.60,16.09)$ \\
\hline Forced to move & $24(1.0)$ & $3(0.2)$ & $3.75(1.66,8.49)^{*}$ & $4.53(0.41,50.01)$ & $4.95(2.20,11.11)^{*}$ & b \\
\hline
\end{tabular}


Affective dysregulation was associated with incident Psychotic Impairment; within the sample of subjects without Psychotic Impairment at T2 and presence of at least one psychotic experience at T3 (risk set $n=191$ ), the probability of Psychotic Impairment at $\mathrm{T}_{3}$ was progressively higher with higher (Hypo)mania Score at $\mathrm{T}_{3}$ (OR linear trend 4 categories=1.37, 95\%CI: 1.02, 1.83; p=.036) and higher Depression Score at T3 (OR linear trend 6 categories=1.28, 95\%CI: 1.10 , $1.49 ; \mathrm{p}=.002)$.

Associations between affective dysregulation and specific psychotic experiences An overview of specific psychotic experiences and associations with binary depression (at least three symptoms) and (hypo)mania (at least two symptoms) variables is provided in Table 6. For both depression and (hypo)mania symptoms, no specific trend or pattern was apparent among the different psychotic experiences.

\section{Discussion}

Clinical studies in help-seeking samples suggest that early intervention in the prodromal phase of psychotic disorder may be feasible ${ }^{38}$. However, knowledge on the developmental mechanisms underlying the epidemiology of prodromal states in the general population remains very limited. The current study connects reality distortion and affective dysregulation in a general population setting from a perspective of risk and a perspective of understanding links with normal mentation. The results suggest that psychotic experiences in the general population are non-specifically associated with affective dysregulation, in a bidirectional dose-response fashion. Second, persistence of psychotic experiences and the onset of impairment associated with reality distortion occur more often if there is a context of affective dysregulation.

\section{Co-expression as a reflection of overlapping genetic liabilities}

Although the delusions and hallucinations of psychosis can be readily recognized, classifying psychotic states remains a major challenge. Psychosis is not exclusive to schizophrenia and occurs across a range of diagnostic categories of psychotic disorder, and even amongst the category of non-psychotic mood disorders ${ }^{39}$. The criteria used to distinguish between the different categories of psychotic disorder are based on duration, dysfunction, associated substance use, "bizarreness" of delusions and presence of depression or (hypo)mania. However, the resulting 
diagnostic categories of psychotic disorder show overlap in genetic liability amongst themselves. For example Kendler and colleagues ${ }^{40}$ demonstrated a significant familial relationship between non-schizophrenic psychotic disorders with both schizophrenia and schizotypal personality disorder. Family and twin studies similarly demonstrate a degree of overlap in genetic liability between nonaffective psychotic disorder and bipolar disorder ${ }^{3-5}$.

Co-expression of (subclinical) affective dysregulation and psychotic experiences in general cohort studies may thus in part reflect overlapping distributed genetic vulnerabilities. The majority of general cohort studies on transition rates from subclinical symptoms to clinical syndromes did not examine co-expression of reality distortion and affective dysregulation. Multiple studies suggest that subclinical psychotic experiences increase the risk for non-affective psychotic disorder ${ }^{19-24}$ and, similarly, subthreshold depression and/or (hypo)mania symptoms have been shown to increase the risk for bipolar disorder ${ }^{35,36}$. Overall, affective dysregulation and reality distortion have been shown to represent the behavioral expression of risk for more severe psychotic states including schizophrenia and bipolar disorder in the general population. In light of the accumulating evidence on overlap in genetic liability ${ }^{3-5}$, which suggests a broad underlying vulnerability across the different categories, our findings of associations between affective dysregulation and psychotic experiences in the general population may, therefore, simply reflect passive clustering of the behavioral expression of overlapping genetic risks.

\section{Co-expression as a reflection of causal influence}

The finding that co-expression of affective dysregulation predicted persistence of reality distortion and impairment associated with psychotic experiences suggest that, in addition to correlated genetic liabilities, a direct impact of affective dysregulation on the onset of psychotic experiences may be hypothesized. Existent psychological models of symptom formation suggest that the emotional context, and associated beliefs or appraisals, may induce bias in logical reasoning processes and, therefore, provoke reality distortion in healthy individuals ${ }^{2,15}$. In the psychological model described by Garety and colleagues ${ }^{1}$, the experience of a stressful event is thought to potentially give rise to altered pre-existing beliefs and ongoing appraisals of experiences, due to a certain emotional change or a cognitive processing bias. These distorted processes may lead to aberrant experiences which may seem personally significant to the individual and are 
likely to trigger a search for an explanation as to their meaning and cause that is consistent with affect-associated beliefs. Biased appraisal processes may contribute to a judgment that the experience is in fact externally caused. It is the interpretation that causes the associated distress and disability, rather than the experience itself. Thus, maladaptive appraisal patterns, induced by emotional processes, are suggested to increase the risk for positive symptom formation in vulnerable individuals ${ }^{1}$. Our findings provide support for a cognitive model of symptom formation, by demonstrating involvement of affective processes in the onset and persistence of reality distortion outside the context of disorder.

\section{Linking genetic and cognitive mechanisms}

Evidence on the role of cognitive processes suggests that cognitive biases and appraisals can help explain onset of psychosis ${ }^{1}$. Attempts have been made to integrate cognitive and neurobiological theories into a single model of psychotic states $^{1,16,41}$. Thus, evidence indicates that genetic risk for psychotic disorder is associated with underlying alterations in the dopamine system, including increased dopamine synaptic availability ${ }^{42}$, increased striatal dopamine synthesis $^{43,44}$ and increased dopamine reactivity to stress ${ }^{45,46}$. Under normal circumstances, it is the context-driven activity of the dopamine system that mediates the experience of novelty and the acquisition of appropriate motivational salience, detecting new rewards in the environment that facilitate learning and goal-directed behavior. Certain cerebral vulnerabilities, occasioned by interplay between genetic and environmental risks, could trigger contextindependent or context-inappropriate release of dopamine. A dysregulated dopamine system may cause aberrant assignment of salience and motivational significance to external objects (leading to delusions) and internal representations of percepts and memories (leading to hallucinations) ${ }^{47}$. Thus, theory derived from existent psychological models of psychotic symptom formation predicts that affective dysregulation may impact directly on risk for reality distortion. An integrated model would additionally suggest that the risk to develop a clinical disorder is particularly high in those who additionally have a genetic liability for dopaminergic dysregulation, facilitating aberrant salience attribution.

\section{Limitations}

Several limitations should be taken into account when interpreting these results. First, the study was epidemiological, and no direct measurements of affective and 
cognitive processes such as aberrant salience attribution were available, limiting the explanatory power of the findings on these mechanisms. Second, although longitudinal, measurements were too far apart for dynamic models of the onset of impairment as a function of affective dysregulation. Third, assessment of psychotic experiences, while better than lay-interviewer assessed self-reports, will likely contain false positive answers, even when interviewers are clinical psychologists. However, it is unlikely that false positive assessments would produce spurious associations with affective dysregulation - the opposite, more conservative alternative is more likely. Furthermore, the substantial literature on self-reported psychotic experiences, including those assessed with the DIA-X/MCIDI, indicates substantial predictive and other forms of validity of these phenomena $^{18}$. Fourth, lifetime rates in excess of $22 \%$ may seem high, given an estimate of $5 \%-8 \%$ in a recent systematic review ${ }^{18}$. However, in another systematic review we are preparing, it is apparent that rates of psychotic experiences are critically dependent on the number of items assessing different psychotic experiences. Previous work using the CIDI also detected rates close to $20 \%{ }^{48}$. Finally, it could be argued that the measure of psychotic impairment used was broad, resulting in a lifetime rate of $9 \%$, which may be considered very high for psychosis. The high rate is in part inherent to the population-based research paradigm of EDSP, which will always detect many more cases compared to the much lower administrative rates reflecting treatment at the level of services. Furthermore, even the rate of narrowly defined clinical psychotic disorder, when assessed completely, may be as high as $3.5 \%{ }^{49}$. In addition, to the degree that our definition of impairment was broad, it can be argued that in this context, sensitivity is more important than specificity, given the fact that the main clinical application of research on extended phenotypes ultimately is situated in the area of early detection.

\section{Conclusion}

Our findings suggest that correlated genetic liabilities underlying affective and non-affective psychotic syndromes may be expressed as correlated dimensions in the general population. Also, affective dysregulation may contribute causally to the persistence and clinical relevance of reality distortion, possibly by facilitating a mechanism of aberrant salience attribution. 


\section{References}

Garety P, Bebbington P, Fowler D, Freeman D, Kuipers E (2007). Implications for neurobiological research of cognitive models of psychosis: a theoretical paper. Psychol Med, 37:1377-91

Myin-Germeys I, Van Os J (2007). Stress-reactivity in psychosis: evidence for an affective pathway to psychosis. Clin Psychol Rev, 27(4):409-24

Cardno A, Rijsdijk F, Sham P, Murray R, McGuffin P (2002). A twin study of genetic relationships between psychotic symptoms. Am J Psychiatry, 159(4):539-45

Craddock N, Owen M (2007). Rethinking psychosis: the disadvantages of a dichotomous classification now outweigh the advantages. World Psychiatry, 6(2):84-91

Lichtenstein P, Yip B, Bjork C (2009). Common genetic determinants of schizophrenia and bipolar disorder in Swedish families: a population-based study. The Lancet, 373(9659):234-9 Dunayevich E, Keck P (2000). Prevalence and description of psychotic features in bipolar mania. Curr Psychiatry Rep, 2(4):286-90

Sareen J, Cox B, Goodwin R, Asmundson G (2005). Co-occurrence of post-traumatic stress disorder with positive psychotic symptoms in a nationally representative sample. J Trauma Stress, 18(4):313-22

Peralta V, Cuesta M (2009). Characterization of affective domains within the nonaffective psychotic disorders. Schizophr Res, $111(1-3): 61-9$

Zisook S, McAdams L, Kuck J, Harris M, Bailey A, Patterson T, Judd L, Jeste D (1999). Depression symptoms in schizophrenia. Am J Psychiatry, 156:1736-43

Debbane M, Van der Linden M, Gex-Fabry M, Eliez S(2009). Cognitive and emotional associations to positive schizotypy during adolescence. J Child Psychol Psychiatry, 5०(3):326-34

1 Bentall R, Rowse G, Shryane N (2009). The cognitive and affective structure of paranoid delusions: a transdiagnostic investigation of patients with schizophrenia spectrum disorders and depression. Arch Gen Psychiatry, 66(3):236-47

Green C, Garety P, Freeman D (2006). Content and affect in persecutory delusions. Br J Clin Psychol, 45(4):561-77

3 Smith B, Fowler D, Freeman D (2006). Emotion and psychosis: links between depression, self-esteem, negative schematic beliefs and delusions and hallucinations. Schizophr Res, $86(1-3): 181-8$

4 Holt D, Tinone D, Long S, Goff D, Cather C, Raugh S, Judge A, Kuperberg G (2006). The misattribution of salience in delusional patients with schizophrenia. Schizophr Res, 83:24756

Garety P, Kuipers E, Fowler D, Freeman D, Bebbington P (2001). A cognitive model of the positive symptoms of psychosis. Psychol Med, 31(2):189-95

Kapur S (2003). Psychosis as a state of aberrant salience: a framework linking biology, phenomenology and pharmacology in schizophrenia. Am J Psychiatry, 160:13-23

Van Os J, Kapur S (2009). Schizophrenia. The Lancet, 374(9690):635-45

Van Os J, Linscott R, Myin-Germeys I, Delespaul P, Krabbendam L (2009). A systematic review and meta-analysis of the psychosis continuum: evidence for a psychosis pronenesspersistence-impairment model of psychotic disorder. Psychol Med, 39(2):179-95

Chapman L, Chapman J, Kwapil T, Eckblad M, Zinser M (1994). Putatively psychosis-prone subjects 10 years later. J Abnorm Psychol, 103(2):171-83 
Poulton R, Caspi A, Moffitt T, Cannon M, Murray R, Harrington H (2000). Children's selfreported psychotic symptoms and adult schizophrenicform disorder: a 15-year longitudinal study. Arch Gen Psychiatry, 57(11):1053-8

Welham J, Scott J, Williams G (2008). Emotional and behavioural antecedents of young adults who screen positive for non-affective psychosis: a 21 -year birth cohort study. Psychol Med, 39(4):625-34

Dominguez M, Wichers M, Lieb R, Wittchen H, Van Os J (2009). Evidence that onset of clinical psychosis is the outcome of progressively more persistent subclinical psychotic experiences: an 8-year cohort study. Schizophr Bull, PUBMED publication:doi:10.1093/schbul/sbpo22

Hanssen M, Bak M, Bijl R, Vollebergh W, Van Os J (2005). The incidence and outcome of subclinical psychotic experiences in the general population. Br J Clin Psychol, 44(2):181-91

Werbeloff N, Drukker M, Dohrenwend B (2009). Self-reported psychotic symptoms in the community are associated with increased risk of later hospitalisation for non-affective psychotic disorders. Schizophr Bull, 35(suppl 1):74

5 Cougnard A, Marcelis M, Myin-Germeys I (2007). Does normal developmental expression of psychosis combine with environmental risk to cause persistence of psychosis? A psychosis proneness-persistence model. Psychol Med, 37(4):513-27

Cannon T, Cornblatt B, McGorry P (2007). The empirical status of the ultra high-risk (prodromal) research paradigm. Schizophr Bull, 33(3):661-4

Lieb R, Isensee B, Von Sydow K, Wittchen H (2000). The early developmental stages of psychopathology study (EDSP): a methodological update. Eur Addict Res, 6(4):170-82

Wittchen H, Perkonigg A, Lachner G, Nelson C (1998). Early developmental stages of psychopathology study (EDSP): objectives and design. Eur Addict Res, 4(1-2):18-27

Wittchen H, Pfister H. DIA-X-Interviews: Manual fur screening-verfahren und interview; interviewheft langsschnittuntersuchung (DIA-X-Lifetime); enganzungsheft (DIA-XLifetime); interviewheft Querschnittsuntersuchung (DIA-X-Monatsversion); erganzungsheft (DIA-X-12 Montasversion); PC-programm zur durchfuhrung der interviews (Langsund Querschnittsuntersuchung). Ausertungsprogramm. Swets \& Zeitlinger. Frankfurt, Germany, 1997

Reed V, Gander F, Pfister H, Steiger A, Sontagg H, Trenkwalder C, Hundt W, Wittchen H (1998). To what degree does the Composite International Diagnostic Interview (CIDI) correctly identify DSM-IV disorders? Testing validity issues in a clinical sample. Int J Meth Psychiatry Res, 7:619-27

Wittchen H (1994). Reliability and validity studies of the WHO-Composite International Diagnostic Interview (CIDI): a critial review. J Psychiatr Res, 28(1):57-84

Wittchen H, Robins L, Cottler L, Sartorius N, Burke J, Regier D (1991). Cross-cultural feasability, reliability and sources of variance of the Composite International Diagnostic Interview (CIDI). The multicenter WHO/ADAMHA Fields trials. Br J Psychiatry, 159:645-53 Overall J, Gorham D (1962). The brief psychiatric rating scale. Psychol Reports, 10:799-812 Krabbendam L, Myin-Germeys I, De Graaf R, Vollebergh W, Nolen W, Van Os J (2004). Dimensions of depression, mania and psychosis in the general population. Psychol Med, 34:1177-86 prospective study of the transition rates of subthreshold (hypo)mania and depression in the general population. Psychol Med, 36:619-27 

Common Developmental Phenotype: An 8-year Cohort Study in Young People. Psychol Med, Epub ahead of print. Doi:10.1017/So033291709006138

STATACORP. Statistical software: release 10.0: TXS Stata corporation, college station TX, 2008

Cannon T, Cadenhead K, Cornblatt B (2008). Prediction of psychosis in youth at high clinical risk: a multisite longitudinal study in North America. Arch Gen Psychiatry, 65(1):28-

37

Hanssen M, Peeters F, Krabbendam L, Radstake S, Verdoux H, Van Os J (2003). How psychotic are individuals with non-psychotic disorders? Soc Psychiatry Psychiatr Epidemiol, 38(3):149-54

Kendler K, McGuire M, Gruenberg A, Spellman M, O'Hare A, Walsh D (1993). The Roscommon family study II. The risk of nonschizophrenic nonaffective psychoses in relatives. Arch Gen Psychiatry, 5o(8):645-52 Van Os J (2009). A salience dysregulation syndrome. Br J Psychiatry, 194:101-3 Hirvonen J, Van Erp T, Huttunen J (2005). Increased caudate dopamine D2 receptor availability as a genetic marker for schizophrenia. Arch Gen Psychiatry, 62(4):371-8 Huttunen J, Heinimaa M, Svirskis T, Nyman M, Kajander J, Forsback S, Solin O, Ilonen T, Korkeila J, Ristkari T, McGlashan T, Salokangas R, Hietala J (2008). Striatal dopamine synthesis in first-degree relatives of patients with schizophrenia. Biol Psychiatry, 63(1):1147

Meyer-Lindenberg A, Miletich R, Kohn P (2002). Reduced prefrontal activity predicts exaggerated sriatal dopaminergic function in schizophrenia. Nature Neuroscience 5(3):26771

Brunelin J, d'Amato T, Van Os J, Cochet A, Suaud-Chagny M, Saoud M (2008). Effects of acute metabolic stress on the dopaminergic and pituitary-adrenal axis activity in patients with schizophrenia, their unaffected siblings and controls. Schizophr Res, 100(1-3):206-11 Myin-Germeys I, Marcelis M, Krabbendam L, Delespaul P, Van Os J (2005). Subtle fluctuations in psychotic phenomena as functional states of abnormal dopamine reactivity in individuals at risk. Biol Psychiatry, 58(2):105-10

Kapur S, Mizrahi R, Li M (2005). From dopamine to salience to psychosis: linking biology, pharmacology and phenomenology of psychosis. Schizophr Res, 79:59-68 continuum in the general population? Schizophr Res, 45(1-2):1 1-20

Perälä J, Suvisaari J, Saarni SI, Kuoppasalmi K, Isometsa E, Pirkola S, Partonen T, TuulioHenriksson A, Hintikka J, Kieseppa T, Harkanen T, Koskinen S, Lonnqvist J (2007). Lifetime prevalence of psychotic and bipolar I disorders in a general population. Arch Gen Psychiatry, 64(1):19-28 


\section{3}

\section{The context of the rate of symptom improvement in acute mania}

Published:

Jim Van Os, Inge Van Rossum, Maarten Boomsma, Eduard Vieta, Iris Goetz, Catherine Reed, Josep Maria Haro, and the EMBLEM Advisory Board (2007).

Social Psychiatry and Psychiatric Epidemiology, 42(8):631-8 


\begin{abstract}
Introduction. Knowledge of moderators of symptom improvement over time in acute mania improves predictability of individual patient outcomes. This study attempted to identify such moderators of the rate of symptom improvement.

Methods. In 3459 patients, clinical and social moderators of the rate of response in mania symptoms were examined. Additionally, moderators of symptom improvement in individuals with high baseline levels of comorbid depression $(\mathrm{n}=815)$ and psychosis $(\mathrm{n}=1849)$ were identified.
\end{abstract}

Results. Within three months, mania, depression and psychotic symptoms were reduced significantly. High levels of baseline depression, greater illness severity in the past year, lower age of onset and rapid cycling reduced the rate of mania symptom improvement. Social variables indicating disadvantage similarly had negative contributions. Several reasons for change of medication, involving patient choice, patient compliance, side effects and lack of effectiveness, impacted negatively. For the psychosis dimension, both low mania scores and high depression scores at baseline impacted negatively, whereas rate of reduction in depression was not conditional on baseline psychopathology.

Conclusion. The rate of symptom improvement in acute mania is to a large extent conditional on the context as provided by the social and psychopathological environment. 


\section{Introduction}

Given the fact that the significant clinical heterogeneity observed in bipolar disorder (BD) hampers prediction of individual patient outcomes ${ }^{1}$, knowledge of the factors that influence the probability of response to treatment not only represent a useful aid to clinicians, but also have the potential to enhance traditional interventions by providing a context that is more conducive to a favourable response. However, moderators of symptom improvement are not often examined because moderation is assessed by means of statistical interactions that treatment studies are rarely powered for.

Although several factors have been suggested as predictive of poor response in the treatment of bipolar disorder, conflicting results have been reported $^{2}$. The following factors have been reported to be associated with poorer acute treatment outcome: demographics (male / higher age ${ }^{3}$ ); lower age of onset ${ }^{t^{-6}}$; greater illness severity ${ }^{6,9}$; longer duration of illness ${ }^{3,7}$; longer episode duration ${ }^{4,9}$; more frequent episodes ${ }^{8,9}$; shorter hospitalisation ${ }^{4}$; more frequent hospitalisation ${ }^{6}$; more suicidality ${ }^{4,10}$; presence of mixed states $^{5,9,11,12}$; psychotic features ${ }^{8}$; comorbid psychiatric disorders ${ }^{4,9,13}$; substance abuse and dependence ${ }^{9,14}$ and rapid cycling $^{15,16}$. Very little, however, is known about the impact of social adversity, and the interaction between medication and patient, affecting the decision to stop or change an existing treatment.

One way of improving the accuracy of prediction of response, and reducing inconsistencies in the literature, is to attempt to take into account the fact that improvement takes place over the course of time where the onset of improvement may be apparent from anywhere between the first few days to the last week of a 3-month period. Similarly, qualitative response patterns may be apparent over time that cannot be derived from net endpoint effects, and adjustment for confounders in multivariate models may shed light on their relative independence. Thus, while predictors of endpoints may be helpful in choosing a treatment course, numerous moderators may influence the course of individual symptom improvement over time once treatment is initiated. To our knowledge, no research has been directed towards the identification of the moderators of the rate of symptom improvement over time in acute mania. In the current study, hypotheses about a selection of potential moderators of the rate of symptom improvement during the first 12 weeks of the treatment of acute mania in patients with BD were tested. 


\section{Methods}

Data from the EMBLEM study was utilized for the current analyses. The study design was described elaborately in Chapter 1. In short, the EMBLEM is a large European prospective observational study, studying patients with a change in pharmacological treatment for acute mania. For the current analyses, data from the acute phase (assessments as baseline and after 1, 2, 3, 6 and 12 weeks) were employed.

\section{Measures: clinical outcome}

Symptom severity of mania and depression where captured using the following clinical assessment scales: i) Clinical Global Impression-Bipolar Disorder (CGI-BP) overall illness in the 12 months prior to enrolment; CGI-BP overall illness, mania, depression and CGI hallucinations/delusions respectively assessing current status at each visit (all rated for severity on a seven-point scale ${ }^{17}$ ); ii) the Young Mania Rating Scale (YMRS, score range o- $64^{18}$ ); iii) the 5 -item version of the Hamilton Depression Rating Scale (HAMD-5, score range o-18), defined by principal component analysis by González-Pinto and colleagues, in order to find the core depressive symptoms of mania (depressive mood, suicide ideation, guilt, obsessions, psychic anxiety $\left.{ }^{19}\right)$.

\section{Analyses}

The analyses focused on moderators of the rate of symptom improvement, i.e. the rate of reduction in mania, depression and psychosis severity over the six visits (visit 1 to visit 6, hereafter: Time). For ease of interpretation, relative (i.e. setting the baseline value at $100 \%$ and expressing subsequent measurements as percentages of the baseline value) rather than absolute reductions in symptomatology over time were modelled, so that effect sizes could be expressed in \% differences of reduction in symptomatology (hereafter: relative CGI-BP mania, relative CGI-BP depression and relative CGI hallucinations/delusions).

\section{Mania}

In order to examine hypotheses about baseline moderators of rate of treatment outcome, models were fitted with relative CGI-BP mania (baseline set as 100\% and time1, time2, time3, time 4 and time 5 as percentages relative to baseline) as the dependent variable and Time as the independent variable, adjusted for country and baseline absolute CGI-BP mania score. The strong linear effect of 
Time in this model (see results section), representing the reduction of relative CGI-BP mania over the three months, was used as an indicator of treatment outcome. In order to assess hypothesized moderating effects on treatment outcome, moderator x Time variables were fitted. From this latter model, linear effect sizes for Time were calculated separately for the different strata of the moderator variable by applying and testing the appropriate linear combinations using the STATA LINCOM command. Main effects and interactions were assessed by Wald test $^{20}$. As there was more than one observation per individual, compromising statistical independence of observations clustered within the same individual, a multilevel random regression analysis ${ }^{21}$ was carried out. Effect sizes were expressed as the regression coefficient B, which can be interpreted identically to the coefficient from a standard multiple regression equation (change in dependent variable with one unit change in the independent variable).

\section{Psychosis and depression}

For the relative CGI-BP depression and relative CGI hallucination/delusion outcomes, similar analyses were conducted. However, as the inclusion criteria for the EMBLEM study only specified high scores on the mania dimension (CGI-BP mania at least 3), two subgroups were identified for additional analyses of symptomatology reduction over time: i) the subgroup of patients with a baseline CGI-BP depression score of at least $3(n=815,24 \%)$ and ii) the subgroup with a baseline CGI hallucinations/delusions score of at least $3(n=1849,53 \%)$. In these two subgroups, similar analyses were conducted examining the effect of moderators on the rate of symptom improvement over the three-month treatment period, adjusting for the baseline CGI measure of the outcome dimension. In these analyses, baseline YMRS was additionally tested as a moderator (expressed as quintile groups).

\section{Moderators}

Guided by previous literature as indicated above, the following moderators at baseline were investigated: i) demographic (sex, age, social economic status [SES] expressed as educational achievement [ 1 =university, $2=$ post-secondary vocational training, $3=$ secondary school-higher, $4=$ =secondary school-lower, $5=$ primary school, $6=$ none]); ii) historical clinical status (age at onset, baseline inpatient status, baseline CGI-BP overall illness in the past 12 months, reason for change of medication at baseline); iii) current clinical status (YMRS, compliance, a variable 
indicating abuse or dependence of cannabis as well as alcohol and other substances (i.e., heroin), rapid cycling, baseline psychosis [measured with the CGI baseline hallucinations/delusions: a score of 1 to 2 versus a score of 3 to 7 , hereafter: CGI binary hallucinations/delusions], baseline Hamilton Depression 5item score [HAMD-5; expressed as quintile groups]).

Moderating effects of social functioning was examined using five variables measuring independent living (o=no, $1=y e s$ ), work impairment (o=no impairment, $1=$ mild impairment, $2=$ moderate impairment, $3=$ severe impairment, $4=$ unable to work due to mental illness), current relationship (o=no, 1=yes), low frequency of social activities in the last 4 weeks ( 5 or more times to o times) and number of dependents to care for ( $\mathrm{O}=\mathrm{O}$ to $4=4$ or more dependents).

\section{Confounders}

Confounders (most of which also served as hypothesized moderators) were decided upon by EMBLEM advisory board members and included the following variables: age and age at onset of first symptoms of bipolar disorder (analysed as quartile groups), sex, compliance at baseline as rated by the investigators ( $1=$ always compliant, $2=$ compliant about half the time or never, $3=$ not prescribed medication), reason for start of new oral medication at baseline ( $1=$ no medication, $2=$ compliance, 3 =lack of efficacy, $4=$ patient request, $5=$ intolerability, $6=$ other), country, baseline alcohol, cannabis and other substance use (all coded: $\mathrm{o}=$ no use, $1=$ use, $2=$ abuse, $3=$ dependence), baseline rapid cycling (no=0-3 episodes per year, yes=at least 4 episodes per year), baseline CGI-BP overall illness in the past 12 months, baseline CGI-BP depression, baseline CGI hallucinations/delusions, SES, outpatient status at baseline (o=no, $1=y e s)$, and medication cohort at baseline (o=none, $1=$ =monotherapy with atypical antipsychotic $[\mathrm{AP}], 2=$ monotherapy with typical AP, $3=$ anticonvulsant monotherapy, $4=$ lithium monotherapy, $5=>1$ atypical AP, $6=$ more than 1 typical AP, $7=$ more than 1 anticonvulsant, $8=$ typical \& atypical AP, 9=atypical AP \& lithium, 10=atypical AP \& anticonvulsant(s), 11=typical AP \& lithium, 12=typical AP \& anticonvulsant(s), 13=lithium \& anticonvulsant(s), 14=atypical AP \& lithium \& anticonvulsant(s), 15=typical AP \& lithium \& anticonvulsant(s), 16=other (atypical AP \& typical AP \& lithium), 17=other (atypical AP \& typical AP \& anticonvulsant), 18=atypical \& typical \& lithium \& anticonvulsant, $100=$ other combination). 
Sample size and a priori effect size

Per individual analysis, all patients with non-missing values on the moderator variable as well as all covariates were included. Consequently, a range of $63-100 \%$ of the sample was included in the various models. Given the large sample size likely to yield statistically significant results for findings with no clinical relevance, we set an a priori difference in symptom improvement rate over the six visits of at least $5 \%$ between two groups (or the two extremes if more than two groups) as the lower limit of clinical relevance. Thus, a moderator can be statistically significant, but if the effect size does not exceed $5 \%$, it is not interpreted.

\section{Results}

\section{Sample description}

A total of 3692 subjects participated in EMBLEM, of whom 3459 had a baseline rating of relative mania (CGI-BP mania $\geq 3$ ) and were included in the current analyses. Of these, 39\% were inpatients, $45 \%$ were male and the mean age was 44.6 years (sd 13.4). The mean age of onset was 29.9 year (sd 11.0). Seventeen percent of the patients fulfilled rapid cycling criteria. Around $19 \%$ of patients had been in treatment for mood symptoms for less than 5 years, and $21 \%$ of the patients were not using medication at study entry. Table 1 provides an overview of baseline and 3 month clinical outcome and social functioning measures.

Table 1. Clinical treatment outcome and social functioning measures at baseline and after 3 months $(\mathrm{n}=3459)$.

\begin{tabular}{lcc}
\hline & Baseline & 3 Months \\
\hline CGI-BP overall illness (mean, sd) & $4.1(1.3)$ & $2.7(1.3)$ \\
CGI-BP mania (mean, sd) & $4.8(1.0)$ & $2.2(1.2)$ \\
CGI hallucinations/delusions (mean, sd) & $3.0(1.8)$ & $1.6(1.0)$ \\
CGI-BP depression (mean, sd) & $1.9(1.2)$ & $1.8(1.1)$ \\
YMRS (mean, sd) & $26.4(9.9)$ & $6.4(7.5)$ \\
HAMD-5 (mean, sd) & $2.8(2.8)$ & $2.1(2.5)$ \\
Independent living (\%) & $58 \%$ & $59 \%$ \\
Current relationship (\%) & $59 \%$ & $60 \%$ \\
Severe work impairment / unable to work (\%) & $51 \%$ & $45 \%$ \\
\hline
\end{tabular}




\section{Descriptives}

There were no correlations between post-baseline relative CGI-BP mania and either age $(r=0.0089)$ or age of onset $(r=-0.025)$.

\section{$\underline{\text { Reductions in mania, depression and psychosis }}$}

The level of relative CGI-BP mania, relative CGI-BP depression (in the subgroup of those with high baseline depression) and relative CGI hallucinations/delusions (in the subgroup of those with high baseline levels of psychosis) declined sharply with time, representing a $52 \%$ reduction for mania $(n=3442,-10.6 \%$ per visit, $95 \%$ CI: $-10.8,-10.5, \mathrm{P}<.001)$, a $56 \%$ reduction for psychosis $(\mathrm{n}=1848,-11.4 \%$ per visit, 95\% CI: $-11.6,-11.1, \mathrm{P}<.001)$, and a much smaller reduction for depression of $36 \%$ $(\mathrm{n}=814:-7.1 \%$ per visit, $95 \% \mathrm{CI}:-7.5,-6.7, \mathrm{P}<.001)$. Figure 1 illustrates these findings.

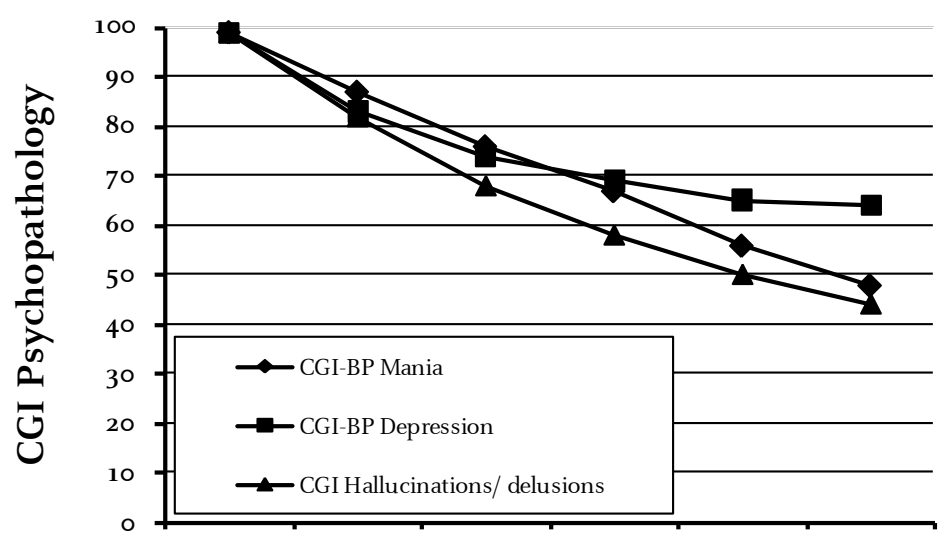

Figure 1. Rate of psychopathological symptom improvement.

Summary reduction, expressed as percentage of baseline value, adjusted for country and absolute baseline value of CGI score. Over 12 weeks, there was a 52\% reduction in mania raw score $(n=3442)$, a $36 \%$ reduction in depression raw score $(n=814)$ and a $56 \%$ reduction in hallucinations/delusions raw score ( $n=1848)$.

\section{Mania Moderators: demographic factors}

For age and sex, the moderator $\mathrm{x}$ Time interactions failed to achieve the combination of reaching statistical significance and exceeding the a priori limit of at least $5 \%$ difference in rate of symptom improvement, in contrast to the moderator $\mathrm{x}$ Time interactions of both SES and age of onset (SES: interaction: $\chi^{2}=33.5, \mathrm{df}=5, P<0.001: 10 \%$ less improvement over 12 weeks in lowest compared 
to highest category; age of onset: interaction: $\chi^{2}=27.2, \mathrm{df}=1, P<0.001: 5 \%$ less improvement over 12 weeks in lowest compared to highest onset quartile group).

Mania Moderators: medication at baseline

The moderator $\mathrm{x}$ Time interaction for compliance and antipsychotic treatment at baseline both failed to achieve the combination of reaching statistical significance and exceeding the a priori limit of at least $5 \%$ difference in rate of symptom improvement. Compared to being prescribed medication because the patient was not taking any at inclusion, several reasons for change of medication at baseline significantly moderated symptom improvement. Results are presented in Table 2.

Table 2. Moderating effects on mania symptom improvement of reasons for change of medication at baseline $(n=2389)$.

\begin{tabular}{lcc}
\hline & $\begin{array}{c}\text { Decrease in improvement rate } \\
\text { over } 12 \text { weeks }\end{array}$ & Interaction \\
\hline Compliance & $6 \%$ & $\chi^{2}=11.3(\mathrm{df}=1, P<0.001)$ \\
Lack of efficacy & $9 \%$ & $\chi^{2}=78.4(\mathrm{df}=1, P<0.001)$ \\
Patient requests change & $10 \%$ & $\chi^{2}=25.5(\mathrm{df}=1, P<0.001)$ \\
Lack of tolerability & $14 \%$ & $\chi^{2}=47.2(\mathrm{df}=1, P<0.001)$ \\
Other reasons & $5 \%$ & $\chi^{2}=6.7(\mathrm{df}=1, P=0.016)$ \\
\hline
\end{tabular}

The category 'no medication prescribed' served as reference category for all analyses. For each category of 'Reason for change', the summary reduction in CGI-BP mania was calculated. The difference in summary reduction per visit between categories, multiplied by 5, represents the total difference in symptom improvement over the three-month period.

\section{Mania Moderators: clinical factors}

Both higher baseline HAMD-5-score (interaction: $\chi^{2}=113.3, \mathrm{df}=4, P<0.001 ; 10 \%$ less symptom improvement over 12 weeks in highest vs. lowest group; Fig. 2) and higher baseline CGI-BP overall illness severity in the 12 months prior to inclusion (interaction: $\chi^{2}=71.0, \mathrm{df}=6, P<0.001 ; 15 \%$ less improvement over 12 weeks in highest vs. lowest group; Fig. 3) reduced the rate of improvement. The moderating effects of CGI binary hallucinations/delusions and any use or abuse of alcohol, cannabis and other substances at baseline all failed to exceed the a priori limit of at least $5 \%$ difference in rate of symptom improvement. In contrast, baseline outpatient status (interaction: $\chi^{2}=86.7, \mathrm{df}=1, P<0.001 ; 9 \%$ less improvement over 12 weeks) and rapid cycling (interaction: $\chi^{2}=70.8, \mathrm{df}=1, P<0.001 ; 10 \%$ less improvement over 12 weeks) did reduce the rate of improvement (Fig. 4a). 


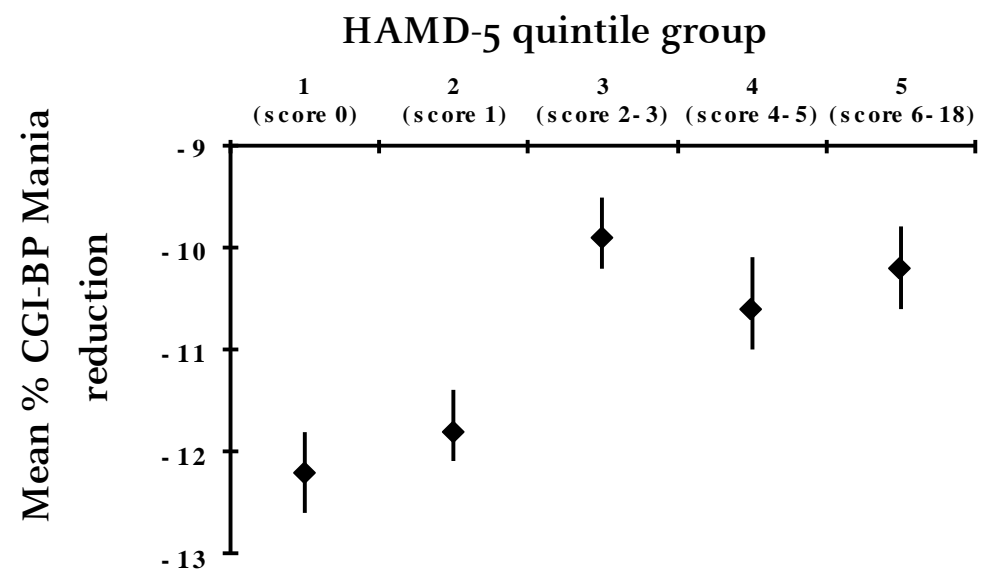

Figure 2. Rate of mania symptom improvement per visit as a function of baseline HAMD-5 quintile group.

Summary reduction in CGI-BP mania per visit $(n=2304)$. Markers represent effect size; lines represent upper and lower limits of 95\% confidence interval. The difference in summary reduction between group 1 (lowest HAMD score) and 5 (highest HAMD score) was $2.0 \%$, representing a $5 \times 2.0=10 \%$ difference in symptom improvement over the three-month period.

\section{CGI-BP Overall illness severity past 12 months}

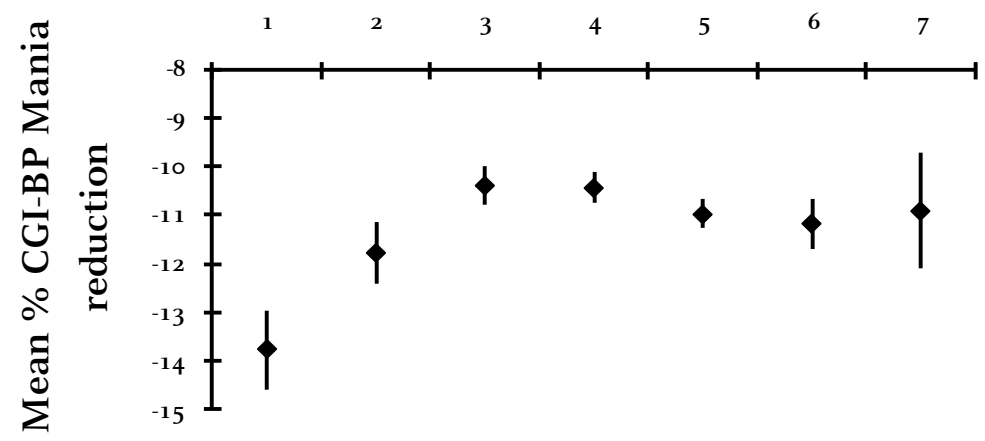

Figure 3. Rate of mania symptom improvement per visit as a function of baseline CGI-BP overall illness severity in the past 12 months.

Summary reduction in CGI-BP mania per visit (n=2363). Markers represent effect sizes; lines represent upper and lower limits of 95\% confidence interval. The difference in summary reduction between category 1 (normal, not ill) and category 7 (very severely ill) was $2.9 \%$, representing a 5x2.9=14.5\% difference in symptom improvement over the three-month period. 


\section{Categorical baseline moderators}

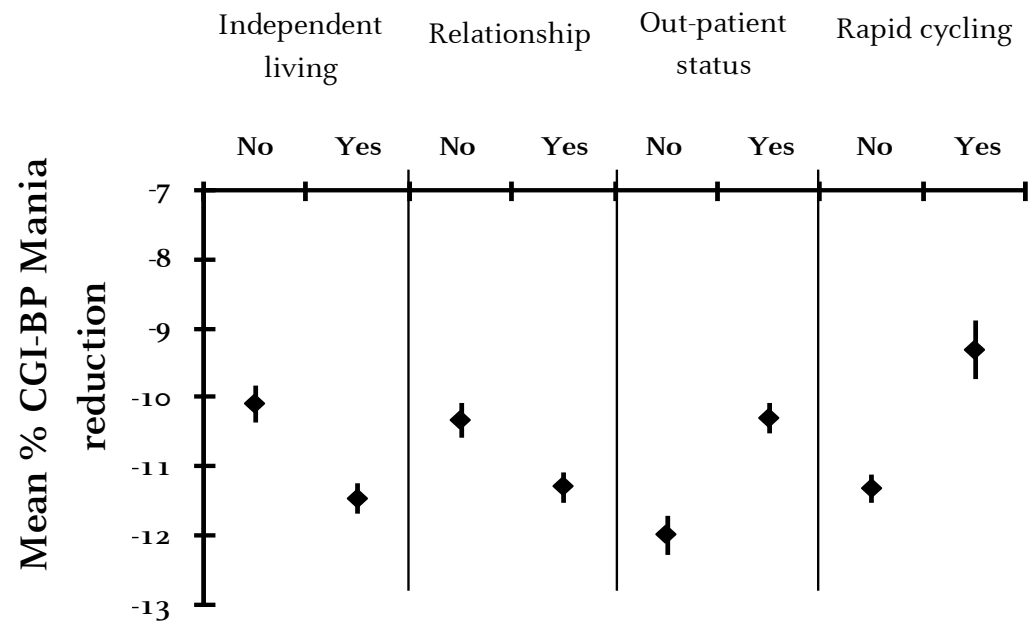

Figure 4a. Rate of mania symptom improvement per visit as a function of categorical baseline moderators.

Summary reduction in CGI-BP mania. Markers represent effect sizes; lines represent upper and lower limits of $95 \%$ confidence interval. The difference in summary reduction between moderator categories, multiplied by 5, represents the total difference in symptom improvement over the three-month period. All exceeded the a priori limit of 5\%: independent living: $5 \times 1.4 \%=7 \%$; relationship $5 \times 1 \%=5 \%$; in-patient status: $5 \times 1.7 \%=8.5 \%$; rapid cycling: $5 \times 2 \%=10 \%$.

\section{Mania Moderators: social factors}

Most social variables at baseline predicted the rate of symptom improvement (Fig. $4 \mathrm{a}-\mathrm{c})$. Exact results are presented in Table 3. 'Number of dependents' was the only social variable not reaching significance.

\section{$\underline{\text { Psychosis Moderators in manic patients with evident psychosis }}$}

The results for the moderating influences of the YMRS and HAMD-5 scores on the course of psychotic symptoms within the subgroup of patients with a high CGI hallucinations/delusions baseline score are displayed in figures $5^{\mathrm{a}}$ and $5 \mathrm{~b}$. Low mania co-morbidity at baseline predicted a reduction in improvement on psychosis symptoms of $22 \%$ over 12 weeks (interaction: $\chi^{2}=96.7, \mathrm{df}=4, P<0.001$ ), while high depression co-morbidity predicted a reduction of $14 \%$ (interaction: $\left.\chi^{2}=61.8, \mathrm{df}=4, P<0.001\right)$. 
Table 3. Moderating effects of social variables on mania symptom improvement.

\begin{tabular}{lcc}
\hline & $\begin{array}{c}\text { Decrease in } \\
\text { improvement rate over } \\
12 \text { weeks }\end{array}$ & Interaction \\
\hline Lack of independent living $^{1}$ & $7 \%$ & $\chi^{2}=62.2$, \\
& & $\mathrm{df}=1, P<0.001$ \\
No current relationship $^{2}$ & $5 \%$ & $\chi^{2}=30.2$, \\
& & $\mathrm{df}=1, P<0.001$ \\
Severe work impairment $^{3}$ & $7 \%$ & $\chi^{2}=17.4$, \\
& & $\mathrm{df}=1, P<0.001$ \\
Inability to work $^{3}$ & $14 \%$ & $\chi^{2}=70.2$, \\
& & $\mathrm{df}=1, P<0.001$ \\
Lowest frequency of social activities $^{4}$ & $10 \%$ & $\chi^{2}=79.2$, \\
& & $\mathrm{df}=5, P<0.001$ \\
\hline
\end{tabular}

N=3459. Reference categories: ${ }^{1}=$ independent living; ${ }^{2}=$ current relationship; ${ }^{3}=$ no impairment; $4=$ highest frequency of social activity (interaction based on all 5 categories). Summary reduction in CGI-BP mania was calculated. The difference in summary reduction between categories, multiplied by 5 , represents the total difference in symptom improvement over the three-month period.

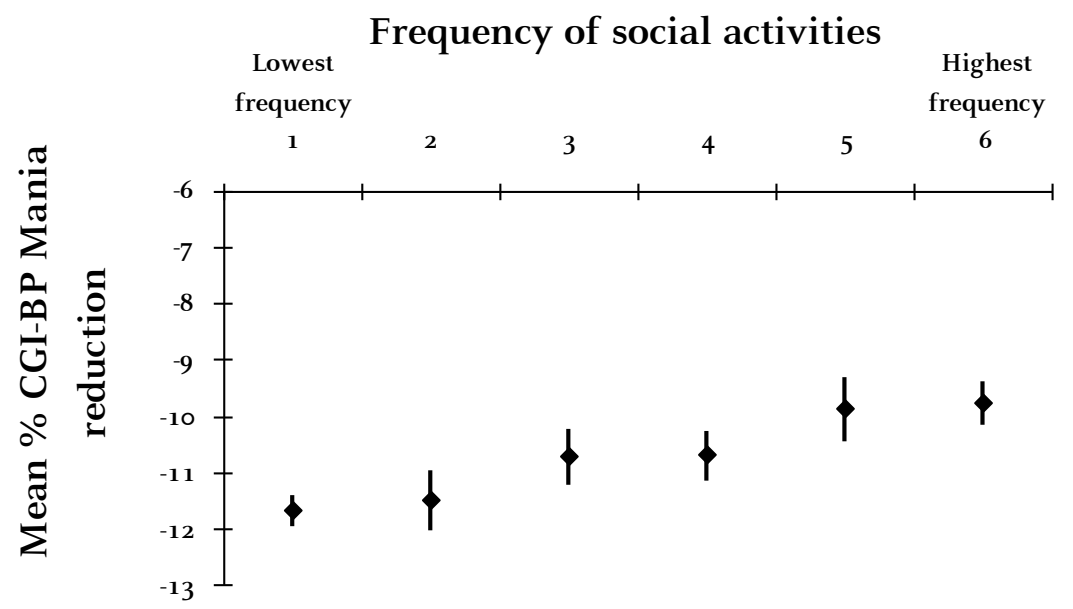

Figure 4 b. Rate of mania symptom improvement per visit as a function of baseline frequency of social activities (from lowest to highest).

Summary reduction in CGI-BP mania (n=2357). Markers represent effect sizes; lines represent upper and lower limits of 95\% confidence interval. The difference in summary reduction between group 1 (highest frequency) and group 6 (lowest frequency) was 1.9\%, representing a $5 \times 1.9=9.5 \%$ difference in symptom improvement over the three-month period. 
Impairment level

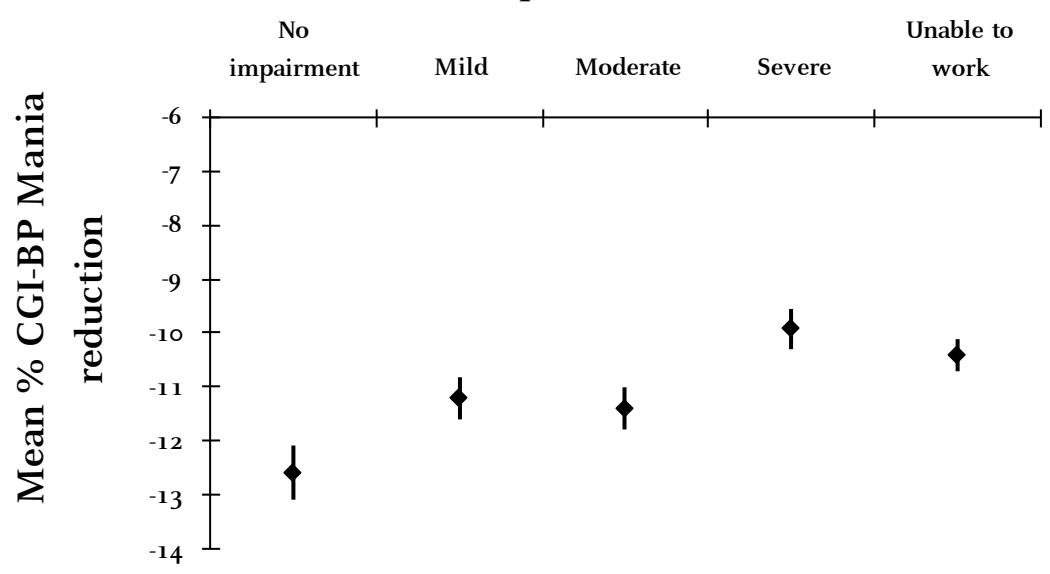

Figure 4c. Rate of mania symptom improvement per visit as a function of baseline level of work impairment.

Summary reduction in CGI-BP mania (n=2345). Markers represent effect sizes; lines represent upper and lower limits of 95\% confidence interval). The contrast in symptom improvement over three months between the reference category of no impairment and severe impairment $(5 \times 1.4 \%=7 \%)$ and unable to work $(5 \times 2.7 \%=13.5 \%)$ exceeded the a priori limit of $5 \%$.

\section{YMRS quintile group}

1

2

3

4 5

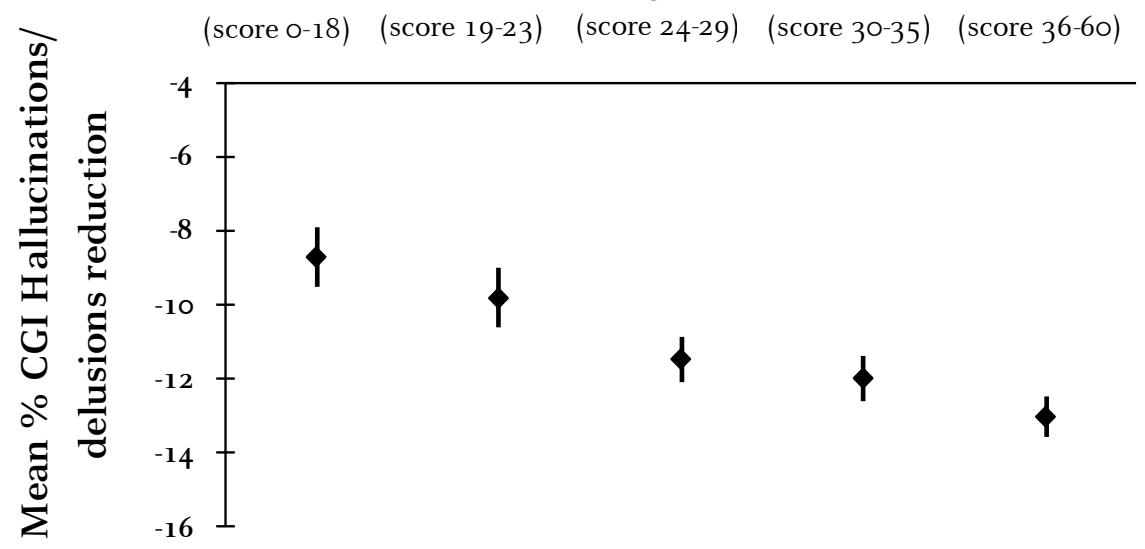

Figure 5a. Rate of psychosis symptom improvement per visit as a function of baseline YMRS quintile group.

For each YMRS quintile group (raw score range provided), the summary reduction in CGI hallucinations/delusions ( $n=1191)$ was calculated. Markers represent effect sizes; lines represent upper and lower limits of 95\% confidence interval). The difference in summary 
reduction between group 1 (lowest score) and group 5 (highest score) was 4.3\%, representing a $5 \times 4.3=21.5 \%$ difference in symptom improvement over the three-month period.

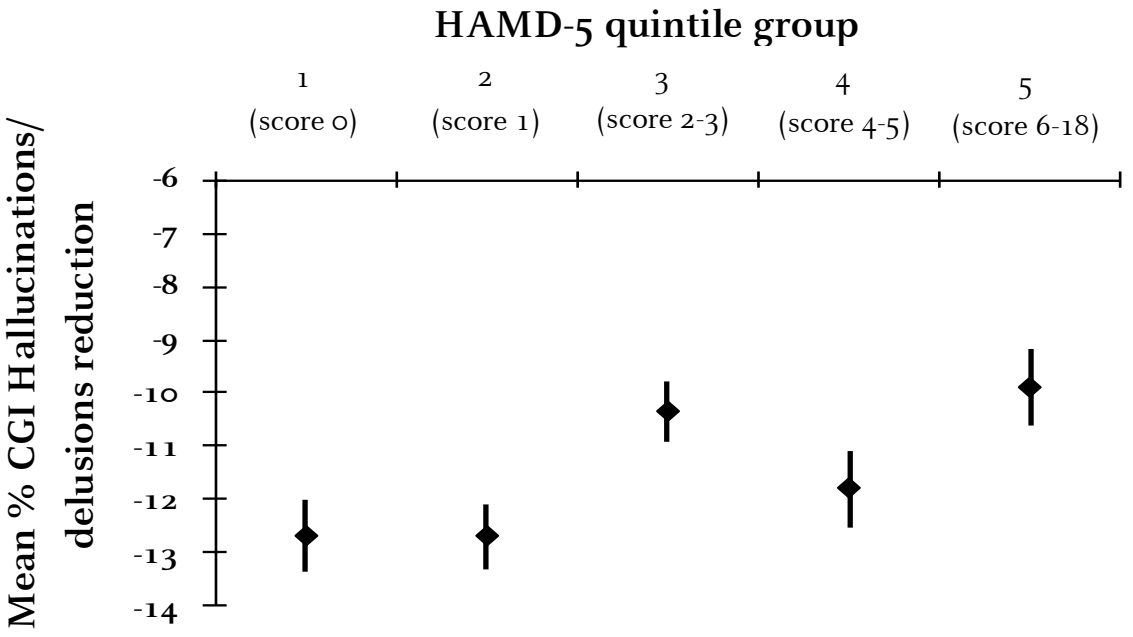

Figure $\mathbf{5}$ b. Rate of psychosis symptom improvement per visit as a function of baseline HAMD-5 quintile group.

For each HAMD-5 quintile group (raw score range provided), the summary reduction in CGI hallucinations/delusions ( $n=1238)$ was calculated. Markers represent effect sizes; lines represent upper and lower limits of $95 \%$ confidence interval). The difference in summary reduction between group 1 (lowest score) and group 5 (highest score) was $2.8 \%$, representing a $5 \times 2.8=14 \%$ difference in symptom improvement over the three-month period.

Depression Moderators in manic patients with evident depression

The rate of improvement on relative CGI-BP depression was not moderated by either baseline YMRS (interaction: $\chi^{2}=4.7, \mathrm{df}=4, P=0.32$ ) or CGI binary hallucinations/delusions (interaction: $\chi^{2}=3.0, \mathrm{df}=1, P=0.09$ ) within the subgroup of patients with a high CGI-BP depression baseline score.

\section{Discussion}

Given the longitudinal nature and large sample size, EMBLEM provides an invaluable source to understand the context of response in patients receiving pharmacological treatment for mania in bipolar disorder.

In this study, mania symptoms as well as psychotic and depressive symptoms were found to be reduced significantly over the course of three months. Higher baseline depression, higher baseline illness severity, higher age of 
onset, rapid cycling, an outpatient status as well as several social and patient factors related to changes in medication were found to be negative moderators of rate of improvement on mania symptoms. Some of these variables have also been reported as predictors of response in acute mania in current literature, but many have not been reported before, particularly those in the social and patient realm. Our findings demonstrate the predictive importance of these specific dimensions, and additionally add a new dimension to the impact of these variables, in terms of their effect on rate of improvement over time. They deserve particular attention throughout the treatment of acute mania as they exert significant influence as predictor as well as moderator variables on individual rate of symptom improvement.

Moderating effects were not confirmed for some of the variables, most importantly substance abuse and dependence, and the CGI hallucinations/ delusions score. Compliance demonstrated moderating effects only if specifically related to reason for changing the medication at baseline, and even then its effect size was modest. Even though the predictive quality of compliance in acute mania treatment has not been reported in the current literature, it was found to have predictive power in the long term ${ }^{22}$ and a moderating effect could reasonably be hypothesized. It is likely, however, that any impact of compliance is secondary to the many covariates that were adjusted for in the realm of clinical and social variables and therefore no strong effect was apparent. Thus, the analyses sheds light on which factors may be primary, and which factors may be secondary moderators of rate of symptom improvement. Furthermore, the impact of poor compliance on treatment outcome may be much more important with regard to long-term rather than short-term outcome ${ }^{23}$, and this study only examined outcome over 3 months.

This explanation may also hold for the absence of a moderating effect of substance abuse and dependence. For example, Calabrese and colleagues ${ }^{24}$ showed that alcohol and drug abuse did not affect the overall response rate in compliant patients treated for acute mania - i.e., if compliance is held constant (is corrected for) the impact of substance and alcohol abuse on treatment outcome is less apparent. Thus, co-morbidity of substance abuse may alter the prognosis by increasing the prevalence of poor compliance and by having an impact on longterm rather than short-term outcome.

The CGI hallucinations/delusions score was found not to have a moderating effect on the rate of improvement regarding mania symptoms. At the 
same time, both low mania and high depression comorbidity at baseline predicted a reduction in improvement of the psychosis dimension in patients with evident psychosis at baseline. This is an interesting finding; a moderating effect of mania symptoms on psychotic symptoms is found in a subgroup of psychotic patients, but not the other way around in the entire sample. A plausible explanation for this finding is that the CGI hallucinations/delusions does have a moderating effect on mania symptoms when analyzed within a homogeneous subgroup of patients with evident psychosis, but is weakened and therefore not significant within this heterogeneous sample.

The rate of improvement on depressive symptoms was not associated with baseline mania and psychosis, which might be caused by a primary treatment focus on mania symptoms. This is illustrated by the $36 \%$ reduction in depression, as opposed to a $52 \%$ and $56 \%$ reduction in mania and psychosis symptoms, respectively. Nevertheless, the absence of a moderating effect of psychosis on treatment outcome regarding depressive symptoms is in line with the report by Dilsaver and co-workers ${ }^{11}$, who failed to find a difference in response on depressive symptoms after controlling for psychosis in a mixed state sample. Indeed, the treatment of depressive symptoms is much less successful than is the treatment of manic symptoms in bipolar disorder ${ }^{25}$.

An important finding was that variables indicating social adversity, social isolation and social inequality such as lower SES, were strongly associated with symptom improvement. Although not unexpected, given the ubiquitous negative influence of social adversity on medical outcomes ${ }^{26}$, the finding serves as a reminder that the outcome of pharmacological treatment is modified by social context. Similarly, any of a range of adverse outcomes of patient-treatment interactions, expressed in this study as compliance, patient requesting change in medication, tolerability and lack of effectiveness, was strongly associated with the rate of improvement in the following twelve weeks. These data suggest that more attention should be directed towards baseline patient-medication interactions as powerful modifiers of subsequent response.

\section{Limitations}

Certain limitations should be taken into account when interpreting these results. Firstly, although limited inclusion criteria were employed, solely patients with an acute manic episode requiring change or initiation of medication were enrolled, whereas in clinical practice often a dose increase with or without co-medication is 
initiated in patients with an acute manic episode. However, due to the observational design of the EMBLEM study, as well as the limited number of inclusion/exclusion criteria, external validity may even be higher as compared to randomised controlled trials, thus enhancing generalisability of the results ${ }^{27,28}$.

Secondly, patients were evaluated by a large number of experienced psychiatrists with reliable but simple scales, which could easily be completed during daily practice. Given that investigators from 14 European countries participated in the study, differences in health care systems may decrease the extent to which data is representative. Additionally, the reliability of the assessments may be reduced by the high number of investigators. Conversely, the naturalistic design of the study provides the unparalleled opportunity to explore this extensive source of clinically relevant information.

Finally, as bipolar disorder is unique in its complexity, a number of factors with a potential moderating effect were not included in the EMBLEM study. For instance, literature indicates that comorbid psychiatric disorders are highly related to the treatment outcome in acute mania, in particular anxiety; patients with high levels of anxiety symptoms are more likely to exhibit cyclothymia, alcohol abuse and suicidal behaviour ${ }^{29}$. Feinman and co-workers ${ }^{30}$ confirmed a significant association between anxiety and substance abuse, while Feske $^{9}$ found that anxiety might lead to more frequent medication changes to reduce potentially anxiety-evoking side effects. As the lifetime prevalence of panic disorder and obsessive compulsive disorder in patients with BD is substantial $\left(20.8 \%\right.$ and $21 \%$ respectively $\left.{ }^{31,32}\right)$, the absence of anxiety related data in the current study should be taken into account when interpreting the results. Additionally, other factors such as current or childhood stressful life events ${ }^{33}$ may influence mania outcome. Assessing the moderating potential of anxiety and other factors forms a challenge for future research.

\section{Conclusion}

In summary, the rate of symptom improvement in acute mania is conditional to a large extent on the social and psychopathological context. Understanding the context of response in terms of the dynamics of the different social, psychopathological and patient environments is a necessary prerequisite for the development of new interventions that go beyond main effects to creating moderating environments that are conducive to treatment response. In addition, a simple set of variables may be used to predict a substantial part of the variability 
in the rate of short-term treatment outcome of acute mania and comorbid psychopathology. 


\section{References}

1. Alda M (2004). The phenotypic spectra of bipolar disorder. Eur Neuropsychopharmacology, 14(s2):S94-9

2. Kleindienst N, Engel R, Greil W (2005). Which clinical factors predict response to prophylactic lithium? A systematic review for bipolar disorder. Bipolar Disord, 7:404-17 Zarate CA, Narendran R, Tohen M, Greaney JJ, Berman A, Pike S, Madrid A (1998). Clinical predictors of acute response with olanzapine in psychotic mood disorders. J Clin Psychiatry, 59:24-8

Black DW, Winokur G, Hulbert J, Nasrallah A (1988). Predictors of immediate response in the treatment of mania: the importance of comorbidity. Biol Psychiatry, 24:191-8

Cohen S, Khan A, Cox G (1989). Demographic and clinical features predictive of recovery in acute mania. J Nerv Ment Disorders, 177:638-42

Welge JA, Keck PE, Meinhold JM (2004). Predictors of response to treatment of acute bipolar manic episodes with divalproex sodium or placebo in 2 randomized, controlled, parallel-group trials. J Clin Psychopharmacology, 24:607-12

7. Zarate CA, Rothschild A, Fletcher KE, Madrid A, Zapatel J (2000). Clinical predictors of acute response with quetiapine in psychotic mood disorders. J Clin Psychiatry, 61:185-9

8. Calabrese JR, Woyshville MJ, Kimmel SE, Rapport DJ (1993). Predictors of valproate response in bipolar rapid cycling. J Clin Psychopharmacology, 13:280-3

Feske U, Frank E, Mallinger AG, Houck PR, Fagiolini A, Shear MK, Grochocinski VI, Kupfer DJ (2000). Anxiety as a correlate of response to the acute treatment of bipolar I disorder. Am J Psychiatry, 157:956-62 Goldberg JF, Garno JL, Leon AC, Kocsis JH, Portera L (1998). Association of recurrent suicidal ideation with nonremission from acute mixed mania. Am J Psychiatry, 155:1753-5

11. Dilsaver SC, Swann AC, Shoaib AM, Bowers TC, Halle MT (1993). Depressive mania associated with nonresponse to antimanic agents. Am J Psychiatry, 150:1548-51

Prien RF, Himmelhoch JM, Kupfer DJ (1988). Treatment of mixed mania. J Affect Disord, 15:9-15

13. Black DW, Winokur G, Bell S, Nasrallah A, Hulbert J (1988). Complicated mania: comorbidity and immediate outcome in the treatment of mania. Arch Gen Psychiatry, 45:232-6

14. Goldberg JF, Garno JL, Leon AC, Kocsis JH, Portera L (1999). A history of substance abuse complicates remission from acute mania in bipolar disorder. J Clin Psychiatry, 60:733-40

15. Cruz N, Vieta E, Comes M, Haro JM, Reed C, Bertsch J, the EMBLEM advisory board (2008). Rapid-cycling bipolar I disorder: Course and treatment outcome of a large sample across Europe. J Psychiatr Res, 42(13):1068-75

16. Vieta E, Calabrese JR, Hennen J, Colom F, Martinez-Aran A, Sanchez-Moreno J, Yatham LN, Tohen M, Baldessarini RJ (2004). Comparison of rapid cycling and non-rapid-cycling bipolar I manic patients during treatment with olanzapine: analysis of pooled data. J Clin Psychiatry, 65:1420-8

17. Spearing MK, Post RM, Leverich GS (1997). Modification of the Clinical Global Impressions (CGI) Scale for use in bipolar illness (BP): the CGI-BP. Psychiatry Res, 73:159-71

18. Young RC, Biggs JT, Ziegler VE, Meyer DA (1978). A rating scale for mania: reliability, validity and sensitivity. Br J Psychiatry, 133:429-35 
19. González-Pinto A, Ballesteros J, Aldama A, Pérez de Heredia JL, Gutierrez M, Mosquera F, González-Pinto A (2003). Principal components of mania. J Affect Disord, 76:95-102

20. Clayton D, Hills M. Walt Tests. In: Statistical models in epidemiology. Oxford, Oxford Science Publication, 1993

21. Goldstein M. Multilevel models in educational and social research. London, Griffin, 1987

22. Tsai SYM, Chen CC, Kuo CJ, Lee JC, Lee HC, Strakowski SM (2001). 15-year outcome of treated bipolar disorder. J Affect Disord, 63:215-20

23. Colom F, Vieta E, Martinez-Aran A, Reinares M, Benabarre A, Gasto C (200o). Clinical factors associated with treatment noncompliance in euthymic bipolar patients. J Clin Psychiatry, 61:549-55

24. Calabrese JR, Shelton MD, Bowden CL, Rapport DJ, Suppes TM, Shirley ER, Kimmel SE, Caban SJ (2001). Bipolar rapid cycling: focus on depression as its hallmark. I Clin Psychiatry, 62(suppl 14):34-41

25. Judd LL, Akiskal HS, Schettler PJ, Endicott J, Maser J, Solomon DA, Leon AC, Rice JA, Keller MB (2002). The long-term natural history of the weekly symptomatic status of bipolar I disorder. Arch Gen Psychiatry, 59:530-7

26. Wilkinson RG (1992). Income distribution and life expectancy. Brit Med J, 304:165-8

27. Licht RW, Gouliaev G, Vestergard P, Frydenberg M (1997). Generalisability of results from randomised drug trials: a trial on antimanic treatment. Brit J Psychiatry, 170:264-7

28. Wells KB (1999). Treatment research at the crossroads: the scientific interface of clinical trials and effectiveness research. Am J Psychiatry, 156:5-10

29. Young LT, Cooke RG, Robb JC, Levitt AJ, Joffe RT (1993). Anxious and non-anxious bipolar disorder. J Affect Disord, 29:49-52

30. Feinman JA, Dunner DL (1996). The effect of alcohol and substance abuse on the course of bipolar affective disorder. J Affect Disord, 37:43-9

31. Chen YW, Dilsaver SC (1995). Comorbidity of panic disorder in bipolar illness: evidence from the Epidemiologic Catchment Area Survey. Am J Psychiatry, 152:280-2

32. Chen YW, Dilsaver SC (1995). Comorbidity for obsessive-compulsive disorder in bipolar and unipolar disorders. Psychiatry Res, 59:57-64

33. Johnson SL, Miller I (1997). Negative life events and time to recovery from episodes of bipolar disorder. J Abnorm Psychol, 106:449-57 


\section{4}

\section{Stability and treatment outcome of distinct classes of mania}

Published:

Inge van Rossum, Josep Maria Haro, Diederik Tenback, Maarten Boomsma, Iris

Goetz, Eduard Vieta, Jim van Os for the EMBLEM Advisory Board (2008).

European Psychiatry, 23:360-7 


\begin{abstract}
Introduction. Psychopathological heterogeneity in manic syndromes may in part reflect underlying latent classes with characteristic outcome patterns. Differential treatment course and outcome after 12 weeks of treatment was examined for 3 distinct classes of patients with acute mania in bipolar disorder.
\end{abstract}

Methods. 3459 Patients with acute mania were divided into 3 distinct mania classes; 'Typical', 'Psychotic' and 'Dual' (i.e. co-morbid substance use) Mania. Persistence of class differences and social outcomes were examined, using multilevel regression analyses and odds ratios.

Results. The 3 classes showed substantial stability post-baseline in the pattern of associations with class-characteristic variables. Psychotic and Dual Mania predicted poorer outcome in terms of psychosis comorbidity, and demonstrated more severe overall bipolar and mania symptoms. Dual Mania additionally predicted poorer outcome of alcohol and substance abuse. Worse social outcomes were observed for both Dual and Psychotic Mania.

Conclusion. The identified distinct classes are stable and associated with differential treatment outcome. Overall, Dual and Psychotic Mania show less favourable outcomes compared to Typical Mania. These findings additionally give rise to concern on generalisability of RCT's. 


\section{Introduction}

Treatment possibilities for bipolar disorder have extended in recent years, reflecting the necessity to accommodate the clinician's need for multiple options to treat this complex disease. However, it remains unclear to what degree treatment outcomes in Randomized Clinical Trials (RCT's) are applicable to the wider population under natural treatment conditions ${ }^{1}$. The application of relatively strict in- and exclusion criteria in RCT's significantly reduces generalization to routine clinical practice. Literature shows that the very exclusion criteria used in RCT's may themselves be associated with outcome; more suicidality $^{2,3}$, substance abuse and dependence ${ }^{4-7}$, more comorbidity ${ }^{2,6}$, and greater illness severity ${ }^{6,8,9}$ are associated with worse outcome in acute mania, suggesting bias may be introduced by not including patients fulfilling these RCT exclusion criteria.

In a recent paper, Haro and colleagues ${ }^{10}$ reported heterogeneity of manic psychopathology, demonstrating that commonly utilized RCT exclusion criteria characterise one distinct class of patients. By combining 20 variables in a Latent Class Analysis approach, the authors found a cluster of 6 baseline clinical and psychopathological patient characteristics, which were able to differentiate three distinct classes of patients with acute mania: 'Typical Mania', 'Psychotic Mania' and 'Dual Mania', constituting 59\%, 28\% and 13\% of the sample, respectively. The authors concluded that exclusion criteria selectively keep out patients from the Dual Mania class (referring to misuse of substances) from RCT's, which may create a gap in our knowledge on treatment effectiveness.

The purpose of the current analyses is to elaborate on the distinction recently made by Haro and co-workers ${ }^{10}$ in the same sample of patients. First, validity of the classes was examined in terms of continued discriminate ability over time, hypothesising that analyses would show persistent differences between classes in terms of psychopathology and substance misuse over the follow-up period. Second, the hypothesis that differential treatment response, in terms of change from baseline, would exist between the classes in both the psychopathological and social domains, with less favourable treatment outcomes for the Psychotic Mania and Dual Mania classes, was examined. The main goal of the analyses was to examine to what degree the three groups would remain separate over time, similar to the classic design of follow-up studies of different diagnostic categories within severe mental illness, in order to establish whether there are differences in outcome that would validate the continuing use of the 
diagnostic classification. However, given the fact that any outcome difference between diagnostic groups must be mediated by other variables, we hypothesised that the 6 patient characteristics that discriminated between the 3 classes at baseline $^{10}$ would also mediate outcome separations between the classes after 12 weeks of treatment.

\section{Methods}

Data from the EMBLEM study was utilized for the current analyses. The study design was described elaborately in Chapter 1 and in previous reports ${ }^{10,11}$. In short, the EMBLEM is a large European prospective observational study, studying patients with a change in pharmacological treatment for acute mania. For the current analyses, data from the acute phase (assessments as baseline and after 1, 2, 3, 6 and 12 weeks) were employed.

\section{$\underline{\text { Classes }}$}

For 3425 patients, sufficient data was available to assign them to the Typical $(\mathrm{n}=2020,59.0 \%)$, Psychotic $(\mathrm{n}=960,28.0 \%)$ or Dual Mania $(\mathrm{n}=445,13.0 \%)$ class for the purpose of the current analyses. This classification was based on a previous analysis of the baseline data of the same patient sample by Haro et al. ${ }^{10}$. Psychotic Mania was characterised by a relatively high percentage of patients with a Clinical Global Impression Bipolar Disorder (CGI-BP) overall illness score of at least 6 (severely ill), and the presence of hallucinations and/or delusions in all instances. Patients with Dual Mania showed comorbid substance use problems, a higher risk of suicide attempts and hospitalisation, poorer treatment compliance and a higher level of functional impairment. Typical Mania patients were characterised by a low prevalence of both psychotic symptoms and substance use problems.

\section{Psychopathology: persistent differences between classes}

In order to test for persistent differences in psychopathology between classes, CGI measures of psychopathology were used, measured at baseline and after 1, 2, 3, 6 and 12 weeks. Thus, symptom severity of bipolar disorder, mania, psychosis and depression was captured using the following clinical assessment scales: CGI-BP overall illness; CGI-BP mania, CGI hallucinations/delusions, and CGI-BP depression, respectively (all rated for severity on a seven-point scale ${ }^{12}$ ). 
$\underline{\text { Substance misuse measures }}$

Investigators were requested to assess the patients' current use of cannabis, alcohol and other substances, based on the patient's self-report and the investigator's clinical experience and judgement. In order to test for persistent differences in substance use between classes, and to test for differences in outcome of substance use, assessments at baseline and after 12 weeks on alcohol use, cannabis use and other drug use (e.g. heroin) in the past three months $(\mathrm{o}=$ no use, $1=$ use, $2=$ abuse, $3=$ dependence) were used (these measures had not been collected at visits in between).

\section{Psychopathology: treatment outcome differences between classes}

In order to test for differences between classes in treatment outcome of psychopathology, the Young Mania Rating Scale ${ }^{13}$ (YMRS) and the 5-item version of the Hamilton Depression Rating Scale ${ }^{14}$ (HAMD-5) were used. The HAMD-5 was constructed on the basis of factor analyses, demonstrating five independent and clinically interpretable factors corresponding to depressive mood, suicide ideation, guilt, obsessions and psychic anxiety. These scales were administered at baseline and again after 6 and 12 weeks. In addition, measures of the CGI-BP overall illness, CGI-BP mania, CGI hallucinations/delusions and CGI-BP depression were used in order to assess differences in treatment outcome in these dimensions.

\section{$\underline{\text { Social outcome: differences between classes }}$}

In order to test for differences in social outcome between the classes, measures of social circumstances, administered at baseline and 12 weeks post-baseline, were used. Social factors were examined using non-validated but simple rating scales, measuring: i) independent living (o=living independently, $1=$ not living independently); ii) work impairment ( $\mathrm{o}=$ no impairment, $1=$ mild impairment, $2=$ moderate impairment, $3=$ severe impairment, $4=$ unable to work due to mental illness); iii) relationship (o=relationship, $1=$ no relationship); iv) frequency of social activities in the past 4 weeks $(1=5$ or more times to $5=0$ times); v) number of dependents to care for ( $\mathrm{O}=\mathrm{O}$ dependents to $4=4$ dependents or more) and vi) satisfaction with life (1=very satisfied, $2=$ satisfied, $3=$ neither satisfied nor dissatisfied, $4=$ dissatisfied, $5=$ very dissatisfied). 


\section{Analyses}

Analyses were carried out using the STATA statistical program ${ }^{15}$. As the Typical Mania class comprised almost $60 \%$ of the study population ${ }^{10}$, this class served as the reference group in all analyses. All analyses were adjusted for country. Other covariates were included as described per analysis below. The sample sizes for the individual analyses varied somewhat on the basis of the availability of complete data for all included variables (minimum 2491, maximum 3351).

\section{Persistent differences between classes in psychopathology}

The purpose of this analysis was to establish whether the diagnostic distinction of the classes would continue to be evident post-baseline. As it was not the purpose of the analyses to examine which variables mediated this distinction, no covariates other than country were introduced in the models. Thus, in order to test whether the three classes would continue to demonstrate differences in psychopathology post-baseline, the effect of baseline class type (independent variable) on post-baseline CGI-BP overall, CGI-BP mania, CGI hallucinations/delusions, and CGI-BP depression (dependent variable) was calculated. As in these analyses there were five post-baseline observations per individual, compromising statistical independence of observations clustered within the same individual, a multilevel random regression analysis ${ }^{16}$ was performed. Effect sizes were expressed as B coefficients and their 95\% Confidence Intervals (CI's).

\section{Persistent differences between classes in substance use}

In order to test whether the three classes would continue to demonstrate differences in measures of substance use, the effect of baseline class type (independent variable) on alcohol use, cannabis use and substance use after 12 weeks (dependent variable), was calculated using multiple linear regression analysis.

\section{Differences between classes in psychopathological treatment outcome}

The purpose of this analysis was to establish whether the diagnostic distinction of the classes would predict differential change in selected outcomes. As it was not the purpose of the analyses to examine which variables mediated differential change, no covariates other than country and baseline measure of the outcome were introduced in the models. Thus, in order to examine whether the three 
classes would demonstrate a differential treatment response, the effect of baseline class type (independent variable) on post-baseline HAMD-5, YMRS, CGI-BP overall illness, CGI-BP mania, CGI hallucinations/delusions and CGI-BP depression at 6 and 12 weeks post-baseline was calculated. These analyses were adjusted for their baseline measures (i.e. post adjusted for pre), in order to assess possible differences between classes in change in HAMD-5, YMRS and CGI-BP scores over the 12 week period. As in these analyses there were two post-baseline observations per individual, compromising statistical independence of observations clustered within the same individual, a multilevel random regression analysis $^{16}$ was performed. Effect sizes were expressed as B coefficients and their 95\% Confidence Intervals (CI's).

\section{Differences between classes in substance use outcome}

In order to determine whether the three classes would demonstrate differences in substance use outcome post-baseline, the effect of baseline class type (independent variable) on post-baseline measures of alcohol, cannabis and other substance use at visit 6, 12 weeks post-baseline (dependent variable), was calculated, adjusted for country and their baseline measures (i.e. post adjusted for pre), in order to assess the impact of class type on change in substance use variables. Multiple linear regression models were utilized, providing effect sizes as B coefficients and their 95\% Confidence Intervals (CI's).

\section{Differences between classes in social outcome}

For the 3 dichotomous social variables, a logistic regression model was applied, in which the effect of baseline class type (independent variable) was calculated on social outcome at 12 weeks post-baseline (dependent variable), adjusting for the baseline measure of the social outcome variable. This model (post adjusted for pre) in effect assess change over time in social outcome as a function of the class type at baseline. Effect sizes were expressed as odds ratios and 95\% CI's. For the 3 continuous social variables, a similar analysis was conducted using multiple linear regression.

\section{Mediation of discriminating factors between classes}

Finally, analyses were conducted in order to determine to what extent the factors that discriminated between the 3 classes at baseline ${ }^{10}$ mediated outcome separations after 12 weeks of treatment. The 6 factors were: high CGI-BP mania 
score $(\mathrm{o}=$ score of 1 to $5 ; 1=$ score of 6 or 7 ), presence of hallucinations/delusions in current episode $(\mathrm{o}=\mathrm{no}$, indicating CGI Hallucinations/delusions score of 1 or 2; $1=y e s$, indicating CGI Hallucinations/delusions score of 3 or higher), alcohol problem ever ( $\mathrm{o}=$ no, $1=$ yes), cannabis problem ever ( $\mathrm{o}=$ no, $1=y e s)$, other substance problem ever $(\mathrm{o}=\mathrm{no}, 1=\mathrm{yes})$, current cannabis use (o=no use, $1=$ use/abuse/dependence). In order to test mediating effects, the six discriminating factors were additionally added to the multilevel regression models of the effects of classes on outcome variables described previously. Factors were regarded as mediators of differential outcomes between classes when the association between a class and an outcome variable did not persist after including the discriminating factors into the model. Effect sizes were expressed as B coefficients and their 95\% Confidence Intervals (CI's).

\section{Results}

\section{Sample description}

A total of 3684 subjects participated in EMBLEM. 3425 patients fulfilled the requested criteria ${ }^{11}$ and additionally presented with sufficient data to assign them to one of the three classes, and were therefore included in the current analyses. An extensive overview of demographic and clinical characteristics of the three classes of patients in this sample, as well as the inclusion criteria, are given in a previous report $^{10}$. Table 1 provides baseline demographic and clinical characteristics for the complete patient sample as well as the 3 distinct 'Typical Mania', 'Psychotic Mania' and 'Dual Mania' classes.

Table 1. Demographic and clinical characteristics of 3425 patients in 3 distinct mania classes.

\begin{tabular}{lcccc}
\hline & $\begin{array}{c}\text { Complete } \\
\text { group } \\
(\mathrm{n}=3425)\end{array}$ & $\begin{array}{c}\text { Typical mania } \\
(\mathrm{n}=2020)\end{array}$ & $\begin{array}{c}\text { Psychotic } \\
\text { mania } \\
(\mathrm{n}=960)\end{array}$ & $\begin{array}{c}\text { Dual } \\
\text { mania } \\
(\mathrm{n}=445)\end{array}$ \\
\hline Number of patients (\%) & 100 & 59.0 & 28.0 & 13.0 \\
Age (mean, sd) & $44.6(13.4)$ & $47.3(13.2)$ & $44.0(12.8)$ & $34.1(9.7)$ \\
Age of onset (mean, sd) & $29.9(11.0)$ & $31.3(11.4)$ & $30.2(10.8)$ & $23.7(6.9)$ \\
Female (\%) & 55.4 & 59.0 & 59.7 & 29.8 \\
Inpatient status (\%) & 58.1 & 62.6 & 53.4 & 47.9 \\
Rapid cycling (\%) & 17.3 & 19.6 & 12.2 & 17.8 \\
\hline
\end{tabular}


Table 2 provides an overview of scores on the CGI scales, YMRS and HAMD-5, substance use and social factors at baseline and after 12 weeks. Table 3 shows the prescribed medication by class after 12 weeks of treatment. Medication differences were in the expected direction, with psychotic mania having the highest rate of combination therapy. Detailed drug status of the three classes was described by Haro and colleagues ${ }^{10}$. Dropout rate was $20 \%$ over 6 weeks, most commonly due to loss of contact after discharge from the hospital or change of treating clinician.

\section{Class differences in post-baseline psychopathological symptoms}

Compared to the Typical Mania class, both the Psychotic Mania (B=0.52, CI: 0.44 , $0.60 ; \mathrm{P}<.001)$ and the Dual Mania class ( $\mathrm{B}=0.37, \mathrm{CI}: 0.27,0.48 ; \mathrm{P}<.001)$ showed significantly higher scores on the CGI-BP overall illness at the post-baseline measurements. The CGI-BP mania scores were found to be significantly higher post-baseline in the Psychotic Mania ( $\mathrm{B}=0.58, \mathrm{CI}$ : 0.50, 0.66 ; $\mathrm{P}<.001)$ and the Dual Mania classes $(\mathrm{B}=0.42, \mathrm{CI}: 0.31,0.52 ; \mathrm{P}<.001)$, compared to the Typical Mania class. Similar results were apparent for the YMRS scores (Psychotic: B=0.22, CI: 0.16, 0.27; $\mathrm{P}<.001$; Dual: $\mathrm{B}=0.29$, CI: $0.21,0.36 ; \mathrm{P}<.001)$.

Class difference in post-baseline substance abuse and change in substance abuse At baseline, the Dual Mania class patients were characterised by substance use problems, in contrast to the other classes. Post-baseline, the Dual Mania class continued to show significantly higher rates of cannabis, alcohol and other substance use, compared to the Typical Mania class, after adjustment for country, indicating persistence of class differences in terms of substance abuse (cannabis: $\mathrm{B}=0.47, \mathrm{CI}: 0.44,0.50 ; \mathrm{P}<.001$; alcohol: $\mathrm{B}=0.35, \mathrm{CI}: 0.29,0.41 ; \mathrm{P}<.001$; other substances: $\mathrm{B}=0.15, \mathrm{CI}: 0.12,0.18 ; \mathrm{P}<.001)$.

When additionally adjusting for baseline measures of substance use, thus effectively assessing possible differences between classes in change in substance abuse over the 12 weeks period, the differences between the Dual Mania and the Typical Mania class largely remained, indicating less reduction in cannabis and alcohol abuse (cannabis: $\mathrm{B}=0.11, \mathrm{CI}$ : 0.06, 0.15; $\mathrm{P}<.001$; alcohol: $\mathrm{B}=0.16, \mathrm{CI}$ : 0.11 , $0.22 ; \mathrm{P}<.001)$; change in use of other substances, however, were not significantly different. 
Page 78

Table 2 (continued on next page). Clinical and social variables at baseline and after 12 weeks of 3 mania classes.

\begin{tabular}{|c|c|c|c|c|c|}
\hline & & $\begin{array}{l}\text { Complete group } \\
\qquad(\mathrm{n}=3425)\end{array}$ & $\begin{array}{l}\text { Typical mania } \\
\quad(\mathrm{n}=2 \mathrm{O} 20)\end{array}$ & $\begin{array}{l}\text { Psychotic mania } \\
(\mathrm{n}=960)\end{array}$ & $\begin{array}{l}\text { Dual mania } \\
\quad(\mathrm{n}=445)\end{array}$ \\
\hline \multirow{2}{*}{$\begin{array}{l}\text { CGI-BP overall } \\
\text { illness (mean, sd) }\end{array}$} & Baseline* & $4.1(1.3)$ & $3.9(1.2)$ & $4.4(1.5)$ & $4.3(1.3)$ \\
\hline & $12 \mathrm{wks}$ & $2.7(1.3)$ & $2.6(1.3)$ & $2.7(1.3)$ & $2.7(1.4)$ \\
\hline \multirow{2}{*}{$\begin{array}{l}\text { CGI-BP mania } \\
\qquad(\text { mean, sd })\end{array}$} & Baseline & $4.8(1.0)$ & $4.4(0.8)$ & $5.6(0.7)$ & $4.9(0.9)$ \\
\hline & $12 \mathrm{wks}$ & $2.2(1.2)$ & $2.1(1.2)$ & $2.3(1.3)$ & $2.3(1.3)$ \\
\hline \multirow{2}{*}{$\begin{array}{l}\text { CGI-BP hallucinations / } \\
\text { delusions (mean, sd) }\end{array}$} & Baseline & $3.0(1.8)$ & $2.1(1.4)$ & $4.5(1.4)$ & $3.4(1.7)$ \\
\hline & $12 \mathrm{wks}$ & $1.6(1.0)$ & $1.4(0.9)$ & $1.8(1.2)$ & $1.7(1.1)$ \\
\hline \multirow{2}{*}{$\begin{array}{l}\text { CGI-BP depression } \\
\qquad(\text { mean, sd })\end{array}$} & Baseline & $1.9(1.2)$ & $1.9(1.2)$ & $1.8(1.2)$ & $1.8(1.1)$ \\
\hline & $12 \mathrm{wks}$ & $1.8(1.1)$ & $1.8(1.1)$ & $1.7(1.1)$ & $1.7(1.1)$ \\
\hline \multirow[t]{2}{*}{ YMRS (mean, sd) } & Baseline & $27.6(10.5)$ & $23.6(8.8)$ & $34.7(9.4)$ & $30.8(10.3)$ \\
\hline & $12 \mathrm{wks}$ & $6.7(7.9)$ & $6.0(7.0)$ & $7.6(9.0)$ & $8.3(9.2)$ \\
\hline \multirow[t]{2}{*}{ HAMD-5 (mean, sd) } & Baseline & $2.8(2.8)$ & $2.9(2.7)$ & $2.8(2.9)$ & $2.7(2.8)$ \\
\hline & $12 \mathrm{wks}$ & $2.1(2.5)$ & $2.1(2.6)$ & $2.0(2.4)$ & $2.1(2.3)$ \\
\hline \multirow[t]{2}{*}{ Alcohol use current** (\% ) } & Baseline & $43 \%$ & $38 \%$ & $38 \%$ & $76 \%$ \\
\hline & $12 \mathrm{wks}$ & $27 \%$ & $25 \%$ & $22 \%$ & $52 \%$ \\
\hline \multirow[t]{2}{*}{ Cannabis use current** $(\%)$} & Baseline & $12 \%$ & $1 \%$ & $4 \%$ & $75 \%$ \\
\hline & $12 \mathrm{wks}$ & $5 \%$ & $1 \%$ & $2 \%$ & $37 \%$ \\
\hline \multirow{2}{*}{$\begin{array}{l}\text { Other substance use } \\
\text { current** }(\%)\end{array}$} & Baseline & $7 \%$ & $3 \%$ & $3 \%$ & $32 \%$ \\
\hline & $12 \mathrm{wks}$ & $3 \%$ & $2 \%$ & $1 \%$ & $13 \%$ \\
\hline
\end{tabular}


Table 2 (continued from previous page). Clinical and social variables at baseline and after 12 weeks of 3 mania classes.

\begin{tabular}{|c|c|c|c|c|c|}
\hline & & $\begin{array}{l}\text { Complete group } \\
\qquad(\mathrm{n}=3425)\end{array}$ & $\begin{array}{c}\text { Typical mania } \\
\qquad(\mathrm{n}=2 \mathrm{O} 20)\end{array}$ & $\begin{array}{l}\text { Psychotic mania } \\
\qquad(\mathrm{n}=960)\end{array}$ & $\begin{array}{c}\text { Dual mania } \\
(\mathrm{n}=445)\end{array}$ \\
\hline Independent living situation & Baseline & $42 \%$ & $37 \%$ & $47 \%$ & $52 \%$ \\
\hline$(\%)$ & $12 \mathrm{wks}$ & $41 \%$ & $35 \%$ & $49 \%$ & $53 \%$ \\
\hline \multirow[t]{2}{*}{ Current relationship (\%) } & Baseline & $59 \%$ & $63 \%$ & $59 \%$ & $43 \%$ \\
\hline & $12 \mathrm{wks}$ & $60 \%$ & $63 \%$ & $59 \%$ & $44 \%$ \\
\hline Severe work impairment / & Baseline & $38 \%$ & $32 \%$ & $45 \%$ & $51 \%$ \\
\hline unable to work (\%) & $12 \mathrm{wks}$ & $25 \%$ & $20 \%$ & $32 \%$ & $34 \%$ \\
\hline
\end{tabular}

${ }^{*}$ CGI BP overall illness measure at baseline relates to symptoms severity during the past year. ${ }^{* *}$ Current substance use is the sum of use, abuse and dependence 
Table 3. Prescribed medication after 12 weeks of treatment for the 3 mania classes.

\begin{tabular}{lccc}
\hline & $\begin{array}{c}\text { Typical } \\
\text { Mania } \\
(\mathrm{n}=2020)\end{array}$ & $\begin{array}{c}\text { Psychotic } \\
\text { Mania } \\
(\mathrm{n}=960)\end{array}$ & $\begin{array}{c}\text { Dual } \\
\text { Mania } \\
(\mathrm{n}=445)\end{array}$ \\
\hline No medication (\%) & 2.6 & 1.2 & 0.3 \\
Monotherapy total (\%) & 37.9 & 27.0 & 32.9 \\
Monotherapy antipsychotics (\%) & 22.8 & 19.2 & 22.9 \\
Monotherapy anticonvulsants (\%) & 11.4 & 3.8 & 7.8 \\
Monotherapy lithium (\%) & 3.6 & 4.0 & 2.2 \\
& & & 66.8 \\
Combination therapy total (\%) & 59.5 & 71.8 & 4.4 \\
Combination therapy multiple & 3.8 & 4.1 & 11.3 \\
$\quad$ antipsychotics (\%) & & & \\
Combination therapy antipsychotic \& & 13.0 & 14.4 & 34.8 \\
$\quad$ lithium (\%) & & & \\
Combination therapy antipsychotic \& & 29.8 & 34.3 & \\
$\quad$ anticonvulsant (\%) & & & 18.9 \\
Other combinations (\%) & 13.0 & & \\
\hline
\end{tabular}

Class differences in changes in social outcome

For the calculation of odds ratios for dichotomous social variables, Typical Mania again served as the reference class. Patients from the Psychotic Mania as well as the Dual Mania class showed significantly higher probabilities of changing from an independent to a dependent living situation over 12 weeks of treatment (Psychotic Mania OR=1.95, CI: 1.35, 2.82; P<.001; Dual Mania OR=2.36, CI: 1.48, 3.78; $\mathrm{P}<.001)$. Additionally, patients from the Psychotic and Dual Mania classes had a significantly higher probability of changing from having a relationship to not having a relationship $(\mathrm{OR}=1.71, \mathrm{CI}: 1.03,2.83 ; \mathrm{P}=.049$ and $\mathrm{OR}=2.72, \mathrm{CI}: 1.49$, 4.97; $\mathrm{P}=.001$, respectively). Furthermore, the Dual Mania class had significantly less dependents to care for, compared to the Typical Mania class (B=-0.07, CI: -0.13, -0.02; $\mathrm{P}=.012$ ). Finally, both Psychotic and Dual Mania classes showed significantly higher probabilities of experiencing an increase in work impairment (OR=2.72, CI: 1.80, 4.12; $\mathrm{P}<.001 ; \mathrm{OR}=2.47, \mathrm{CI}: 1.44,4.26 ; \mathrm{P}=.001$, respectively) and demonstrated less satisfaction with life $(\mathrm{B}=0.11, \mathrm{CI}$ : $0.02,0.20 ; \mathrm{P}=.018 ; \mathrm{B}=0.14, \mathrm{CI}$ : $0.02,0.26$; $\mathrm{P}=.023$, respectively). The classes did not differ in the frequency of social activities. 
Class differences in changes in psychopathological outcome

Differential psychopathological outcomes between the classes were determined by adjusting analyses for baseline values, therefore assessing differences in improvement of psychopathological symptoms over the 12 week period between the classes. The Psychotic as well as the Dual Mania class showed less change on the CGI-BP overall illness after 12 weeks, indicating less improvement over the course of the acute treatment phase $(\mathrm{B}=14.01, \mathrm{CI}$ : 10.60, 17.42; $\mathrm{P}<.001$ and $\mathrm{B}=8.43$, CI: 3.89, 12.97; $\mathrm{P}<.001$, respectively). Changes in CGI-BP mania, CGI hallucinations/delusions, CGI-BP depression and the HAMD-5 were not significantly different between the classes. However, there was significantly less improvement as measured by the YMRS in the Dual Mania class after 3 months of treatment ( $\mathrm{B}=0.11, \mathrm{CI}: 0.03,0.18 ; \mathrm{P}=.005)$.

Table 4. Associations between classes and outcome measures after adding the six classdiscriminating variables to the outcome model.

\begin{tabular}{|c|c|c|}
\hline & Psychotic Mania $†$ & Dual Mania $\dagger$ \\
\hline CGI Hallucinations/ & $\mathrm{B}=0.12$ & $\mathrm{~B}=0.13$ \\
\hline delusions & $(95 \%$ CI:०.০8, o.16; P<.001) & (95\%CI:0.03, 0.22; $\mathrm{P}=.007$ ) \\
\hline \multirow[t]{2}{*}{ Cannabis use } & $*$ & $\mathrm{~B}=0.19$ \\
\hline & & (95\%CI:0.14, 0.23; P<.001) \\
\hline \multirow[t]{2}{*}{ Alcohol use } & * & $\mathrm{B}=0.09$ \\
\hline & & (95\%CI:०.00, 0.18; P=.048) \\
\hline Higher chance of living & $\mathrm{OR}=1.75$ & $\mathrm{OR}=2.30$ \\
\hline dependently & (95\%CI:.1.06, 2.88; P=.029) & $(95 \% C I ; 1.08,4.94 ; \mathrm{P}=.032)$ \\
\hline Higher chance of not & $\ddagger$ & $\mathrm{OR}=3.49$ \\
\hline having a relationship & & (95\%CI:1.31, 9.30; $\mathrm{P}=.012$ ) \\
\hline Less dependents & * & $B=-0.11$ \\
\hline to care for & & $(95 \%$ CI:-0.20, -0.02; P=.015) \\
\hline \multirow[t]{2}{*}{ Higher work impairment } & $\mathrm{OR}=2.13$ & $\mathrm{OR}=2.24$ \\
\hline & $(95 \% \mathrm{CI} ; 1.23,3.70 ; \mathrm{P}=.007)$ & (95\%CI: $1.00,5.13 ; \mathrm{P}=.050$ ) \\
\hline
\end{tabular}

$*=$ not significant in original analyses, therefore mediation was not tested. $\dagger=$ reference group is Typical Mania. $\ddagger=$ significant association did not persist 
Mediation of discriminating factors between classes

Mediation of the 6 factors that discriminated the 3 classes at baseline was tested for all significant associations found. After including these variables into the models, several mediating effects became apparent. The differential outcomes between the Psychotic and Dual classes on the one hand and Typical Mania on the other in the individual models of CGI-BP overall illness, depression and mania scores as well as the YMRS, substance use and satisfaction with life did not persist. However, for the CGI Hallucinations/delusions score and the social outcomes there was no evidence of mediation with the exception of not being in a relationship (Table 4).

\section{Discussion}

As a large prospective, observational study, the EMBLEM provides a unique opportunity to unravel the context of response in patients receiving pharmacological treatment for mania in bipolar disorder. The results of the current study strengthen the findings of Haro and colleagues ${ }^{10}$; the 3 classes of patients that were previously distinguished using the baseline data were stable in terms of discriminatory power over the course of the acute treatment phase. The Psychotic as well as the Dual Mania Class showed both a higher CGI-BP mania and a higher CGI-BP overall illness score after 3 months, compared to the Typical Class, replicating findings at baseline ${ }^{10}$. While Psychotic and Dual Mania continued to score higher on psychosis, the Dual Mania class additionally persisted in demonstrating significantly more alcohol, cannabis and substance abuse. Haro and colleagues found these 3 variables (severity of mania, presence of psychosis and substance abuse) to be most important in defining the latent classes.

Additionally, the 3 classes were associated with differential treatment response after 12 weeks of treatment, confirming diagnostic heterogeneity in manic psychopathology. Dual and Psychotic Mania displayed inferior response to treatment: after adjusting for baseline values, significantly higher ratings of mania symptoms in the Dual Mania class were found after 12 weeks of treatment, and both classes displayed less improvement on overall bipolar symptoms, compared to Typical Mania. Moreover, compared to the reference group of Typical Mania, patients from the Psychotic Mania as well as the Dual Mania class had poorer social outcomes in terms of independent living, current relationships, work impairment and satisfaction with life. Dual Mania patients had the poorest outcome in terms of number of dependents to care for. Overall, this may indicate 
that the Psychotic and Dual Mania classes suffer from a more severe manic syndrome, compared to Typical Mania, albeit in different contexts with regard to psychotic symptoms and substance abuse.

The validity of the diagnostic subtypes is underscored by the finding that most psychopathological differences between the classes after 12 weeks of treatment were mediated by the 6 factors that defined the classes initially ${ }^{10}$. The only exception was the persistently higher CGI Hallucinations/delusions score in the Dual and Psychotic classes compared to Typical Mania, which may indicate that other demographic or clinical differences between the groups at baseline or during the study additionally affect this symptom cluster. For example, earlier work shows that a lower age of onset reduces the rate of treatment response in acute mania ${ }^{8}$. Additionally, Lin and colleagues demonstrated that age of onset was associated with clinical heterogeneity ${ }^{17}$. Specifically, 3 normal distributions of age of onset could be identified within a group of bipolar patients. The subgroup with a younger age of onset was associated with comorbid substance use problems as well as a higher risk of suicide attempts; factors that were characteristic of our Dual Mania class $^{12}$. Despite the uneven distribution of this variable across the classes, and even though these differences may not be crucial for the statistical separation of subgroups, they nevertheless may impact treatment outcome. This principle may also explain the finding that the 6 factors did not account for the differences in social outcome and the rate of substance abuse between the classes.

The findings are in line with existing literature; substance abuse and dependence were previously found to be associated with worse outcome in acute mania $^{4,5,6,7}$, which is confirmed by the Dual Mania Class outcomes in the current study. Both Dual and Psychotic Mania classes showed significantly higher CGI-BP mania scores at baseline ${ }^{10}$ as well as after 12 weeks of treatment, which corresponds with the findings of Welge and co-workers ${ }^{9}$ that greater illness severity is associated with an unfavourable outcome. This association is reflected in differential non-psychopathological outcomes that were observed; the Psychotic as well as the Dual Mania class showed significantly higher probabilities of unfavourable changes in social circumstances. These findings may be partly explained by a slower recovery of symptoms due to more severe clinical symptomatology in these patients. This is in line with recent findings by our group $^{8}$, as greater baseline illness severity was found to significantly reduce the rate of improvement in mania symptoms. Furthermore, it confirms the finding by 
Kessing $^{19}$, who demonstrated prolonged hospitalisation for manic patients with psychotic symptoms, compared to patients without these symptoms.

The classes did not differ on all outcome measures. There were no differences in changes over the 12 week period in the number of social activities, which might be related to the relatively short follow-up period of 12 weeks. Restoring social circumstances may be part of a longer-term recovery process after an acute manic episode.

Overall, the clinical heterogeneity at baseline reported by Haro and colleagues $^{10}$ persisted over a period of 12 weeks, and the classes additionally displayed distinctive treatment responses. Heterogeneity of manic patients is not a new phenomenon; Kraepelin ${ }^{20}$ was the first to distinguish subgroups, which were partly confirmed in the past $\operatorname{decade}^{21,22}$. Although the results are far from homogeneous, the existence of a group of patients with psychotic mania is frequently observed, as well as other groups with aggressive or irritable mania and mania with anxiety symptoms ${ }^{10}$. Dysphoric and euphoric subgroups have also been reported $^{23}$. Even though we were not able to investigate all reported subgroups, the currently reported distinction results in differential treatment outcomes of three classes, and therefore should be taken into account when treating individual patients for realistic treatment expectations to be set. Furthermore, these findings are clinically relevant in a second perspective; generalisability of RCT's. As RCT's of pharmacological treatments for acute mania focus on the first few months of treatment, the current findings suggest that RCT's are conducted with patients representing roughly $60 \%$ of the bipolar patient population, and efficacy results are therefore not representative of the target population. Moreover, the patients with a less favourable outcome are usually excluded from these studies, based on factors that characterise the Psychotic and Dual Mania classes.

Strict placebo-controlled trials are imperative to determine anti-manic efficacy of new compounds. As correctly stated by Mant and colleagues ${ }^{24}$, it is a basic principle of epidemiology that the internal validity of a study is more important than its generalisability, since it is never appropriate to generalize an invalid finding. However, reports on RCT's rarely disclose the patient sample composition, which complicates the application of results to the patients seen in different clinical settings. Moreover, most RCT's investigate efficacy of monotherapy, whereas our patient sample suggests that the majority of patients is prescribed combination therapy. Naturalistic studies using broad inclusion criteria, 
comparing the various treatments, alone or in combination, are necessary to investigate effectiveness of treatments in clinical practice. The results of controlled clinical studies with selected samples of patients need to be complemented by these naturalistic studies as demonstrated by our findings.

\section{Limitations}

Several limitations should be considered when interpreting these results. First of all, solely patients with an acute manic episode requiring change or initiation of medication were enrolled. In contrast, in clinical practice often a dose increase with or without co-medication is initiated in patients with an acute manic episode ${ }^{25,26}$. However, in line with the current discussion, due to the observational design of the EMBLEM study as well as the limited number of inclusion and exclusion criteria, external validity may be higher compared to RCT's ${ }^{27,28}$ as a broader range of patients is included.

Secondly, a large number of experienced psychiatrists from 14 European countries evaluated the included patients, which may decrease the extent to which data is representative due to differences in health care systems. Additionally, the high number of investigators may have reduced the reliability of the assessments. To reduce the impact of the latter aspect, reliable but simple scales which could easily be completed during usual practice, were chosen for evaluation of the patients. Although scales such as the CGI-hallucinations/delusions have not been formally validated, the face validity of a procedure requiring an experienced clinician to make a global judgment on the presence of positive symptoms of psychosis using a simple scale is high, as it resembles to a high degree the judgment that the clinician uses in routine practice to make treatment decisions. There is face validity to the supposition that psychiatrists can be trusted to make a global judgment on the presence of psychotic symptoms in the treatment of their patients with bipolar disorder.

Finally, measurement of substance abuse was based on self-report of the patients interviewed by their doctor, which may not be a highly sensitive assessment. Wilkins and colleagues ${ }^{29}$ reported discrepancies between patients' reports and urine analysis, as $43 \%$ of patients with a positive urine drug screen denied substance use in the week prior to assessment ${ }^{29}$. However, that study did not assess measurements of past substance use problems, which comprises 3 out of 6 latent class characteristics of our three groups. Furthermore, urine drug tests are not full proof, as it is impossible to distinguish an occasional user from an 
abuser or dependent person over a short period of time. Nevertheless, even though the use of self-report as well as a urine drug screen would have been preferable, the observational nature of the current study prevented the use of an additional invasive urine drug screen.

\section{Conclusion}

The distinction between three identified classes persisted through 12 weeks of treatment, and is associated with differential treatment outcomes as well as inferior improvement on various symptoms. These findings confirm stability of heterogeneity in manic psychopathology. Overall, the Dual Mania and Psychotic Mania classes were stable and showed a less favourable outcome compared to the Typical Mania class. As the first 2 classes comprise $41 \%$ of our sample, and commonly utilized RTC exclusion criteria particularly characterise the Dual Mania class, these findings additionally give rise to concern on generalisability of RCT's. Patient sample composition of RCT's is usually not disclosed, which hampers application of results to the patients seen in different clinical settings. 


\section{References}

1. Vieta E, Carne X (2005). The use of placebo in clinical trials on bipolar disorder: a new approach for an old debate. Psychother Psychosom, 74:10-6

2. Black DW, Winokur G, Hulbert J, Nasrallah A (1988). Predictors of immediate response in the treatment of mania: The importance of comorbidity. Biol Psychiatry, 24:191-8

3. Goldberg JF, Garno JL, Leon AC, Kocsis JH, Portera L (1998). Association of recurrent suicidal ideation with nonremission from acute mixed mania. Am J Psychiatry, 155:1753 5

4. Cassidy F, Ahearn EP, Carroll BJ (2001). Substance abuse in bipolar disorder. Bipolar Disord, 3:181-8

5. Feinman JA, Dunner DL (1996). The effect of alcohol and substance abuse on the course of bipolar affective disorder. J Affect Disord, 37:43-9

6. Feske U, Frank E, Mallinger AG, Houck PR, Fagiolini A, Shear MK, Grochocinski VJ, Kupfer DJ (2000). Anxiety as a correlate of response to the acute treatment of bipolar I disorder. Am J Psychiatry, 157:956-62

7. Goldberg JF, Garno JL, Leon AC, Kocsis JH, Portera L (1999). A history of substance abuse complicates remission from acute mania in bipolar disorder. J Clin Psychiatry, 60:733-40

8. Van Os J, Van Rossum I, Boomsma M, Vieta E, Goetz I, Reed C, EMBLEM Advisory Board (2007). The social, psychopathological and consumer context of rate of response in acute mania. Social Psychiatry Psychiatric Epidemiol, 42(8):631-8

9. Welge JA, Keck PE, Meinhold JM (2004). Predictors of response to treatment of acute bipolar manic episodes with divalproex sodium or placebo in 2 randomized, controlled, parallel-group trials. J Clin Psychopharmacol, 24:607-12

10. Haro JM, Van Os J, Vieta E, Reed C, Lorenzo M, Goetz I, EMBLEM Advisory Board (2006). Evidence for three distinct classes of 'Typical', 'Psychotic' and 'Dual' mania: results from the EMBLEM study. Acta Psychiatr Scand, 113:112-20

11. Goetz I, Tohen M. Reed C, Lorenzo M, Vieta E, the EMBLEM Advisory Board (2007). Functional impairment in patients with mania: Baseline results of the EMBLEM study. Bipolar Disord, 9(1-2):45-52

12. Spearing MK, Post RM, Leverich GS (1997). Modification of the Clinical Global Impressions (CGI) Scale for Use in Bipolar Illness (BP): the CGI-BP. Psychiatry Res, 73:159-71

13. Young RC, Biggs JT, Ziegler VE, Meyer DA (1978). A Rating Scale for Mania: Reliability, Validity and Sensitivity. Br J Psychiatry, 133:429-35

14. González-Pinto A, Ballesteros J, Aldama A, Pérez de Heredia JL, Gutierrez M, Mosquera F, González-Pinto A (2003). Principal components of mania. J Affect Disord, 76:95-102

15. STATACORP. Stata Statistical Software: Release 9.1. Stata Corporation: College Station, TX 15,2005

16. Goldstein H. Multilevel models in educational and social research. London, Griffin, 1987

17. Lin PI, McInnis MG, Potash JB, Willour V, MacKinnon DF, DePaulo JR, Zandi PP (2006). Clinical correlates and familial aggregation of age at onset in bipolar disorder. Am J Psychiatry, 163:240-6

18. Brady KT, Sonne SC (1995). The relationship between substance abuse and bipolar disorder. J Clin Psychiatry, 56:19-24

19. Kessing LV (2004). Subtypes of manic episodes according to ICD-10 prediction of time to remission and risk of relapse. J Affect Disord, 81:279-85 

GM, ed. New York: Arno Press, 1976

21. Cassidy F, Forest K, Murry E, Carroll BJ (1998). A factor analysis of the signs and symptoms of mania. Arch Gen Psychiatry, 55:27-32

22. Sato T, Bottlender R, Kleindienst N, Moller HJ (2002). Syndromes and phenomenological subtypes underlying acute mania: a factor analytic study of 576 manic patients. Am J Psychiatry, 159:968-74

23. Dilsaver SC, Chen YR, Shoaib AM, Swann AC (1999). Phenomenology of mania: evidence for distinct depressed, dysphoric, and euphoric presentations. Am J Psychiatry, 156(3):42630

24. Mant J, Dawes M, Graham-Jones S (1996). Internal validity of trials is more important than generalisibility. Br J Medicine,312: 779

25. APA Practice Guidelines for the Treatment of Patients with Bipolar Disorder. American Psychiatric Association, 2002

26. Fountoukalis KN, Vieta E, Sanchez-Morena J, Kaprinis SG, Goikolea JM, Kaprinis GS (2005). Treatment guidelines for bipolar disorder: a critical review. J Affect Disord, 86:1-10

27. Licht RW, Gouliaev G, Vestergard P, Frydenberg M. (1997). Generalisability of results from randomised drug trials: a trial on antimanic treatment. Br J Psychiatry, 170:264-7

28. Wells KB (1999). Treatment research at the crossroads: the scientific interface of clinical trials and effectiveness research. Am J Psychiatry, 156:5-10

29. Wilkins JN, Shaner AL, Patterson CM, Setoda D, Gorelick D (1991). Discrepancies between patient report, clinical assessment and urine analysis in psychiatric patients during inpatient admission. Psychopharmacol Bull, 27:149-54 


\title{
5 \\ Does cannabis use impact on treatment outcome in bipolar illness?
}

\author{
A longitudinal analysis
}

Published:

Inge van Rossum, Maarten Boomsma, Diederik Tenback, Catherine Reed, Jim van Os and the EMBLEM Advisory Board (2009). Journal of Nervous and Mental Disease, 197(1):35-40 


\begin{abstract}
Introduction. Research suggests that cannabis use impacts negatively on onset and outcome of schizophrenia, but less is known about possible effects in mood disorders.

Methods. 3459 bipolar patients were enrolled in an observational study. The influence of cannabis exposure on clinical and social treatment outcome measures was examined over the course of 1 year, as well as the effects on these associations of third, mediating, variables.

Results. Over 12 months of treatment, cannabis users exhibited less compliance and higher levels of overall illness severity, mania and psychosis compared to non-users. Additionally, cannabis users experienced less satisfaction with life and had a lower probability of having a relationship compared to non-users. There was little evidence that cannabis-outcome associations were mediated by third variables.
\end{abstract}

Conclusion. An independent impact of cannabis use on psychopathological outcomes in patients with $\mathrm{BD}$ was apparent, whereas the impact on social outcomes was modest. 


\section{Introduction}

There is evidence of a deleterious effect of cannabis use on the course of illness in schizophrenia ${ }^{1-4}$. Little is known, however, about its prognostic effects in mood disorders, in particular bipolar disorder $(\mathrm{BD})^{5,6}$. This is topical, as high rates of cannabis use have been reported in patients with $\mathrm{BD}$, with current use ranging from $8-22 \%$ and lifetime use ranging from 30-64\% ${ }^{7}$. Additionally, the psychotic symptomatology frequently associated with BD may complicate or worsen the clinical effects of cannabis use, and vice versa. Despite these indications of a plausible influence of cannabis use on the course of BD, little research has been conducted on the long term effects within this specific population.

Understanding the role of cannabis use within the complex course of bipolar illness may offer valuable insights into treatment strategies. Therefore, the purpose of the current analyses was to unravel the influence of cannabis use on 12-month clinical and social treatment outcome within a population of patients with $\mathrm{BD}$, hypothesizing negative effects of cannabis exposure on course and outcome.

\section{Method}

Data from the EMBLEM study was utilized for the current analyses. The study design was described elaborately in Chapter 1 and previous reports ${ }^{8,9}$. In short, the EMBLEM is a large European prospective observational study, studying patients with a change in pharmacological treatment for acute mania. For the current analyses, data from the acute phase (assessments as baseline and after 1, 2, 3, 6 and 12 weeks) as well as a part of the maintenance phase (assessments at 6 and 12 months after baseline) were employed.

\section{Measures: cannabis use}

Investigators were requested to assess patients' current cannabis use, based on the patient's self-report and the investigator's clinical experience and judgment. Current cannabis use was determined at baseline and after 12 weeks, 6 months and 1 year ( $\mathrm{o}=$ no use, $1=$ use, $2=$ abuse, $3=$ dependence). Each measurement covered the 3-month period preceding the time of assessment, therefore resulting in an assessment of cannabis use during a 15-month period (with a cumulative 15month cannabis score ranging from o to 12). We wished to examine differences between groups as a function of any cannabis use during the study, hypothesising that those prone to using cannabis would be likely to experience effects on the 
course and outcome of bipolar illness. Thus, in order to examine the effect of cannabis use, regardless of level of dependency or duration of use, the cumulative 15-month cannabis score was dichotomised (hereafter: "any cannabis use"; o=no use over 15 months, $1=$ any use/abuse/dependence over 15 months). Given the hypothesis of broad effects and the very small number of individuals rated as dependent, no separate hypotheses were tested regarding the level of cannabis dependence.

\section{Measures: clinical treatment outcome}

Severity of psychopathology was measured at each observation using the following clinical assessment scales: CGI-BP overall illness; CGI-BP mania, CGI hallucinations/delusions and CGI-BP depression (all rated for severity on a sevenpoint scale $\left.{ }^{10}\right)$. Additionally, at each observation, compliance to medication as judged by the investigator was assessed ( $\mathrm{o}=$ always compliant, $1=$ compliant about half the time or never). Thus, psychopathology and compliance were measured over a one-year period. Finally, use of alcohol and other substances (e.g. cocaine and heroin) was assessed at baseline and after 12 weeks, 6 months and 1 year ( $\mathrm{o}=$ no use, $1=$ use, $2=$ abuse, $3=$ dependence), based on the patient's self-report and the investigator's clinical experience and judgment. As a high prevalence of polydrug use was expected in our sample, the effects of severe levels of craving for drugs, expressed as poly-drug use, may hamper interpretation of possible effects of the use of alcohol and/or other substances. Since we were interested in the effects of exposure to alcohol and/or other substances instead of effects associated with the extreme of the distribution of severe craving, these variables were also dichotomized to $\mathrm{O}=$ no use over 15 months, $1=$ any use/abuse/dependence over 15 months.

\section{Measures: social treatment outcome}

Social factors examined were: i) independent living (o=living independently, $1=$ living dependently); ii) work impairment (o=no impairment, $1=$ mild impairment, 2 =moderate impairment, $3=$ severe impairment, $4=$ =unable to work due to mental illness); iii) relationship (o=relationship, $1=$ no relationship); iv) frequency of social activities in the previous 4 weeks $(1=5$ or more times to $5=0$ times); v) satisfaction with life ( $1=$ very satisfied, $2=$ satisfied, $3=$ neither satisfied nor dissatisfied, $4=$ =dissatisfied, $5=$ =very dissatisfied); vi) number of dependents to care for ( $\mathrm{O}=\mathrm{O}$ to $4=4$ dependents or more). All measurements assessed the current 
status and were administered at baseline and 12 weeks, 6 months and 1 year postbaseline. Thus, social treatment outcomes were measured over a one-year period.

Analyses

Analyses were carried out using the STATA statistical program ${ }^{11}$. For all outcomes examined, data were hierarchically clustered in that there were multiple follow-up observations clustered within the same individual. In order to take into account clustering of the data within individuals, multilevel random regression analyses ${ }^{12}$ were conducted in STATA. The XTREG routine for continuous data was applied, yielding the regression coefficient $B$ and its 95\% confidence interval (CI) as effect size. The XTGEE routine was used for dichotomous data, yielding the odds ratio (OR) and its 95\% confidence interval as effect size. For all outcomes, models included all post-baseline observations of the outcome variable of interest, while controlling for the baseline value of this outcome variable. This model effectively assesses the effect of the cannabis exposure on change in the outcome variable over the course of one year.

\section{Mediation}

All analyses were adjusted for country. In order to examine to what degree any significant associations between any cannabis use and selected outcomes were statistically reducible to other (third) variables associated with both cannabis use and outcome, the following individual variables were examined for mediation by adding them separately to the model: sex (o=male, $1=$ female), compliance, age, age of onset (i.e., the age at which the first symptoms of bipolar disorder were experienced) and use of alcohol and other drugs. These variables with potentially mediating qualities were selected a priori, and not on the basis of statistical significance. A variable was regarded a mediator when the association between cannabis use and the outcome variable did not persist after including the mediator variable into the model, whereas the association between the mediator and the outcome variable was statistically significant (for example see Fig. 1).

\section{Sample size}

Not all countries participated in the maintenance phase of the study (12 weeks onwards), resulting in a decrease in the sample size after the 12 weeks observation ( $\mathrm{n}=1891$; Switzerland, Denmark, Germany and Spain only participated in the acute phase). The variable 'completer' ( $1=$ completer, $2=$ non- 
completer) indicated whether each individual patient continued into the maintenance phase of the study, or only participated in the acute phase, respectively. In order to rule out differences in associations between any cannabis use and the outcome variables on the basis of being a 'completer' or not, interaction effects between cannabis use and completer status were assessed for all significant associations between cannabis use and outcome variables. For this purpose, any cannabis use and completer status were included in the model, as well as their interaction. Apart from the decrease in overall sample size, the samples for the individual analyses varied somewhat on the basis of the availability of complete data for variables included in the separate models (minimum n=2291, maximum $\mathrm{n}=3356$ ).

\section{Results}

\section{Sample description}

A total of 3684 subjects participated in EMBLEM, of whom 3459 fulfilled the requested criteria with a baseline rating of mania (CGI-BP mania $\geq 3)^{8}$. For 33 patients, all four assessments of cannabis use were missing, and therefore they were excluded from the analyses. Of the remaining 3426 patients, 39.2\% were inpatients, $44.6 \%$ were male and the mean age was 44.6 years (sd 13.4). The mean age of onset was 29.9 year (sd 11.0). Table 1 provides an overview of the demographic characteristics for the entire group as well as by any cannabis use. The distribution of cannabis use, abuse and dependence within the group of cannabis users, assessed at baseline and after 3,6 and 12 months, is presented in Table 2 .

Table 1. Baseline demographic characteristics of the complete group of 3426 patients, stratified by any cannabis use.

\begin{tabular}{lccc}
\hline & $\begin{array}{c}\text { Complete } \\
\text { group }\end{array}$ & $\begin{array}{c}\text { Cannabis } \\
\text { non-users }\end{array}$ & $\begin{array}{c}\text { Cannabis } \\
\text { users }\end{array}$ \\
\hline Number of patients (\%) & $3426(100 \%)$ & $2990(87.3 \%)$ & $436(12.7 \%)$ \\
Age (mean, sd) & $44.6(13.4)$ & $46.2(13.1)$ & $33.8(9.7)$ \\
Age of onset (mean, sd) & $29.9(11.0)$ & $30.8(11.3)$ & $24.1(6.8)$ \\
Male (\%) & $44.6 \%$ & $41.2 \%$ & $67.8 \%$ \\
Inpatient status (\%) & $39.2 \%$ & $36.8 \%$ & $56.1 \%$ \\
\hline
\end{tabular}


Clinical treatment outcomes

Baseline and 3, 6 and 12-month clinical treatment outcome measures are shown in Table 3. Cannabis users demonstrated higher scores on the CGI-BP overall illness. In the multilevel random regression analysis, there was a significant association between any cannabis use and baseline-corrected CGI-BP overall illness over 1 year follow-up ( $\mathrm{B}=0.13, \mathrm{CI}$ : $0.04,0.22 ; \mathrm{P}=0.004)$. This association was not mediated by any of the third variables. Thus, after including the individual third variables into the model, the association between any cannabis use and a higher CGI-BP overall illness score persisted.

Table 2. Type of cannabis use within the group of cannabis users $(n=436)$ over a period of 15 months.

\begin{tabular}{lcccc}
\hline & Baseline & 3 months & 6 months & 12 months \\
\hline No cannabis use & $11.3 \%$ & $52.1 \%$ & $56.6 \%$ & $61.8 \%$ \\
Cannabis use & $54.4 \%$ & $37.0 \%$ & $28.6 \%$ & $27.5 \%$ \\
Cannabis abuse & $27.5 \%$ & $9.6 \%$ & $12.8 \%$ & $10.1 \%$ \\
Cannabis dependence & $6.8 \%$ & $1.3 \%$ & $2.0 \%$ & $0.6 \%$ \\
\hline
\end{tabular}

\section{Clinical treatment outcomes}

Baseline and 3, 6 and 12-month clinical treatment outcome measures are shown in Table 3. Cannabis users demonstrated higher scores on the CGI-BP overall illness. In the multilevel random regression analysis, there was a significant association between any cannabis use and baseline-corrected CGI-BP overall illness over 1 year follow-up ( $\mathrm{B}=0.13, \mathrm{CI}$ : $0.04,0.22 ; \mathrm{P}=0.004)$. This association was not mediated by any of the third variables. Thus, after including the individual third variables into the model, the association between any cannabis use and a higher CGI-BP overall illness score persisted.

The multilevel random regression analyses revealed a significant association between any cannabis use and the CGI-BP mania score ( $\mathrm{B}=0.15, \mathrm{CI}$ : $0.06,0.24 ; \mathrm{P}=0.001)$. This association was also not mediated by any of the third variables. Higher scores on the CGI hallucinations / delusions were also associated with any cannabis use $(\mathrm{B}=0.11, \mathrm{CI}$; 0.03, 0.19 ; $\mathrm{P}=0.006)$, which was not mediated by any of the third variables.

Any cannabis use was associated with less treatment compliance $(\mathrm{OR}=1.38, \mathrm{CI}: 1.12,1.72 ; \mathrm{P}=0.003)$, which was mediated by the use of other substances; that is, the association between any cannabis use and treatment compliance did not persist when other substance use was included in the model, 
Table 3 (continued on next page). Baseline and 12-month clinical treatment outcome measures of the complete group of patients stratified by any cannabis use.

\begin{tabular}{|c|c|c|c|c|}
\hline & & Complete group & Cannabis non-users $\dagger$ & Cannabis usersł \\
\hline \multirow{4}{*}{$\begin{array}{l}\text { CGI-BP overall illness } \\
\text { (mean, sd) }\end{array}$} & Baseline $(n=3370)$ & $4.7(1.0)$ & $4.6(1.0)$ & $4.8(1.1)$ \\
\hline & 3 months $(n=2721)$ & $2.7(1.3)$ & $2.6(1.3)$ & $2.8(1.4)$ \\
\hline & 6 months $(n=1861)$ & $2.4(1.4)$ & $2.4(1.4)$ & $2.7(1.6)$ \\
\hline & 12 months $(\mathrm{n}=1700)$ & $2.3(1.4)$ & $2.3(1.4)$ & $2.4(1.4)$ \\
\hline \multirow{4}{*}{$\begin{array}{l}\text { CGI-BP mania } \\
\text { (mean, sd) }\end{array}$} & Baseline $(\mathrm{n}=3410)$ & $4.8(1.0)$ & $4.7(1.0)$ & $5.0(1.0)$ \\
\hline & 3 months $(n=2730)$ & $2.2(1.2)$ & $2.2(1.2)$ & $2.3(1.4)$ \\
\hline & 6 months $(\mathrm{n}=1874)$ & $1.9(1.2)$ & $1.9(1.2)$ & $2.1(1.4)$ \\
\hline & 12 months $(\mathrm{n}=1707)$ & $1.9(1.3)$ & $1.9(1.2)$ & $2.0(1.3)$ \\
\hline \multirow{4}{*}{$\begin{array}{l}\text { CGI-BP hallucinations / } \\
\text { delusions } \\
\text { (mean, sd) }\end{array}$} & Baseline $(\mathrm{n}=3444)$ & $3.0(1.8)$ & $2.9(1.8)$ & $3.5(1.8)$ \\
\hline & 3 months $(\mathrm{n}=2731)$ & $1.5(1.0)$ & $1.5(1.0)$ & $1.7(1.2)$ \\
\hline & 6 months $(\mathrm{n}=1878)$ & $1.4(0.9)$ & $1.4(0.9)$ & $1.7(1.2)$ \\
\hline & 12 months $(\mathrm{n}=1708)$ & $1.4(0.9)$ & $1.4(0.9)$ & $1.6(1.1)$ \\
\hline \multirow{4}{*}{$\begin{array}{l}\text { CGI-BP depression } \\
\text { (mean, sd) }\end{array}$} & Baseline $(\mathrm{n}=3357)$ & $1.9(1.2)$ & $1.9(1.2)$ & $1.8(1.2)$ \\
\hline & 3 months $(\mathrm{n}=2709)$ & $1.8(1.1)$ & $1.8(1.1)$ & $1.7(1.1)$ \\
\hline & 6 months $(\mathrm{n}=1855)$ & $1.7(1.1)$ & $1.7(1.1)$ & $1.8(1.2)$ \\
\hline & 12 months $(\mathrm{n}=1689)$ & $1.7(1.0)$ & $1.7(1.0)$ & $1.7(1.0)$ \\
\hline
\end{tabular}


Table 3 (continued from previous page). Baseline and 12-month clinical treatment outcome measures of the complete group of patients stratified by any cannabis use.

\begin{tabular}{|c|c|c|c|c|}
\hline & & $\begin{array}{c}\text { Complete } \\
\text { group }\end{array}$ & $\begin{array}{c}\text { Cannabis } \\
\text { non-users } \dagger\end{array}$ & $\begin{array}{c}\text { Cannabis } \\
\text { users } \ddagger\end{array}$ \\
\hline Alcohol use current* & Baseline $(n=3285)$ & $42.8 \%$ & $37.2 \%$ & $80.3 \%$ \\
\hline \multirow[t]{3}{*}{$(\%)$} & 3 months $(\mathrm{n}=2731)$ & $27.1 \%$ & $23.3 \%$ & $58.3 \%$ \\
\hline & 6 months $(\mathrm{n}=1879)$ & $25.8 \%$ & $22.3 \%$ & $54.2 \%$ \\
\hline & 12 months $(\mathrm{n}=1712)$ & $27.0 \%$ & $23.7 \%$ & $55.6 \%$ \\
\hline Other substance use & Baseline $(n=3383)$ & $6.5 \%$ & $2.6 \%$ & $34.3 \%$ \\
\hline current* & 3 months $(\mathrm{n}=2732)$ & $3.1 \%$ & $1.5 \%$ & $16.1 \%$ \\
\hline \multirow[t]{2}{*}{$(\%)$} & 6 months $(n=1878)$ & $1.9 \%$ & $0.8 \%$ & $10.9 \%$ \\
\hline & 12 months $(\mathrm{n}=1712)$ & $1.9 \%$ & $0.9 \%$ & $10.1 \%$ \\
\hline Inpatient & Baseline $(\mathrm{n}=3417)$ & $39.2 \%$ & $36.8 \%$ & $56.1 \%$ \\
\hline \multirow[t]{3}{*}{$(\%)$} & 3 months $(n=2731)$ & $8.4 \%$ & $7.6 \%$ & $14.8 \%$ \\
\hline & 6 months $(\mathrm{n}=1866)$ & $5.6 \%$ & $5.2 \%$ & $8.9 \%$ \\
\hline & 12 months $(\mathrm{n}=1700)$ & $4.4 \%$ & $3.9 \%$ & $9.0 \%$ \\
\hline
\end{tabular}

Only patients without missing values on relevant variables were included in the individual analyses. ${ }^{*}$ Percentage is the sum of use, abuse and dependence. $+n=2990 ; \neq n=436$. 
Table 4 (continued on next page). Baseline and 12-month social treatment outcome measures of the complete group of patients, stratified by any cannabis use.

\begin{tabular}{|c|c|c|c|c|}
\hline & & $\begin{array}{c}\text { Complete } \\
\text { group }\end{array}$ & $\begin{array}{l}\text { Cannabis } \\
\text { non-users }\end{array}$ & $\begin{array}{c}\text { Cannabis } \\
\text { users }\end{array}$ \\
\hline \multirow{4}{*}{$\begin{array}{l}\text { Independent living } \\
\text { situation } \\
(\%)\end{array}$} & Baseline $(n=3425)$ & $58.0 \%$ & $59.3 \%$ & $49.5 \%$ \\
\hline & 3 months $(\mathrm{n}=2728)$ & $58.6 \%$ & $59.6 \%$ & $50.8 \%$ \\
\hline & 6 months $(\mathrm{n}=1876)$ & $61.5 \%$ & $62.0 \%$ & $56.7 \%$ \\
\hline & 12 months $(n=1710)$ & $62.2 \%$ & $62.2 \%$ & $62.4 \%$ \\
\hline \multirow{4}{*}{$\begin{array}{l}\text { Current relationship } \\
(\%)\end{array}$} & Baseline $(n=3425)$ & $59 \cdot 3 \%$ & $61.5 \%$ & $44.6 \%$ \\
\hline & 3 months $(\mathrm{n}=2733)$ & $59.9 \%$ & $61.6 \%$ & $46.4 \%$ \\
\hline & 6 months $(\mathrm{n}=1879)$ & $61.1 \%$ & $62.4 \%$ & $50.7 \%$ \\
\hline & 12 months $(n=1710)$ & $62.9 \%$ & $63.9 \%$ & $54.5 \%$ \\
\hline \multirow{4}{*}{$\begin{array}{l}\text { Severe work impairment } \\
\text { or unable to work } \\
(\%)\end{array}$} & Baseline $(\mathrm{n}=3389)$ & $38.2 \%$ & $36.4 \%$ & $50.9 \%$ \\
\hline & 3 months $(n=2681)$ & $25.0 \%$ & $24.0 \%$ & $33.3 \%$ \\
\hline & 6 months $(\mathrm{n}=1875)$ & $22.8 \%$ & $21.4 \%$ & $34.5 \%$ \\
\hline & 12 months $(n=1710)$ & $22.0 \%$ & $21.3 \%$ & $27.7 \%$ \\
\hline \multirow{4}{*}{$\begin{array}{l}\text { No social activities } \\
(\%)\end{array}$} & Baseline $(n=3415)$ & $19.9 \%$ & $20.5 \%$ & $16.1 \%$ \\
\hline & 3 months $(\mathrm{n}=2719)$ & $13.5 \%$ & $14.0 \%$ & $9.6 \%$ \\
\hline & 6 months $(\mathrm{n}=1871)$ & $11.6 \%$ & $11.9 \%$ & $9.4 \%$ \\
\hline & 12 months $(n=1702)$ & $8.7 \%$ & $9.1 \%$ & $5.1 \%$ \\
\hline
\end{tabular}


Table 4 (continued from previous page). Baseline and 12-month social treatment outcome measures of the complete group of patients, stratified by any cannabis use.

\begin{tabular}{|c|c|c|c|c|}
\hline & & $\begin{array}{l}\text { Complete } \\
\text { group }\end{array}$ & $\begin{array}{l}\text { Cannabis } \\
\text { non-users }\end{array}$ & $\begin{array}{c}\text { Cannabis } \\
\text { users }\end{array}$ \\
\hline (Very) dissatisfied with life & Baseline $(\mathrm{n}=3415)$ & $40.5 \%$ & $39.7 \%$ & $45.6 \%$ \\
\hline \multirow[t]{3}{*}{$(\%)$} & 3 months $(n=2723)$ & $21.8 \%$ & $21.0 \%$ & $27.7 \%$ \\
\hline & 6 months $(\mathrm{n}=1878)$ & $16.7 \%$ & $16.5 \%$ & $23.6 \%$ \\
\hline & 12 months $(\mathrm{n}=1710)$ & $15.2 \%$ & $14.3 \%$ & $22.4 \%$ \\
\hline \multirow{4}{*}{$\begin{array}{l}\text { Number of dependents to } \\
\text { care for (mean, sd) }\end{array}$} & Baseline $(n=3384)$ & $0.7(1.0)$ & $0.7(1.0)$ & $0.4(0.8)$ \\
\hline & 3 months $(n=2605)$ & $0.7(1.0)$ & $0.7(1.0)$ & $0.3(0.8)$ \\
\hline & 6 months $(n=1787)$ & $0.6(1.0)$ & $0.6(1.0)$ & $0.4(0.8)$ \\
\hline & 12 months $(n=1612)$ & $0.6(1.0)$ & $0.7(1.0)$ & $0.4(0.9)$ \\
\hline
\end{tabular}

Only patients without missing values on relevant variables were included in the individual analyses. 
whereas the association between compliance and other substance use did (OR=1.36, CI: 1.04, 1.78; P=0.025).

Patients who used cannabis demonstrated more alcohol use/abuse/dependence $\quad(\mathrm{B}=0.10, \quad \mathrm{CI}: \quad 0.07, \quad 0.13 ; \quad \mathrm{P}<0.001), \quad$ and more use/abuse/dependence of substances other than cannabis and alcohol $(B=0.11, C I$ : 0.09 , 0.13; $\mathrm{P}<0.001)$. None of the other variables examined mediated these associations. No significant association was found between any cannabis use and the CGI-BP depression score.

For all significant associations between any cannabis use and clinical outcome variables, the interaction between any cannabis use and completer status was assessed. This interaction was statistically significant when included in the compliance model, indicating a stronger association between any cannabis use and less compliance for patients who completed the study, compared those who discontinued after the acute phase (i.e., 3 months). The other demonstrated associations were not moderated by completer status.

\section{$\underline{\text { Social treatment outcomes }}$}

Baseline and 3,6 and 12-month social treatment outcome measures are shown in Table 4. Patients with any cannabis use were more likely to not have a relationship ( $\mathrm{OR}=1.64, \mathrm{CI}: 1.13,2.38$; $\mathrm{P}=0.009)$ during one year of treatment. This association was not mediated by any of the seven hypothesized mediator variables, as the association between any cannabis use and not having a relationship persisted after including the variables in the model.

Any cannabis use was associated with engaging in more social activities ( $\mathrm{B}=-0.19, \mathrm{CI}:-0.35,-0.03 ; \mathrm{P}=0.023)$. This association was strongly mediated by age, age of onset and alcohol abuse, as the association between cannabis use and the number of social activities did not persist when these individual variables were included in the separate models, whereas the association between social activities and the individual variables did (age: $\mathrm{B}=0.01, \mathrm{CI}: 0.01,0.01 ; \mathrm{P}<0.001$; age of onset: $\mathrm{B}=0.01$, CI: $0.00,0.01$; $\mathrm{P}=0.023$; alcohol abuse: $\mathrm{B}=-0.12$, CI: $-0.23,-0.01 ; \mathrm{P}=0.031$; Fig $1)$.

Patients with any cannabis use experienced less satisfaction in life ( $\mathrm{B}=0.14, \mathrm{CI}: 0.05,0.24 ; \mathrm{P}=0.003$ ) compared to non-users. This association was mediated by the use of other substances, as the association between any cannabis use and satisfaction with life did not persist when other substance use was 
included in the model, whereas the association between satisfaction with life and other substance use did ( $\mathrm{B}=0.17, \mathrm{CI}$ : 0.04, 0.29; $\mathrm{P}=0.007$ ).

There was no significant association between any cannabis use and independent living, the number of dependents to care for and the extent of work impairment. For all significant associations between any cannabis use and social outcome variables, the interaction between any cannabis use and completer status was assessed. None of the interactions were large or statistically significant, indicating that the demonstrated associations were not moderated by completer status.

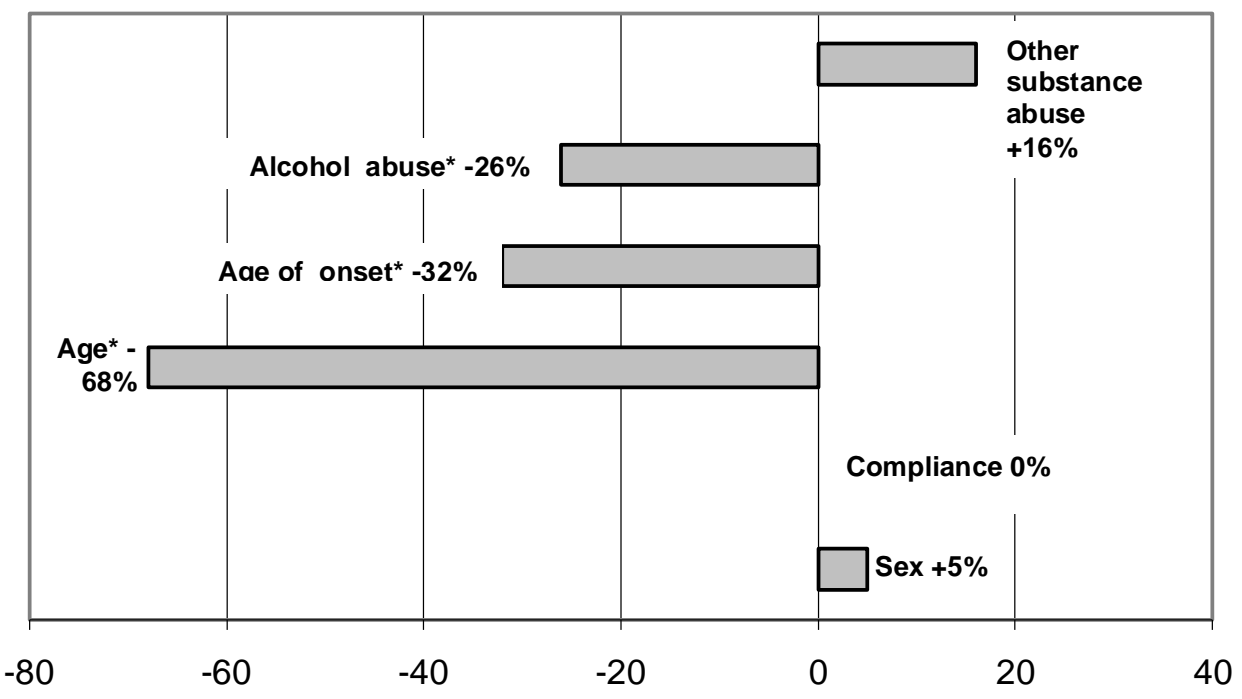

Figure 1. Mediating effects of six variables on the association between any cannabis use and number of activities engaged in (higher is worse).

Changes in effect size of the association between cannabis and social activities $(B=-19)$ were expressed as percentage change. 'Activities' is scored as ' $1=5$ or more activities to $5=0$ activities', thus higher is worse. *These variables strongly mediated the association.

\section{Discussion}

Little research has been directed towards associations between cannabis use and specific treatment outcomes exceeding a 12-week treatment period in a population of patients with BD. Although the observational study design did not allow us to determine the degree of causality underlying associations between cannabis exposure and treatment outcome, the results are indicative of an unfavourable association between cannabis use and BD symptoms in the long term. Cannabis users demonstrated more severe overall BD illness, mania and 
psychosis symptoms during 1 year of treatment. Use and abuse of both alcohol and other substances were significantly higher in those who used cannabis. Less compliance was demonstrated for cannabis users. Social outcomes were found to be moderately affected by any cannabis use, as users engaged in more social activities, but had a higher probability of not having a relationship and experienced less satisfaction with life. A set of variables (including abuse of alcohol and substances other than alcohol and cannabis) was found to exert a limited influence on some associations between any cannabis use on the one hand and psychopathological and social outcomes on the other. No associations between cannabis use and depressive symptoms as well as various other social outcome measures could be demonstrated.

The suggested association between cannabis use and severity of mania symptoms in the current study is interesting in light of reports from other areas of research. Henquet and colleagues $^{13}$ recently reported that cannabis use increases the risk for onset of manic symptoms in the general population, independent of any association with psychosis. Earlier, Goldberg and co-workers ${ }^{14}$ found that cannabis users were less likely to remit from acute mania, whereas Strakowski et al. ${ }^{15}$ reported on a positive association between duration of cannabis use and duration of manic episodes. In addition to the increased risk of cannabis use for the onset of mania symptoms ${ }^{13}$, our findings indicate that cannabis use is also associated with severity and persistence of mania symptoms. However, divergent study populations, selection criteria and confounding variables employed in these studies prevent grounded assumptions of the underlying mechanism.

The association between cannabis use and more severe psychosis symptoms within a BD population aligns with earlier findings within patient population with psychotic disorders ${ }^{2,3}$ as well as the general population ${ }^{16-19}$. Recent reports have indicated a bi-directional causal relationship between cannabis use and psychotic symptoms in the general population ${ }^{20}$, possibly caused by genes that influence the sensitivity to the psychosis-increasing effects of cannabis whereas other genes may additionally influence the probability that these individuals will start using cannabis in the first place ${ }^{21}$. Future research should apply these suggestions of causality and the interaction between cannabis and genetic vulnerability to the unexplored territory of bipolar disorder. This is especially interesting in light of findings in alcohol research in bipolar patient 
populations, where the sequence of alcohol abuse versus illness onset was found to influence outcome differentially ${ }^{6}$.

The finding that severity of depressive symptoms did not differ between cannabis users and non-users was somewhat surprising, as Strakowski and colleagues $^{6}$ demonstrated a correlation between cannabis use and depressive symptoms during 5 year of treatment. However, the investigated patient population entered the current study while experiencing a manic or mixed episode, which may have biased the results regarding associations with depressive symptoms and reduced the generalisability to some extent. Even though little research has yet been conducted towards an association between cannabis use and bipolar depression, associations with major depressive disorder (MDD) have been studied extensively. Rey and Tennant ${ }^{22}$ and Degenhardt and co-workers ${ }^{5}$ concluded their reviews stating that cannabis use increases risk for depression, which was partly explained by confounding variables. However, BD is a far more complex disease with extensive and more diverse symptom clusters, including a high prevalence of psychotic symptoms, which prevents a simple extrapolation from cannabis-MDD associations to the depressive symptoms within BD.

The association between cannabis use and more frequent abuse of alcohol and other substances was not surprising, as it supports findings in the general population ${ }^{23}$ as well as in the BD population ${ }^{15,24}$. Substance abuse in patients with BD has been studied extensively (substance abuse in general and alcohol abuse in particular). Worse clinical outcome is consistently observed for substance abusers ${ }^{15}$, and substance use in general was found to be associated with a slower rate of symptom improvement ${ }^{25}$. Additionally, an association between medication non-compliance and substance abuse in general has been reported in the literature ${ }^{7}$, which is in agreement with our finding that the association between treatment compliance and cannabis use was mediated by other substance use. This, in combination with the finding that the association between cannabis use and satisfaction with life was also mediated by substance use, justifies a prioritised position of both cannabis and other substance use in diagnosing and treating patients with BD.

\section{$\underline{\text { Social outcomes }}$}

The modest influence that cannabis was found to have on social circumstances during 1 year of treatment could be explained by the suggestion that cannabis users may be socially more competent compared to non-users, which may be a 
prerequisite for obtaining cannabis in the first place ${ }^{26}$. Socially less competent psychiatric patients were reported to be prone to alcohol abuse, which is obtained more easily. However, this finding was based on data from schizophrenic, schizophreniform and schizoaffective disorder patients, and further research is required to determine whether this suggestion can be extrapolated to patients with BD. Another explanation for the lack of effect on social outcome is the relatively low level of cannabis dependency in our sample (Table 2). The effect of cannabis abuse or dependence on social outcome measures may be more pronounced when studied in a population of heavy users.

\section{Mediation}

With the exception of other substance use mediating cannabis-compliance and cannabis-life satisfaction associations, the effects of mediating variables were found to be limited. Most associations between cannabis use and both clinical and social treatment outcomes remained significant when these variables were included into the models. Thus, with the exception of other substance use, there was no pattern of influence in mediating effects that requires specific attention in daily practice. Overall, our findings appear to be similar to the reports in the area of schizophrenia research, where a persistent negative effect of cannabis on outcome measures was reported, while controlling for drug use other than cannabis $^{2,27}$.

\section{Methodological issues}

Several limitations should be taken into account when interpreting these results. First, the size and observational nature of the study forced us to use reliable but simple scales to measure cannabis use, abuse and dependence, which could easily be completed during daily practice. The non-validated nature of this scale might have hampered the distinction between use, abuse and dependence of cannabis. In contrast, the distinction 'no use' versus 'use/abuse/dependence' employed in the current analyses is more straightforward to distinguish and has ample face validity. However, as the assessment of substance abuse was based on the clinicians' knowledge and judgment, taking into account the information reported by the patients, we cannot rule out underreporting due to stigmatisation of drug abuse. Contradicting results have been reported regarding the reliability of selfreport of substance use compared to urine tests and collateral sources ${ }^{28-30}$. As none of these methods is definitive, the combined use of self-report and urine drug 
screens would be preferable. However, the observational nature of the current study prevented the use of an invasive urine drug screen.

Second, our study design made it impossible to explore causality of the demonstrated associations between cannabis and outcome measures and/or of the mediators thereof. We cannot determine whether cannabis and its mediators are the cause or the result of worse clinical outcomes, or whether common demographical or biological factors increase vulnerability for both. However, knowledge on the existence of the demonstrated associations should increase awareness of the importance of a thorough diagnosis and broad treatment strategy for BD patients with comorbid cannabis use.

\section{Conclusion}

An impact of cannabis use on psychopathological outcomes in patients with BD was apparent, whereas the impact on social outcomes was modest. Substance use in general was found to have a negative impact on treatment outcome, however, various outcomes were specifically impacted by the use of cannabis. Understanding the direct and, in particular, the indirect pathways from cannabis use to outcome may offer valuable insight into treatment strategies in bipolar illness. 


\section{References}

1. Caspari D (1999). Cannabis and schizophrenia: results of a follow-up study. Eur Arch Psychiatry Clin Neurosci, 249:45-9

2. Grech A, Van Os J, Jones PB, Lewis SW, Murray RM (2005). Cannabis use and outcome of recent onset psychosis. Eur Psychiatry, 20:349-53

3. Linszen DH, Dingemans PM, Lenoir ME (1994). Cannabis abuse and the course of recentonset schizophrenic disorders. Arch Gen Psychiatry, 51:273-9

4. Verdoux H, Liraud F, Gonzales B, Assens F, Abalan F, Van Os J (2001). Predictors and outcome characteristics associated with suicidal behaviour in early psychosis: a two-year follow-up of first-admitted subjects. Acta Psychiatr Scand, 103:347-54

5. Degenhardt L, Hall W, Lynskey M (2003). Exploring the association between cannabis use and depression. Addiction, 98:1493-504

6. Strakowski SM, DelBello MP, Fleck DE, Adler CM, Anthenelli RM, Keck PE, Arnold LM, Amicome J (2007). Effects of co-occuring cannabis use disorders on the course of bipolar disorder after a first hospitalization for mania. Arch Gen Psychiatry, 64:57-64

7. Brown ES, Suppes T, Adinoff B, Rajan Thomas N (2001). Drug abuse and bipolar disorder: comorbidity or misdiagnosis? J Affect Disord, 65:105-15

8. Goetz I, Tohen M, Reed C, Lorenzo M, Vieta E, the EMBLEM Advisory Board (2007). Functional impairment in patients with mania: Baseline results of the EMBLEM study. Bipolar Disord, 9(1-2):45-52

9. Haro JM, Van Os J, Vieta E, Reed C, Lorenzo M, Goetz I and the EMBLEM advisory board (2006). Evidence for three distinct classes of 'Typical', 'Psychotic' and 'Dual' mania: Results from the EMBLEM study. Acta Psychiatr Scand, 113(2):112-20

10. Spearing MK, Post RM, Leverich (1997). Modification of the Clinical Global Impressions (CGI) Scale for use in bipolar illness (BP): the CGI-BP. Psychiatry Res, 73:159-71

11. STATACORP. Stata Statistical Software: Release 9.1. Stata Corporation: College Station, TX, 2005

12. Goldstein H. Multilevel models in educational and social research. London, Griffin, 1987

13. Henquet C, Krabbendam L, De Graaf R, Ten Have M, Van Os I (2006). Cannabis use and expression of mania in the general population. J Affect Disord, 95:103-10

14. Goldberg JF, Garno JL, Leon AC, Kocsis JH, Portera L (1999). A history of substance abuse complicates remission from acute mania in bipolar disorder. J Clin Psychiatry, 60:733-40

15. Strakowski SM, DelBello MP, Fleck DE, Arndt S (2000). The impact of substance abuse on the course of bipolar disorder. Biol Psychiatry, 48:477-85

16. Fergusson DM, Horwood LJ, Swain-Campbell NR (2003). Cannabis dependence and psychotic symptoms in young people. Psychol Med, 33:15-21

17. Fergusson DM, Horwood LJ, Ridder EM (2005). Tests of causal linkages between cannabis use and psychotic symptoms. Addiction, 100:354-66

18. Van Os J, Bak M, Hanssen M, Bijl RV, De Graaf R, Verdoux H (2002). Cannabis use and psychosis: a longitudinal population-based study. Am J Epidemiol, 156:319-27

19. Verdoux H, Sorbara F, Gindre C, Swendsen JD, Van Os J (2002). Cannabis use and dimensions of psychosis in a nonclinical population of female subjects. Schizophr Res, 59:77-84

20. Ferdinand RF, Sondeijker F, Van der Ende J, Selten JP, Huizink A, Verhulst F (2005). Cannabis use predicts future psychotic symptoms, and vice versa. Addiction, 100:612-8 
21. Van Os J, Henquet C, Stefanis N (2005). Cannabis-related psychosis and the geneenvironment interaction: comments on Ferdinand et al. 2005. Addiction, 100:874-5

22. Rey JM, Tennant CC (2002). Cannabis and mental health. BMJ, 325:1183-4

23. Fergusson DM, Boden JM, Horwood LJ (2006). Cannabis and other illicit drug use: testing the cannabis gateway hypothesis. Addiction, 101:556-69

24. Cassidy F, Ahearn EP, Carroll BJ (2001). Substance abuse in bipolar disorder. Bipolar Disord, 3:181-8

25. Van Os J, Van Rossum I, Boomsma M, Vieta E, Goetz I, Reed C, Haro JM and the EMBLEM advisory board (2007). The social, psychopathological and consumer context of rate of response in acute mania. Soc Psychiatry and Psychiatric Epidemiology, 42(8):631-8

26. Mueser KT, Yarnold PR, Rosenberg SD, Swett C, Miles KM, Hill D (2000). Substances use disorder in hospitalized severely mentally ill psychiatric patients: prevalence, correlates and subgroups. Schizophr Bull, 26(1):179-92

27. Degenhardt L, Hall W (2006). Is cannabis use a contributory cause of psychosis? Can J Psychiatry, 51:556-65

28. Carey KB, Simons J (2000). Utility of collateral information in assessing substance use among psychiatric outpatients. J Substance Abuse, II:139-47

29. Fowler IL, Carr VJ, Carter NT (1998). Patterns of current and lifetime substance use in schizophrenia. Schizophr Bull, 24:443-55

30. Wilkins JN, Shaner AL, Patterson CM, Setoda D, Gorelick D (1991). Discrepancies between patient report, clinical assessment and urine analysis in psychiatric patients during inpatient admission. Psychopharmacology Bull, 27:149-54 


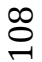

密 


\section{6}

\section{Bipolar disorder and dopamine dysfunction:}

\section{An indirect approach focusing on tardive movement syndromes}

Published:

Inge van Rossum, Diederik Tenback, Jim van Os (2009).

BMC Psychiatry, 9:16-24 


\begin{abstract}
Introduction. It has been suggested that dopamine dysfunction may play a role in bipolar disorder (BD). An indirect approach to examine this issue was developed, focusing on associations between dopamine proximity measures observed in BD (dopamine-related clinical traits using tardive movement syndromes as dopamine proxy measure of reference).
\end{abstract}

Methods. 3459 eligible bipolar patients were enrolled in an observational study. Incidence rates of tardive movement syndromes (Tardive Dyskinesia and Tardive Dystonia; TDD) were examined. A priori hypothesized associations between incident TDD and other dopamine proxies (e.g., prolactin-related adverse effects, bipolar symptoms) were tested over a 2 year follow-up period.

Results. The incidence rate of tardive syndromes was $4.1 \%$. Incident TDD was not only independently associated with use of antipsychotics, but also with more severe bipolar symptoms, other extrapyramidal symptoms and prolactin-related adverse effects of medication.

Conclusion. Apart from the well-known association with antipsychotics, development of TDD was associated with various other dopamine proxy measures, indirectly supporting the notion of generalised dopamine dysregulation in BD. 


\section{Introduction}

Extrapyramidal symptoms (EPS) in general and tardive dyskinesia (TD) in particular have been extensively studied in schizophrenia. Even though a number of studies suggest that bipolar patients experience higher rates of EPS (parkinsonism, dystonia and akathisia) and TD compared to patients with a diagnosis of schizophrenia ${ }^{1,2}$, research within the bipolar disorder (BD) population has been limited.

Berk and colleagues ${ }^{3}$, reviewing converging data on the role of dopamine (DA) in bipolar disorder, recently postulated the Dopamine Dysregulation Syndrome, based on a consilience approach using research from a diversity of domains, including preclinical, genetic, neuroimaging, pharmacological and clinical research. The model proposes a cyclical dysregulation in quantitative DA transmission in $\mathrm{BD}$, the manic phase being associated with an increase in DA transmission. Secondary down regulation of key elements and pre- as well as postsynaptic receptors may subsequently decrease DA transmission, dampening the cycle. A substantial reduction in DA transmission is hypothesized to characterize the depressive phase, which may be alleviated by secondary up-regulation of the same key elements. Up and down regulation may be mediated by endogenous homeostatic mechanisms; individual vulnerabilities exist to the hyper- and hypodopaminergic state, explaining the large inter-individual variability in illness course $^{3}$.

While of major interest, hypotheses about alterations in DA function in severe mental illness are difficult to examine directly. It has been suggested, therefore, that alterations in DA function in severe mental illness (i.e., illness liabilities affecting various aspects of dopamine signaling, separate from effects occasioned by antipsychotic medications) may be explored using clinical variables serving as proximity measures (i.e., indirect measures) for DA neurotransmission in different DA tracts. These may include, for example, presence of (i) prolactinrelated adverse effects as a proxy for alterations in the tuberoinfundibular tract $^{4}$, ii) TD and EPS as proxies for alterations in the nigrostriatal DA tract ${ }^{5}$, whereas (iii) psychotic $^{5,6}$, manic $^{7}$ and depressive ${ }^{8}$ symptoms may reflect altered mesolimbic DA neurotransmission. Using these proxy measures in a prospective study of schizophrenia patients, Tenback and colleagues showed associations between incidence of TD on the one hand and occurrence of EPS ${ }^{9}$, prolactin-related adverse effects $^{4}$ and worsening of psychotic symptoms ${ }^{6}$ on the other, suggesting general DA dysregulation across the different DA tracts in schizophrenia. 
The Dopamine Dysregulation Syndrome for BD, as suggested by Berk and colleagues $^{3}$, is currently limited to DA functioning in the mesolimbic tract, focusing on mania and depression. Similar to schizophrenia, associations between the proxies representing alterations in the different DA tracts may be hypothesized for bipolar disorder as well. In order to validate this hypothesis, DA dysfunction was examined in a sample of patients with bipolar disorder, using the proxy measures defined by Tenback et $\mathrm{al}^{4,6}$. In line with Tenback and colleagues ${ }^{4,6}$, tardive movement syndromes formed the reference outcome for the analyses. Incidence rates of tardive extrapyramidal syndromes were calculated, and associations between these syndromes and proxy measures for alterations in other DA tracts were examined.

\section{Methods}

Data from the EMBLEM study was utilized for the current analyses. The study design is described in Chapter 1 as well as previous reports ${ }^{10,11}$. In short, the EMBLEM is a large European prospective observational study, studying patients with a change in pharmacological treatment for acute mania. For the current analyses, data from both the acute phase (assessments as baseline and after 1, 2, 3, 6 and 12 weeks) as the maintenance phase $(6,12,18$ and 24 months) were employed.

\section{Measures: extrapyramidal symptoms}

Investigators were requested to assess presence and severity of parkinsonism, akathisia, dystonia and TD that they judged to be associated with medications used to treat bipolar disorder. This assessment was based on the investigator's clinical experience and judgment and rated as follows: $0=$ not present; $1=$ present, but does not significantly interfere with patient's functioning; $2=$ present, and significantly interferes with patient's functioning. Guided by previous analyses using these measures ${ }^{4}$, movement disorder variables were analyzed as dichotomous indicators ( $\mathrm{O}=$ not present versus 1 =present; the latter combining scores of ' 1 ' and ' 2 '). These assessments were performed at baseline and all subsequent visits.

The scales used to measure extrapyramidal symptoms were simple and did not include instructions on or specific anchors for differential diagnosis. Therefore, in order to avoid diagnostic misclassification, only persistent dystonia and TD were used in the current analyses. Using the persistence measure ensured 
differentiation from the acute syndromes, as, for example, acute dystonia would be unlikely to persist over two subsequent visits whereas tardive dystonia would. Persistence was defined as the presence of the individual syndromes over at least 2 consecutive visits. Thus, the variable "persistent dystonia" was rated as follows: $\mathrm{O}=$ no or acute/incidental dystonia; $1=$ persistent dystonia. Similarly, "persistent TD" was rated as $\mathrm{O}=$ no or incidental TD; $1=$ persistent TD. Persistent TD and persistent dystonia were analyzed together as a single group (hereafter tardive dyskinesia and/or dystonia, 'TDD': o=no persistent TD or persistent dystonia present, 1 =persistent TD and/or persistent dystonia present). The rational for combining TD and dystonia comes from (i) their strong association ${ }^{12,13}$, (ii) shared risk factors and mechanisms ${ }^{14,15}$ and (iii) the fact that existing scales measuring tardive syndromes do not differentiate between TD and tardive dystonia ${ }^{16,17}$. Parkinsonism and akathisia were also compiled into a single variable, hereafter named EPS (o=neither parkinsonism nor akathisia present, $1=$ parkinsonism and/or akathisia present).

\section{Analyses}

\section{Incidence of $T D D$}

Incidence rates of TDD were determined by allocating each patient person-time for the TDD outcome according to the interval from baseline to the visit in which a patient was diagnosed with TDD. If no such diagnosis was made, the interval covered baseline to the final visit of each patient. Nine time bands were constructed (baseline - week 1; week 1 - week 2; week 2 - week 3; week 3-6 weeks; 6 weeks -3 months; 3 months -6 months; 6 months -12 months; 12 months - 18 months; 18 months - 24 months). The incidence of TDD was calculated by dividing the total number of incident cases of TDD by the total person-years. The same procedures were followed for calculating separate incidence rates for tardive dystonia and TD. All analyses were conducted in the risk set of patients free of TDD at baseline.

\section{Associations between clinical factors and incident TDD}

Cox proportional hazard regression was used to assess survival time without TDD associated with various time-varying clinical variables. The following clinical measures were used as proxies for DA dysregulation:

(i) Psychotic and manic symptoms may be associated with high DA transmission in the mesolimbic pathway ${ }^{5,7}$. Depression may be associated with lower DA 
transmission in the same tract, even though different receptor classes or subregions may be involved ${ }^{5,8}$. In the current analyses, the CGI-BP severity of mania, CGI Hallucinations/delusions and CGI-BP depression were regarded as proxy measures for altered DA transmission within the mesolimbic DA tract. In addition, the CGI-BP overall illness was used as an overall measure of dysregulation in this tract. All CGI scores were rated for severity on a seven-point scale ${ }^{18}$ and assessed at each visit including baseline.

(ii) Both amenorrhea and sexual dysfunction are suggested to be associated with elevated prolactin levels induced by low DA transmission ${ }^{19,20}$ originating in the tuberoinfundibular DA tract. This link is likely stronger for amenorrhea, as sexual disturbances in patients with schizophrenia are of multifactorial origin, and are therefore only in part attributable to illness- or medication-related prolactin levels ${ }^{19,20}$. Presence of amenorrhea and sexual dysfunction were used as proxy measures for altered DA transmission in the tuberoinfundibular tract (both defined as $\mathrm{O}=$ not present; $1=$ present; measured at each visit).

(iii) Extrapyramidal symptoms, including TD, have been hypothesized to reflect low DA transmission in the nigrostriatal DA tract in the brain ${ }^{5}$. Research indicates that EPS (defined as parkinsonism, akathisia and acute dystonia) represents a vulnerability to develop tardive movement disorders, in particular tardive dyskinesia, in patients with schizophrenia ${ }^{9}$. Therefore, presence of EPS as a proxy measure for dysfunctional DA transmission in the nigrostriatal tract, was investigated for association with incident TDD.

(iv) Use of antipsychotics (APs) is known to affect dopamine transmission ${ }^{21}$ and, in addition, is strongly associated with $\mathrm{TD}^{5}$. Use of AP was assessed at each visit and included in the analyses ( $\mathrm{o}=$ no AP use, $1=$ first generation antipsychotic (FGA), $2=$ second generation antipsychotic (SGA)).

The four clusters of proxy measures for DA dysfunction (bipolar symptoms, prolactin-related adverse effects, EPS and use of antipsychotics) were individually included as independent variables in the Cox models in order to determine associations with incident TDD. Finally, all variables were entered simultaneously in the model in order to determine which associations persisted independently of other factors. Effect sizes were expressed as Hazard Ratio's (HR) and $95 \%$ confidence intervals. The two-sided significance level was $5 \%$. 
Adjustment by propensity score

Analyses were performed with and without confounders (adjusted and unadjusted analyses, respectively). For each analysis, all patients with non-missing values on the dependent and independent variables were included, as well as on all confounding variables in case of adjusted analyses. Confounders were based on a review of the literature within patient populations diagnosed with bipolar disorder, schizophrenia or psychotic disorders in general. The following confounders were introduced in the Cox regression models: social economic status (SES, expressed as educational achievement; $1=$ no education, $2=$ primary school, $3=$ secondary school lower, $4=$ secondary school upper, $5=$ post-secondary vocational training, $6=$ university), country, compliance ( $\mathrm{O}=$ no medication prescribed or always complies; $1=$ never complies or about $50 \%$ of the time), age per decade ${ }^{22,23}$, age of onset in years ${ }^{24}$, gender ${ }^{23,25}$ and duration of illness in years ${ }^{26}$. As a decrease in TDD incidence over time was anticipated, analyses were also adjusted for visit number.

It is common practice to increase the dosages of antipsychotics or lithium in response to increased symptom severity. It is widely accepted that antipsychotic use and lithium in itself are associated with an increased risk for developing movement disorders and other adverse effects ${ }^{5}$. As a result, associations between higher symptom severity or the presence of adverse effects with a higher incidence of TDD may represent a confounding effect of AP or lithium use or dose burden. Therefore, multiple treatment-related variables were included as confounders in order to eliminate spurious results for dopamine abnormalities related to the (changes in) use of antipsychotics and lithium, except when testing associations between TDD and the use of antipsychotics. The following treatment-related time-varying variables were included as confounders: (i) use of APs (dichotomous variable: $\mathrm{O}=$ no use of AP, $1=$ use of FGA and/or SGA); (ii) dichotomous variables indicating use ( $\mathrm{O}=$ no use, $1=\mathrm{use}$ ) of the following individual treatments; amisulpride, clozapine, haloperidol, olanzapine, quetiapine, risperidone, ziprazidone, other AP or lithium (iii) dose of treatment used, expressed as dose equivalents; (iv) change in dose of treatment with respect to the previous visit, expressed as dose equivalents. In addition, change in CGI-BP Overall illness score relative to the previous visit was included as confounder, except when testing for an association between the CGI-BP Overall illness and incident TDD. 
As many confounding variables were included in the models, traditional control for confounding by inclusion of covariates in the model may not be sufficient, as the degree of 'control' afforded by such models depends on the overlap in characteristics between the two outcome groups. The use of the propensity score has been suggested as a means to obtain more complete control in these circumstances $^{27}$. The propensity score for an individual, defined as the conditional probability of (in this case) developing TDD given the individual's covariates, can be used to balance the covariates in observational studies, and thereby to reduce bias $^{28}$. In other words, by using propensity scores, a collection of covariates is replaced by a single covariate, being a function of the original ones, while minimizing the loss of degrees of freedom. As the propensity score model could not create sufficient balance between the groups due to the variable 'haloperidol', haloperidol was not included in the propensity score model and was adjusted for separately in the model, together with the dependent variable, the independent variable under investigation and the propensity score representing the other specified confounders.

Not all countries participated in the maintenance phase of the study (12 weeks onwards), resulting in a decrease in sample size after the 12 weeks (Switzerland, Denmark, Germany and Spain only participated in the acute phase). Apart from the decrease in overall sample size, the samples for the individual analyses varied somewhat on the basis of the availability of complete data for variables included in the separate models. All analyses were performed using the computer package STATA, version $10.0^{29}$.

\section{TDD validity: sensitivity analyses}

Sensitivity analyses were conducted using a stricter criterion for incidence in order to exclude any possibility of bias due to carry-over from influences occasioned by factors acting during the period before baseline. To this end, a stricter risk set was defined as the sample of patients free from dystonia or TD at baseline as well as at visit 2 (one week post-baseline). Therefore, first occurrence of any incident tardive syndrome could occur at visit 3 (two weeks post-baseline), while for the purpose of the current analyses incidence could first occur at visit 4, due to the requirement of persistence of symptoms for at least 2 consecutive visits. Consequently, misclassification of the acute form of dystonia, which usually has an onset within 5 days of new antipsychotic treatment ${ }^{3 \circ}$, could be ruled out with even more confidence. 


\section{Results}

Sample description

A total of 3459 subjects participated in the EMBLEM study and fulfilled the CGIBP eligibility criteria (CGI-BP mania $\geq 3$ ). 355 Patients were excluded from the analyses, either due to missing baseline ratings of dystonia and/or TD, or due to presence of dystonia and/or TD at baseline. Of the remaining 3104 patients, $43.5 \%$ were male and the mean age was 44.5 years (sd 13.4). The mean age of onset was 29.9 years $(\mathrm{sd} 11.1$ ). Table 1 provides an overview of the baseline clinical characteristics of the patient sample. As a frame of reference, the medication used at enrollment, as well as the medication prescribed at baseline are presented in Table 2. More than half of the patients did not use any antipsychotic medication at enrollment, while 30\% used antidepressants at that time. Second generation APs were prescribed most frequently at the baseline visit, followed by anticonvulsants.

\section{$\underline{\text { Incidence rate }}$}

The TDD incidence was calculated by dividing the total number of incident cases of TDD by the total person-years. Over two years of treatment, the sample contributed 3163 patient years, while there were 129 new cases of TDD, yielding an incidence rate of $4.1 \%(95 \%$ CI: 3.4 4.8). The separate incidence rates for TD and Tardive Dystonia were 1.0\% (95\% CI: 0.7, 1.4) and 3.3\% (95\% CI: $2.7,4.0)$ respectively. Overall, incidence rates decreased with time, as illustrated by Table 3, where incidence rates are provided per time band.

Table 1. Baseline clinical characteristics of the complete sample $(\mathrm{n}=3104)$.

\begin{tabular}{lc}
\hline Inpatient status (\%) & $40.0 \%$ \\
Rapid cycling (episodes per year $\geq 4 ; \%)$ & $17.2 \%$ \\
CGI-BP overall illness (mean, sd) & $4.7(1.0)$ \\
CGI-BP mania (mean, sd) & $4.8(1.0)$ \\
CGI hallucinations/delusions (mean, sd) & $2.9(1.8)$ \\
CGI-BP depression (mean, sd) & $1.8(1.2)$ \\
\hline
\end{tabular}

Associations between tardive dystonia and TD

In order to examine the validity of combining the tardive dystonia and TD variables into a combined outcome, associations between these tardive movement disorders were calculated using Cox analyses. The probability of incident tardive dystonia in the presence of TD was high $(\mathrm{HR}=9.56,95 \% \mathrm{CI}=6.02,15.18 ; \mathrm{P}<. .001)$, 
while the probability of incident TD in the presence of tardive dystonia was even higher $(\mathrm{HR}=22.25,95 \% \mathrm{CI}=9.20,53.85 ; \mathrm{P}<.001)$.

Table 2. Medications at presentation and prescribed on baseline visit for the complete sample $(\mathrm{n}=3104)$.

\begin{tabular}{lcc}
\hline & $\begin{array}{c}\text { At presentation on } \\
\text { baseline visit }\end{array}$ & $\begin{array}{c}\text { Prescribed at } \\
\text { baseline visit } \dagger\end{array}$ \\
\hline No AP (\%) & $53.2 \%$ & $11.1 \%$ \\
FGA (\%) & $25.4 \%$ & $11.5 \%$ \\
SGA (\%) & $15.4 \%$ & $65.3 \%$ \\
Combination of FGA and SGA (\%) & $6.0 \%$ & $12.1 \%$ \\
Lithium (\%) & $18.8 \%$ & $25.1 \%$ \\
Anticonvulsants (\%) & $29.9 \%$ & $49.1 \%$ \\
Antidepressants (\%) & $30.0 \%$ & $15.6 \%$ \\
Anticholinergics (\%) & $*$ & $8.8 \%$ \\
\hline
\end{tabular}

AP=antipsychotic; $\quad F G A=$ first generation antipsychotic; $S G A=$ second generation antipsychotic; *not assessed; fall patients were prescribed a new treatment at baseline; medication use is extensive in this population, therefore not all used medication is included in this table (e.g. benzodiazepines).

\section{Associations between clinical factors and incident TDD}

Table 4 provides associations between incident TDD and hypothesized dichotomous variables; presence of sexual dysfunction, amenorrhea and EPS were found to be associated with incident TDD. Additionally, compared with no AP use, both FGAs and SGAs showed a stronger association with TDD. Associations between incident TDD and hypothesized bipolar symptom severity are presented in Table 5. Higher symptom severity was consistently found to be associated with incident TDD.

\section{Independence of associations with incident TDD}

In order to test the degree of independence of the different associations between TDD and the various DA-proxies, a model was examined with all predictors included together. This revealed that the CGI-BP Hallucinations/delusions (HR per CGI point=1.13, 95\% CI: 1.01, 1.28; $\mathrm{P}=.041)$, sexual dysfunction $(\mathrm{HR}=1.47,95 \% \mathrm{CI}$ : 1.12, 1.93; $\mathrm{P}=.006)$ and presence of EPS (HR=13.33, 95\% CI: 5.01, 35.50; $\mathrm{P}<.001$ ) were associated with incident TDD independent of other factors. 
Table 3. Incidence of tardive dystonia, tardive dyskinesia and TDD for each time band ( $\mathrm{n}=3104)$.

Tardive dystonia

TD

TDD

\begin{tabular}{lccccccccc}
\hline & $\mathrm{N}$ & Person-years & $\begin{array}{c}\text { Incidence } \\
\text { Rate }\end{array}$ & $\mathrm{N}$ & Person-years & $\begin{array}{c}\text { Incidence } \\
\text { Rate }\end{array}$ & $\begin{array}{c}\mathrm{N}^{\text {a }} \\
\text { Rerson-years }\end{array}$ & $\begin{array}{c}\text { Incidence } \\
\text { Rate }\end{array}$ \\
\hline Visit 3 (week 2) & 37 & 114 & $32.6 \%$ & 7 & 114 & $6.2 \%$ & 41 & 114 & $36.1 \%$ \\
Visit 4 (week 3) & 23 & 56 & $40,7 \%$ & 4 & 57 & $7.0 \%$ & 25 & 56 & $44.3 \%$ \\
Visit 5 (meek 6) & 15 & 141 & $10.6 \%$ & 2 & 144 & $1.4 \%$ & 17 & 141 & $12.0 \%$ \\
Visit 6 (month 3) & 12 & 287 & $4.2 \%$ & 4 & 293 & $1.4 \%$ & 15 & 286 & $5.2 \%$ \\
Visit 7 (month 6) & 5 & 440 & $1.1 \%$ & 4 & 454 & $0.9 \%$ & 8 & 439 & $1.8 \%$ \\
Visit 8 (month 12) & 6 & 753 & $0.8 \%$ & 5 & 776 & $0.6 \%$ & 10 & 750 & $1.3 \%$ \\
Visit 9 (month 18) & 2 & 721 & $0.3 \%$ & 1 & 746 & $0.1 \%$ & 3 & 716 & $0.4 \%$ \\
Visit 10 (month 24) & 5 & 666 & $0.8 \%$ & 6 & 688 & $0.9 \%$ & 10 & 661 & $1.5 \%$ \\
\hline
\end{tabular}

The time band between visit 1 and 2 was not included, due to the definition of persistence (presence of symptoms for at least 2 consecutive visits). ${ }^{a} A s$ some patients may present with both tardive dystonia and TD, $n$ for TDD may be lower than the sum of $n$ for tardive dystonia and TD. 
Table 4. Associations between incident TDD and various dichotomous clinical factors during a period of 2 years $(\mathrm{n}=3104)$.

\begin{tabular}{|c|c|c|c|c|c|c|c|c|c|}
\hline & \multicolumn{3}{|c|}{ TDD rate exposed } & \multicolumn{5}{|c|}{ TDD rate non-exposed } & \multirow[b]{2}{*}{$\begin{array}{c}\text { Sensitivity analyses } \\
\text { (HR adjusted) } \\
95 \% \mathrm{CI})^{\mathrm{b}}\end{array}$} \\
\hline & $\mathrm{N}$ & $\begin{array}{l}\text { Person- } \\
\text { years }^{\mathrm{a}}\end{array}$ & $\begin{array}{l}\text { Rate } \\
(\%)\end{array}$ & $\mathrm{N}$ & $\begin{array}{l}\text { Person- } \\
\text { years }\end{array}$ & $\begin{array}{l}\text { Rate } \\
(\%)\end{array}$ & $\begin{array}{l}\text { HR adjusted } \\
\quad(95 \% \mathrm{CI})\end{array}$ & $\begin{array}{l}\text { HR unadjusted } \\
\quad(95 \% \mathrm{CI})\end{array}$ & \\
\hline Sexual dysfunction & 44 & 505 & 8.7 & 84 & 2637 & 3.2 & $2.68(1.72,4.16)^{*}$ & $2.72(2.20,3.37)^{*}$ & $2.61(1.56,4.39)^{*}$ \\
\hline Amenorrhea & 11 & 126 & 8.7 & 107 & 2810 & 3.8 & $2.54(2.10,3.09)^{*}$ & $2.38(1.74,3.26)^{*}$ & $2.48(1.83,3.36)^{*}$ \\
\hline EPS & 89 & 273 & 32.6 & 40 & 2875 & 1.4 & $13.94(6.90,28.19)^{*}$ & $17.20(9.11,32.47)^{*}$ & $17.79(6.70,47.26)^{*}$ \\
\hline FGA use vs no AP & 31 & 287 & 10.8 & 9 & 768 & 1.2 & $2.64(1.94,3.60)^{*}$ & $2.64(1.97,3.53)^{*}$ & $2.32(1.66,3.24)^{*}$ \\
\hline SGA use vs no AP & 69 & 1902 & 3.6 & 9 & 768 & 1.2 & $2.18(1.20,3.97) \dagger$ & $2.16(1.02,4.54) \dagger$ & $1.50(0.79,2.85)$ \\
\hline
\end{tabular}

${ }^{*} P \leq 0.001 ;+P \leq 0.05 . N=\min .1143$ (as amenorrhea analysis was limited to women), $\max .2025$ for the adjusted analyses; $n=\min .1606$, max. 2953 for the unadjusted analyses. EPS=extrapyramidal symptoms. FGA=first generation antipsychotics. $S G A=$ second generation antipsychotics. AP=antipsychotic. ${ }^{a}$ Person years in follow-up. For instance, for sexual dysfunction, the patients included in the analyses contributed (505 $\left.+2637=\right) 3142$ years of follow-up time. 44 patients that developed TDD presented with comorbid sexual dysfunction (rate of 8.7\%). 84 patients that developed TDD did not present with comorbid sexual dysfunction (rate of $3.2 \%$ ). ${ }^{b}$ Sensitivity analyses were conducted with a stricter criterion for incidence TDD; a stricter risk set was defined as the sample of patients free from dystonia or TD at baseline as well as at visit 2 (one week post-baseline). Consequently, person-years included in this table do not hold for the sensitivity analyses. 
Table 5. Associations between incident TDD and various continuous clinical factors over a 2-year period.

\begin{tabular}{|c|c|c|c|}
\hline & $\begin{array}{c}\text { HR adjusted (95\% CI interval) } \\
\text { per CGI point }\end{array}$ & $\begin{array}{c}\text { HR unadjusted (95\% CI interval) } \\
\text { per CGI point }\end{array}$ & $\begin{array}{c}\text { Sensitivity analysis } \\
\text { HR adjusted ( } 95 \% \text { CI interval) } \\
\text { per CGI point }\end{array}$ \\
\hline CGI-BP Overall illness & $1.59(1.32,1.90)^{*}$ & $1.49(1.24,1.79)^{*}$ & $1.69(1.44,1.79)^{*}$ \\
\hline CGI-BP Hallucinations/delusions & $1.53(1.37,1.70)^{*}$ & $1.49(1.35,1.64)^{*}$ & $1.60(1.42,1.80)^{*}$ \\
\hline CGI Mania & $1.56(1.36,1.78)^{*}$ & $1.47(1.24,1.73)^{*}$ & $1.69(1.53,1.87)^{*}$ \\
\hline CGI-BP Depression & $1.38(1.12,1.71)^{*}$ & $1.30(1.14,1.49)^{*}$ & $1.45(1.18,1.78)^{*}$ \\
\hline
\end{tabular}

${ }^{*} P \leq .002 . N=\min .2013, \max .2016$ for the adjusted analyses; $n=\min .2948, \max .2952$ for the unadjusted analyses. 


\section{$\underline{\text { Sensitivity analyses }}$}

The sample for the sensitivity analyses consisted of 2657 patients. The incidence rate for dystonia decreased to $2.2 \%$, TD to $0.8 \%$ and TDD to $2.9 \%$. All but one association between DA-proxies and TDD remained significant and effect sizes did not change substantially; only the association between SGA use (versus no AP use) and TDD was slightly reduced and no longer significant. Results are included in Tables 4 \& 5 .

\section{Discussion}

One in twenty-five participants experienced new onset tardive dystonia and/or TD over a period of 2 years. Although carry-over effects from previous medications cannot be excluded because (i) the visits used to define persistence were close to each other in time and (ii) there was a linear decrease in incidence of TDD over the entire study period, the results from the sensitivity analyses suggest that carryover effects did not play an important role. Indeed, even if carry-over effects existed, there is no reason to assume that these should per se affect the reported associations with third variables. Reported incidence rates of tardive syndromes in bipolar populations vary widely in the literature, probably due to variation in use of medication (type of antipsychotic, duration of exposure to lithium, polypharmacy), tardive syndrome definitions, characteristics of patient populations, study designs and mood state dependent fluctuations ${ }^{2}$. Indeed, the sensitivity analyses carried out for the purpose of the current analyses clearly show that subtle changes in definition affect incidence rates.

To our knowledge, rates of tardive dystonia have not been reported in a similar population. One of the few reports available on tardive dystonia originates from a sample of chronic psychiatric patients from Curacao, mostly suffering from schizophrenia. The reported incidences for tardive dystonia and TD were $0.7 \%$, and $10.2 \%$, respectively ${ }^{13}$, whereas in our sample tardive dystonia had a higher incidence than TD. However, the Curacao study also reported that the incidence of tardive dystonia diminished over time, whereas the risk of TD followed an inverse pattern ${ }^{30}$. This may explain the discrepancy with our current findings, as the mean age in the current sample was lower (mean age 44 years, sd 13) compared to the chronically ill inpatient population from the Curacao study (mean age 53 years, sd 17). Van Harten and colleagues demonstrated with this study that the rate of tardive dystonia was highest in the age group of 44 years or younger, whereas the rate of TD increased substantially after that age. Indeed, the 
incidence rate for tardive dystonia in the current study $3.3 \% ; 2.3 \%$ when a stricter definition was applied), approximates the $3 \%$ incidence rate reported for patients on long-term antipsychotic treatment in a review by Van Harten ${ }^{31}$. More research is needed within the bipolar spectrum to confirm the absolute risk of tardive syndromes in this specific population.

\section{Expanding the Dopamine Dysfunction Syndrome model?}

A strong association was demonstrated between TDD incidence and various clinical factors, beyond antipsychotic medication, that were regarded as proxy measures for DA dysfunction in different tracts: high symptom severity scores, presence of sexual dysfunction, amenorrhea and EPS. Thus, (proxy) dysfunction in the nigrostriatal tract was found to be associated with (proxy) dysfunctions in the mesolimbic and the tuberoinfundibular DA tracts, indirectly suggesting generalised dopaminergic dysfunction.

The association between EPS and TDD was anticipated based on similar findings in schizophrenia ${ }^{9}$, and the fact that extrapyramidal symptom clusters in general have been linked to low DA transmission in the nigrostriatal tract ${ }^{5}$. Associations between measures of sexual dysfunction and TDD are somewhat more complex as they imply the involvement of different tracts; they are, however, both associated with relatively low DA transmission ${ }^{5,19,20}$.

Explaining the associations between more severe mania and psychotic symptoms on the one hand, and incident TDD on the other, is more complicated, as these symptom clusters seemingly represent high rather than low states of DA transmission, the latter being associated with TDD. To the best of our knowledge, an association between psychosis severity and TDD has not been reported before within a bipolar population. One might argue that the increase in psychotic symptoms and the emergence of TDD may be occasioned simultaneously by withdrawal of $\mathrm{APs}^{32}$. Alternatively, it may reflect increased dose of antipsychotics prescribed in response to increases in psychotic or manic symptoms, causing TDD. Although either of these confounding mechanisms cannot be completely excluded, it may be considered unlikely given that the current analyses were adjusted for changes in AP use and dose, as well as changes in CGI overall symptoms severity.

The association between more severe mania and TDD incidence was surprising, as the limited reports available suggest a decrease of TD severity during manic episodes ${ }^{2}$. It may be attractive to speculate, in combination with the 
association found between TDD and psychotic symptoms, that this finding can be explained using the concept of 'supersensitivity psychosis', which postulates that psychotic symptoms may be produced by increased sensitivity of DA receptors in the mesolimbic tract ${ }^{33}$. Manic symptoms, similar to psychotic symptoms, have been linked to the mesolimbic DA tract ${ }^{5,7}$, suggesting that this theory may be extrapolated to the mania symptom cluster as well. Although speculative, the hypothesis that the concept of supersensitivity may additionally extend to the nigrostriatal tract, could explain the associations found in the current study.

This hypothesis could also explain the finding of decreasing TDD incidence over time, as better BD symptom control might represent a dampening of supersensitivity, which might be extended to multiple tracts. Another explanation for this finding could be that patients who are highly sensitive to TDD development would develop the syndrome early in the study, whereas less sensitive patients either develop the syndrome at a later stage or not at all.

Even though the apparent contrast in the direction of proxy DA transmission status in the mesolimbic (up regulated) and nigrostriatal (down regulated) pathways that were associated with TDD is difficult to explain, it is compatible with the notion of broad dysfunction in the DA system. Alternatively, rather than an absolute interpretation of "high" or "low" states, DA instability or alterations in regulatory influences among the different DA tracts may instead represent the core characteristic driving the observed associations. The limited conclusion that can be drawn at this time is that more severe BD related symptoms are associated with an increased probability of tardive syndromes, the reason for which remains speculative.

\section{Limitations}

The findings of the current study are subject to a number of limitations. First, we depended on proxy measures of DA transmission. The literature indicates that the investigated symptoms and adverse effects are, to a certain extent, related to DA dysfunction in certain areas. However, various external factors may influence these symptoms and effects without (necessarily) altering DA transmission. For instance, use of concomitant medication or antagonism of other receptors by APs may affect sexual dysfunction ${ }^{19,20}$.

Second, if a pan-dopaminergic dysregulation exists within BD, it remains unknown what may cause such a state. For example, a reduction in sensitivity of postsynaptic DA receptors, altered pre-synaptic activity, a reduction in absolute or 
relative DA concentrations or another mechanism yet to be revealed may be involved. Obviously, epidemiological research is not the appropriate methodology to investigate these underlying mechanisms; more neuroimaging and pre-clinical data are needed to shed light on the nature and extent of DA dysfunction within the framework of the hypothesized dopamine dysregulation syndrome proposed by Berk and colleagues ${ }^{3}$ as well as the extensions proposed in the current report.

Third, as cogently discussed by Berk and colleagues ${ }^{3}$, DA transmission is certainly not the sole underlying factor for neural dysfunction in $\mathrm{BD}$; other neurotransmitters are likely to play a role. Even though the current model is far from able to explain all pathology associated with $\mathrm{BD}$, the current literature is not incompatible with a major role of DA. Therefore, the model used may be regarded as an interesting scientific starting point for epidemiological research on the extent and nature of any involvement of DA in the bipolar spectrum.

Fourth and final, the direct effects of lithium or antipsychotics dose adjustments on tardive movement disorders are complicated. Tardive dyskinesia has been reported to abate after dose increases ${ }^{34}$, usually to reappear after some time, whereas acute dystonia often emerges following dose increases ${ }^{5}$. In order to avoid confounding, analyses were controlled for various relevant treatmentrelated variables, including changes in treatment doses. Even with this adjustment, one could question the extent to which dose adjustments may have influenced our results.

\section{Conclusion}

In summary, high rates of TDD, tardive dystonia and tardive dyskinesia were found within a bipolar population. Apart from the well-known associations with antipsychotics, strong associations were demonstrated between TDD incidence and various clinical factors that were regarded as proxy measures for DA dysfunction in different tracts, which implies a generalized dopamine dysfunctional state. Future neuroimaging and pre-clinical data may shed light on the underlying mechanism of this pattern. 


\section{References}

1. Cavazzoni PA, Berg PH, Kryzhanovskaya LA, Briggs SD, Roddy TE, Tohen M, Kane JM (2006). Comparison of treatment-emergent extrapyramidal symptoms in patients with bipolar mania and schizophrenia during olanzapine clinical trials. J Clin Psychiatry, 67:10713

2. Keck PE, McElroy SL, Strakowski SM, Soutullo CA (2000). Antipsychotics in the treatment of mood disorders and risk of tardive dyskinesia. J Clin Psychiatry, suppl 4;61:33-8

3. Berk M, Dodd S, Kauer-Sant'anna M, Malhi GS, Bourin M, Kapczinski F, Norman T (2007). Dopamine dysregulation syndrome: implications for a dopamine hypothesis of bipolar disorder. Acta Psychiatr Scand, 434(suppl):41-9

4. Tenback DE, van Harten PN, Slooff CJ, van Os J; SOHO Study Group (2006). Tardive dyskinesia in schizophrenia is associated with prolactine-related side effects. Neuropsychopharmacology, 31:1832-7

5. Stahl SM. Stahl's essential psychopharmacology. Cambridge University Press, Cambridge, 2008

6. Tenback DE, van Harten PN, Slooff CJ, van Os J; SOHO Study Group (2007). Worsening of psychosis in schizophrenia is longitudinally associated with tardive dyskinesia in the European Schizophrenia Outpatients Health Outcomes study. Compr Psychiatry, 48:436-40

7. Diehl DJ, Gershon S (1992). The role of dopamine in mood disorders. Compr Psychiatry, 33(2):115-20

8. Dunlop BW, Nemeroff CB (2007). The role of dopamine in the pathophysiology of depression. Arch Gen Psychiatry, 64(3):327-37

9. Tenback DE, van Harten PN, Slooff CJ, van Os J; SOHO Study Group (2006). Evidence that early extrapyramidal symptoms predict later tardive dyskinesia. Am J Psychiatry, 163:143840

10. Goetz I, Tohen M, Reed C, Lorenzo M, Vieta E, the EMBLEM Advisory Board (2007). Functional impairment in patients with mania: Baseline results of the EMBLEM study. Bipolar Disord, 9(1-2):45-52

11. Haro JM, Van Os J, Vieta E, Reed C, Lorenzo M, Goetz I, the EMBLEM Advisory Board (2006). Evidence for three distinct classes of 'Typical', 'Psychotic' and 'Dual' Mania: Results from the EMBLEM study. Acta Psychiatr Scand, 113(2):112-20

12. Van Harten PN, Hoek HW, Matroos GE, Koeter M, Kahn R (1997). Inter-relationships of tardive dyskinesia, parkinsonism, akathisia and tardive dystonia: the Curaçao extrapyramidal symdromes study II. Schiz Res, 26(2-3):235-42

13. Van Harten PN, Hoek HW, Matroos GE, Van Os J (2006). Incidence of tardive dyskinesia and tardive dystonia in African Carribean patients on long-term antipsychotic treatment: the Curacao extrapyramidal syndromes study V. J Clin Psychiatry, 67:1920-7

14. Burke RE, Kang UJ (1988). Tardive dystonia: clinical aspects and treatment. Adv Neurol, 49:199-210

15. Sachdev P (1993). Risk factors for tardive dystonia: a case-control comparison with tardive dyskinesia. Acta Psychiatr Scand, 88(2):98-103

16. Chouinard G, Margolese HC (2005). Manual for the Extrapyramidal Symptom Rating Scale (ESRS). Schizophr Res, 76(2-3):247-65

17. Guy WA. Abnormal Involuntary Movement Scale (AIMS). U.S. Department of Health Education and Welfare, Washington, DC 534-537, 1976 
18. Spearing MK, Post RM, Leverich GS (1997). Modification of the Clinical Global Impressions (CGI) Scale for Use in Bipolar Illness (BP): the CGI-BP. Psychiatry Res, 73:159-71

19. Knegtering H, van der Moolen AE, Castelein S, Kluiter H, van den Bosch RJ (2003). What are the effects of antipsychotics on sexual dysfunctions and endocrine functioning? Psychoneuroendocrinology, 28:109-23

20. Knegtering H, van den Bosch R, Castelein S, Bruggeman R, Sytema S, van Os J (2008). Are sexual side effects of prolactin-raising antipsychotics reducible to serum prolactin? Psychoneuroendocrinology, 33:711-7

21. Correll CU, Leucht S, Kane JM (2004). Lower risk for tardive dyskinesia associated with second-generation antipsychotics: a systematic review of 1-year studies. Am J Psychiatry, $161(3): 414-25$

22. Van Os J, Fahy T, Jones P, Harvey I, Toone B, Murray R (1997). Tardive dyskinesia: who is at risk? Acta Psychiatr Scand, 96(3):206-16

23. Van Os J, Walsh E, Van Horn E, Tattan T, Bale R, Thompson SG (1999). Tardive dyskinesia in psychosis: are women really more at risk? UK700 Group. Acta Psychiatr Scand, 99(4):28893

24. Hunt N, Silverstone T (1991). Tardive dyskinesia in bipolar affective disorder: a catchment study. Int Clinical Psychopharmacology, 6:45-50

25. Casey DE (1999). Tardive dyskinesia and atypical antipsychotic drugs. Schizophr Res, 35:S61-66

26. Waddington JL, Brown K, O’Neill J, McKeon P, Kinsella A (1989). Cognitive impairment, clinical course and treatment history in out-patients with bipolar affective disorder: relationship to tardive dyskinesia. Psych Med, 19:897-902

27. Joffe MM, Rosenbaum PR (1990). Invited commentary: propensity scores. Am J Epidemiol, 150:327-33

28. Klungel OH, Martens EP, Psaty BM, Grobbee DE, Sullivan SD, Stricker BH, Leufkens HG, de Boer A (2004). Methods to assess intended effects of drug treatment in observational studies are reviewed. J Clin Epidemiol, 57:1223-31

29. STATACORP. Stata Statistical Software: Release 10.0. Stata Corporation: College Station TX, 2008

30. Van Harten PN, Martoos GE, Hoek HW, Kahn RS (1996). The prevalence of tardive dystonia, tardive dyskinesia, parkinsonism and akathisia. Schizophr Res, 19:195-203

31. Van Harten PN, Kahn RS (1999). Tardive dystonia. Schizophr Bull, 25(4):741-8

32. Moncrieff J (2006). Does antipsychotic withdrawal provoke psychosis? Review of the literature on rapid onset psychosis (supersensitivity psychosis) and withdrawal-related relapse. Acta Psychiatr Scand, 114:3-13

33. Chouinard G, Annable L, Ross-Chouinard A (1986). Supersensitivity psychosis and tardive dyskinesia: a survey in schizophrenic outpatients. Psychopharmacol Bull, 22(3):891-6

34. Nasrallah, H (2006). Focus on lower risk of tardive dyskinesia with atypical antipsychotics. Ann Clin Psychiatry, 18:57-62 
$\stackrel{\infty}{-}$

范 


\section{7 \\ Conclusions}

\section{Interpretation of findings within a dopamine dysfunction model}


The general aim of this thesis was to investigate the nature of BD-related symptoms on two levels; i) on a subclinical level, we wished to investigate the effect of affective dysregulation on the presence, course and impact of reality distortion; ii) on a clinical level, we wished to investigate illness characteristics and factors influencing the short-term and long-term course of bipolar illness.

\section{General findings and implications}

The broad definition of the general aim resulted in diverge hypotheses and findings on topics that had not received much attention in current literature, providing new insights on course and outcome of bipolar symptoms, both on a subclinical and clinical level. Findings are of practical relevance, as they i) identify potential ways to influence course and outcome of the illness, given that some factors impacting course and outcome could be influenced within the treatment setting (e.g. substance use, social circumstances) or ii) at least help create insight into the illness status of individual patients and consequently define realistic treatment expectations (e.g. effects of co-morbid complexities).

Aside from the findings from the individual analyses, an unforeseen higher-level pattern was noticed within the results. Although this was originally not the objective of our research, circumspect evidence on a potential role of dopamine in the onset and course of bipolar disorder accumulated during the course of this research. Despite the use of epidemiological research designs, our findings could be cautiously interpreted within the context of a recently postulated dopamine dysfunction model for bipolar disorder ${ }^{1}$, which is described in more detail below. Moreover, results hinted towards a potentially broader dopamine dysfunctional state than originally proposed by Berk and colleagues ${ }^{1}$. To facilitate the use of our circumstantial findings towards the creation of hypotheses for an expansion of the existent dopamine dysfunction model, the most important findings from the individual analyses comprising this thesis are summarized below per component of this dopamine dysfunction model (mainly bipolar symptoms). Additionally, for each component of the model, a concise overview of current literature on dopamine research is provided as a frame of reference. This overview of our findings embedded into literature will finally lead to a general conclusion, by proposing hypotheses on an extended Dopamine Dysfunction model for bipolar disorder as well as suggestions for future research. 


\section{Findings on mania symptoms}

Mania symptoms as an outcome measure were of specific interest throughout multiple analyses in this thesis. On a subclinical level, mania symptoms were associated with occurrence and persistence of psychotic symptoms as well as psychosis-related impairment (Chapter 2). These findings suggest a fascinating interaction between mania symptoms and the experience of reality distortion in a premorbid phase. Chapter 3 demonstrated that the speed of improvement of mania symptoms was impacted by various illness characteristics (such as a lower age of onset and rapid cycling patterns) as well as social variables (such as independent living and the frequency of social activities). Chapter 4 showed that mania symptoms in the absence of co-morbid complexities (e.g., drug abuse or psychotic symptoms) are associated with a relative good outcome within the context of bipolar disorder. Mania symptoms were found to be more severe in patients exposed to cannabis (Chapter 5), whereas the incidence of tardive movement disorders was higher in patients with higher mania scores (Chapter 6). Overall, our findings indicate that the severity of mania symptoms is impacted by or at least associated with various illness-related factors, some of which can be influenced within the treatment context.

\section{Current literature: Mania symptoms and dopamine}

Currently, mania symptoms are largely conceptualized as the product of unstable and excessive neurotransmission in specific brain circuits. Symptoms such as racing thoughts, grandiosity and flight of ideas may be hypothetically linked to inefficient information processing in brain regions that are part of the mesolimbic dopamine $\operatorname{tract}^{2}$ (Figure 1). Most evidence for this conceptualization arises from studies indirectly investigation dopamine involvement; only few studies have applied a direct approach through PET or SPECT. In one of these latter

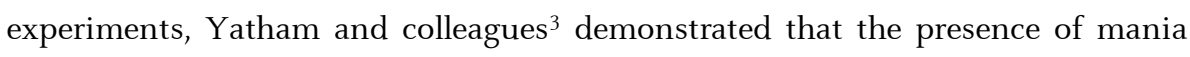
symptoms were not related with the dopamine D2 binding potential in the striatum of nonpsychotic first episode treatment-naïve patients, compared to healthy controls. Associations between D2 binding potential and severity or improvement of mania symptoms were also absent. However, these negative results could be caused by the limited number of manic patients studied $(n=9)$, and a higher level of D2 receptor density could have been obscured by high endogenous dopamine levels using the specific ligand employed ${ }^{3}$. 


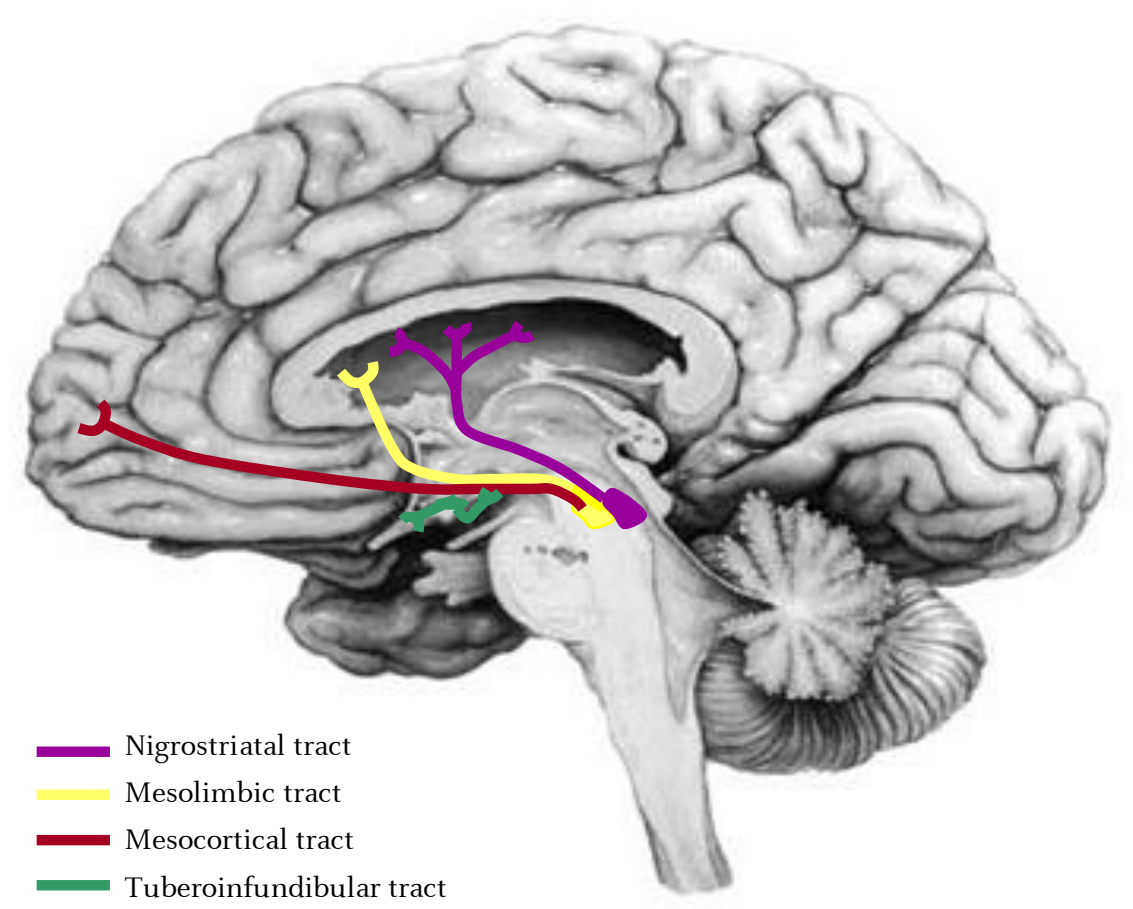

Figure 1: general overview of the 4 dopamine pathways; nigrostriatal tract (projects from substantia nigra to striatum), mesolimbic tract (projects from the ventral tegmental area of the midbrain, via the nucleus accumbens, amygdala and hippocampus to the medial prefrontal cortex and limbic system), mesocortical tract (projects from the ventral tegmental area to cerebral cortex, particularly the frontal lobes) and the tuberoinfundibular tract (projects from hypothalamus to pituitary gland).

A subsequent study by the same research group indicated that presynaptic dopamine activity in the striatum was similar for healthy controls and medication-naïve first episode manic patients. However, dopamine synthesis decreased in patients after valproate use, again without any association with the severity of mania symptoms ${ }^{4}$. A third study reported that there was no difference in striatal D2 receptor binding between euthymic bipolar patients and healthy controls. Nevertheless, the finding that bipolar patients showed a stronger behavioral response (i.e., more severe mania symptoms) to an amphetamine challenge (causing an increase in the level of synaptic dopamine in humans) led the authors to the conclusion that these results are consistent with a stronger 
postsynaptic dopamine response in patients, instead of increased dopamine release ${ }^{5}$.

Indirect evidence for the involvement of dopamine in mania symptoms is originating from the behavioral effects of psychostimulants and antimanic medication. Dopamine agonists and stimulants such as amphetamine (which increases both dopamine and norepinephrine release) have behavioral effects that resemble mania symptoms, while D2-receptor blocking antipsychotics are effective antimanic agents ${ }^{1,3}$. Other indirect evidence is derived from studies using branched-chain amino-acid mixtures depleting the uptake of dopamine precursors. Subsequently, mania symptoms were found to decrease in two patient samples $^{6,7}$, and the psychostimulant mania-like effects of administered methamphetamine were diminished in both healthy controls and manic patients ${ }^{7}$. These findings suggest that mania symptoms are associated with an excess in dopamine, and can be relieved by a reduction of dopamine. An earlier case report demonstrated that a higher urinary dopamine level predicted a manic mood originating 3 days after the sample was taken ${ }^{8}$. In addition, various studies were conducted through measurement of the dopamine metabolite homovanillic acid (HVA), yielding inconsistent results ${ }^{4}$. In 8 studies, manic patients were found to have higher HVA levels compared to healthy control subjects, although 2 other studies were not able to demonstrate a difference.

Overall, from the few studies available, direct research on dopamine activity seems to suggest that mania may be associated with a stronger striatal postsynaptic dopamine response in mania, whereas indirect studies suggest that dopamine metabolism (HVA) is higher in mania patients. Thus far it remains disputable which exact mechanism in dopamine transmission may be affected.

\section{Findings on psychotic symptoms}

Psychotic symptoms are a common feature of bipolar disorder, and therefore received substantial attention in this thesis. In Chapter 2, the occurrence and persistence of subclinical psychotic symptoms was demonstrated to be more likely in the presence of affective dysregulation in a dose dependent manner. Psychosis-related impairment was more likely within the context of affective dysregulation. Chapter 3 showed that the rate of psychotic symptom improvement was negatively affected by less severe mania symptoms. In Chapter 4 , the presence of psychotic symptoms characterized a subgroup of patients with relatively poor outcome, with higher overall illness and mania symptom severity, 
less improvement on overall symptom severity over time and worse social circumstances. In addition to the finding that cannabis exposure was associated with more severe psychotic symptoms (Chapter 5), the incidence of tardive movement disorders was higher in patients with more severe psychotic symptoms (Chapter 6). In general, our findings confirmed a considerable impact of psychotic symptoms on the course of bipolar illness, as well as a significant interaction with affective dysregulation in a premorbid phase.

\section{Current literature: Psychotic symptoms and dopamine}

In contrast to bipolar disorder, an impressive amount of research has focused on dopamine and psychotic symptoms within the context of schizophrenia. Much neuroimaging research within this population targeted striatal dopamine mechanisms. Although individual findings on striatal D2 receptor density were not consistent, a meta-analysis by Laruelle ${ }^{9}$ concluded with a modest elevation in striatal D2 receptor density for drug-naïve or drug free patients with schizophrenia compared to healthy controls. This association was replicated within a population of bipolar patients with and without psychotic symptoms compared to healthy controls, where an elevated level of D2 receptors was demonstrated to be associated with the presence of psychotic symptoms rather than mood abnormality ${ }^{10}$. 6 Out of 8 studies on striatal synaptic availability and release of dopamine, employing amphetamine challenge designs, demonstrated an increase in dopamine release in subjects with schizophrenia ${ }^{9,11,12}$. This increase was found to be related to the severity of amphetamine-induced psychotic symptoms ${ }^{11,12}$. The two studies with contrasting results were conducted in chronically ill patients without current psychotic symptoms, in contrast to the positive studies that investigated patients who were currently in the acute psychotic phase of the illness ${ }^{11}$.

To examine whether dopamine abnormalities precede the onset of the illness or is secondary to its development, Howes and colleagues ${ }^{12}$ conducted a PET experiment in 24 subjects with prodromal symptoms, 7 patients with schizophrenia and 12 matched healthy controls. Striatal dopamine uptake was found to be elevated in prodromal subjects (effect size 0.75) and patients with schizophrenia (effect size 1.25), compared to healthy controls. This elevation was correlated with the severity of prodromal psychopathological and neuropsychological impairment ${ }^{12}$. Additionally, D2 receptor levels were found to be increased in non-ill first degree relatives of schizophrenia patients ${ }^{13}$. These 
findings not only suggest a role for elevated dopamine activity in psychotic symptoms, but also in increased vulnerability to develop psychosis.

Other direct explorations of dopamine dysfunction in schizophrenia concern postmortem studies, often revealing an increase in striatal D2 receptor density. However, results may have been confounded by the frequent exposure of subjects to antipsychotic treatments, which may influence receptor density themselves ${ }^{11,14}$. Assessment of HVA levels in cerebrospinal fluid (CSF), a more circuitous measurement of dopamine activity, gives an indication of dopamine turnover in the brain. The majority of these studies comparing schizophrenia patients with control subjects (either healthy subjects or subjects with a different psychiatric illness) did not find any difference ${ }^{15}$. However, instead of high HVA levels being a trait marker for schizophrenia, it appears to be related to a psychotic state in general; the severity of psychotic symptoms are associated with HVA levels, and a decrease in plasma HVA induced by neuroleptics was found to be associated with the degree of symptom improvement ${ }^{15}$. This finding is substantiated by early research on HVA levels in subjects with non-schizophrenic psychotic disorders ${ }^{15}$.

Circumstantial evidence for the involvement of dopamine in psychotic symptoms comes from pharmacological studies. The psychosis-inducing effects of dopamine agonists (e.g., psychostimulants, L-DOPA) as well as efficacy of dopamine antagonists in treating these symptoms strongly suggest the existence of a dysregulation of dopamine transmission in psychosis ${ }^{11}$. Related to antipsychotic activity, the concept of 'supersensitivity psychosis' received considerable interest in the past decades, suggesting that rapid onset psychotic symptoms may be produced in some patients following discontinuation of chronic neuroleptic treatment blocking dopamine receptors ${ }^{16}$. These symptoms frequently resolve rapidly after reinstitution of treatment ${ }^{17}$. The antagonistic effect of neuroleptics is suggested to increase sensitivity of dopamine receptors in the mesolimbic tract ${ }^{16-18}$. This phenomenon is also demonstrated in patients with bipolar disorder ${ }^{19}$.

An important methodological issue in research on the existence of 'supersensitivity psychosis' is the difficulty to distinguish this concept from relapses as part of the natural course of the illness. Some findings, although not entirely consistent, plead in favor of the supersensitivity psychosis concept: i) an increase in relapse is demonstrated in the first few months after discontinuation of treatment (if the natural course of the illness is revealed by treatment, relapse 
rates would be constant); ii) relapse rates are reduced when discontinuation is gradual instead of abrupt ${ }^{17}$. However, consensus is currently lacking on the existence as well as the underlying mechanism of supersensitivity psychosis ${ }^{17}$.

Overall, there is reasonable evidence in favor of an association between dopamine dysfunction and psychotic symptoms in general. Specifically, striatal dopamine dysfunction appears not to be related to schizophrenia per se, but to psychotic symptoms in a broader context of various psychiatric illnesses ${ }^{11,15}$; higher striatal D2 receptor density was demonstrated, as well as higher HVA levels and more dopamine release after amphetamine challenge. Therefore, even though most research focused on schizophrenia populations, the symptom-based instead of diagnosis-based association partly overcomes the gap in bipolar research on this topic.

\section{Findings on depression symptoms}

Depression was included as moderator or as outcome measure in most analyses. Chapter 2 focused on affective symptoms, indicating that affective dysregulation in general and depression symptoms in particular were associated with the occurrence and persistence of psychotic symptoms, as well as psychosis-related impairment. These findings indicate a substantial role for depression symptoms in experiencing reality distortion in a subclinical context.

With regards to results from the EMBLEM study, reported in chapters 3 through 6, findings on depressive symptoms within this context need to be carefully interpreted, as a selection bias may have distorted these results; patients were eligible for participation in this study when they initiated or changed medication for treatment of manic or mixed episodes, thus excluding patients with a pure depressive episode at baseline. This strengthens our findings on an endophenotype characterized by the presence of mania symptoms, but at the same time introduces bias on findings related to depression symptoms, although most probably by dilution of effects.

Chapter 3 showed that the severity of depressive symptoms at baseline slows down improvement of both mania and psychotic symptoms, but not the other way around. With regards to the Classes analyses, findings on depression symptoms were limited to the Typical Mania class demonstrating higher levels of depression after 3 months of treatment (Chapter 4). The lack of an association between cannabis exposure and the severity of depression (Chapter 5) could be caused by the biased patient sample as described above, as similar research 
without this bias did find an association ${ }^{20}$. Finally, a higher severity of depressive symptoms was associated with a higher chance on developing tardive movement disorders (Chapter 6). Overall, our findings with regards to depression symptoms within the EMBLEM (Chapters 3-6) were limited and need to be interpreted carefully, whereas the EDSP analyses (Chapter 2) indicated an important role for depressive symptoms within a subclinical context.

\section{Current literature: Depression symptoms and dopamine}

The mesolimbic dopamine tract is hypothesized to be involved in depression symptoms $^{21-23}$ (Figure 1), although in contrast to mania and psychotic symptoms, depression symptoms may be associated with decreased dopamine transmission within this tract ${ }^{1,24}$. Despite frequent co-occurrence of these symptoms, this theory is not intrinsically contradictive per se; one plausible explanation may be the involvement of different receptor classes or sub-regions in the different symptom clusters $^{22}$.

The current monoamine theory of depression has been extended from comprising only serotonin $(5 \mathrm{HT})$ and noradrenalin (NA) to a trimonoaminergic neurotransmitter system malfunction, including dopamine ${ }^{2}$. Dopamine is widely accepted as a key neurotransmitter in pleasurable experiences, reward and motivated behavior ${ }^{25}$, which are functions that are implicated in depression. However, as most depression research focused on the role of $5 \mathrm{HT}$ and $\mathrm{NE}$ systems, the role of dopaminergic pathways within this context is only partly understood.

A minority of studies in patients with major depressive disorder employed direct measurements of dopamine function, yielding inconsistent results. Postmortem findings on D2 receptor density remain inconclusive due to, at least in part, variability in age of subjects and exposure to psychotropic medications $^{22}$. Neuroimaging studies were hampered by large variations in medication status of patients as well as variability in levels of anxiety which has been associated with reduced D2 receptor expression ${ }^{22}$. Elevated striatal D2 binding levels were demonstrated in depressed patients, indicating either increased numbers of D2 receptors or a decrease in the availability of synaptic dopamine. These findings were not confirmed in subsequent research, although the control groups were disputable. Conflicting results were additionally reported for studies on D2 binding before and after antidepressant treatment and dopamine transporter density in striatal regions or the basal ganglia ${ }^{22,23}$. Although 
employing a more indirect measurement, most studies examining the concentration of dopamine metabolites in cerebrospinal fluid (primarily HVA) found lower concentrations in depressed patients compared with healthy controls $^{23,26}$, in contrast to a few studies that were not able to demonstrate this difference ${ }^{22}$.

An indirect source of evidence concerns working mechanisms of antidepressants; although some antidepressants affect dopamine transmission directly ${ }^{1,22,23,27}$, most antidepressants work on the brain's 5 HT and NA systems. $5 \mathrm{HT}$ and (to a lesser extent) NA are known to regulate mesolimbic dopamine activity $^{1,27,28}$, for instance, by increasing dopamine $\mathrm{D}_{2} / \mathrm{D}_{3}$ binding activity in the nucleus accumbens ${ }^{23}$, interacting with dopamine systems in the ventral tegmental $\mathrm{area}^{22}$ or by stimulating dopamine release in the prefrontal cortex and nucleus accumbens $^{22}$. In addition, some antipsychotics showed mood stabilizing effects in bipolar patients, including an effect on depressive symptoms. This effect was probably exerted through blockage of $5 \mathrm{HT} 2 \mathrm{~A}$ presynaptic receptors, thereby elevating the inhibition of $5 \mathrm{HT}$ on dopamine release ${ }^{28}$ presumably in the mesocortical pathway ${ }^{22}$. Unfortunately, the complicated interactions between dopamine and $5 \mathrm{HT}$ (the latter consisting of at least 14 receptor subtypes) have not yet yielded straightforward results on the exact underlying principle.

Further evidence from antidepressant actions is the lack of achieving remission in large proportions of depressive patients, which might result from a failure of increased $5 \mathrm{HT}$ or NE neurotransmission to induce similar alterations in dopamine signaling. This is supported by findings that SSRI responders in contrast to non-responders exhibit increased dopamine binding to striatal D2 receptors. In addition, the demonstrated correlation between the degree of increase in binding and improvement of depressive symptoms further supports this suggestion ${ }^{22}$. The clinical observation that antidepressant medication generally requires several weeks to exert clinical effects, despite the fact that the medications affect $5 \mathrm{HT}$ and NE neurotransmission almost immediately, suggests the involvement of other, downstream mechanisms ${ }^{23}$.

In conclusion, there is some evidence that dopamine is involved in depressive symptomatology. The exact characteristics of dopamine dysfunction related to depression symptoms (e.g., impaired dopamine release, receptor subsensitivity and density) are still a matter of debate ${ }^{1}$. Additionally, most research on the involvement of dopamine in depression includes patients with major depressive disorder. The mechanisms underlying depression within the 
context of bipolar disorder may be somewhat different due to the complex nature of the illness, and needs further exploration.

\section{Findings on cannabis exposure and other substance use}

Substance abuse in general is a serious concern within the context of psychiatry, especially in bipolar disorder, where high rates of use have been reported. The limited data on the effect of cannabis use in particular inspired us to dedicate one chapter within this thesis to this specific substance of abuse. We found that exposure to cannabis, regardless of the level of dependency and the duration of use, was associated with worse treatment outcome and social circumstances over a period of 1 year, independent of the effects of alcohol and other substances of abuse (Chapter 5). Additionally, in line with previous reports ${ }^{29}$ cannabis exposure was associated with more use of alcohol and other substances of abuse. In Chapter 3, substance abuse in general was not regarded as a moderating factor in outcome on mania symptoms, plausibly caused by the short follow-up period of 3 months. In contrast, substance use was an important defining factor in the Latent Classes analysis (Chapter 4), with the resulting Dual Mania class demonstrating a significantly worse treatment outcome on various factors. In general, our findings warrant caution regarding the use of substances, in particular cannabis.

\section{Current literature: Cannabis, other substance use and dopamine}

Drugs of abuse share the ability to increase dopamine neurotransmission in certain regions in the brain ${ }^{25,30,31}$. Cannabis is believed to exert its effects on dopamine indirectly. This notion is partly based on the observation that the active component of cannabis, $\Delta^{9}$ THC, is linked to an increase in extracellular dopamine in the nucleus accumbens; this effect is plausibly exerted through i) an indirect excitatory action on the dopamine neurons in the ventral tegmental area, which is the main ascending dopaminergic projection to the nucleus accumbens ${ }^{30}$ or ii) inhibition of GABA activity that normally inhibits mesocortical dopamine neurons ${ }^{32}$. Indeed, these structures are important anatomical substrates for reward in general (e.g., drugs, sex, social interaction ${ }^{25}$ ). In contrast to cannabis, other psychostimulant drugs (e.g., amphetamines) are believed to exert a direct dopamine increasing effect within these structures ${ }^{33}$, and a similar increase in the amygdala and prefrontal cortex ${ }^{34}$. As these structures are components of the mesocortical and mesolimbic dopamine tracts (Figure 1), an interaction may be expected between clinical symptoms associated with dopamine dysfunction 
(mania, depression and psychosis) within these tracts and exposure to psychostimulants as well as cannabis.

From diverging research lines, ranging from epidemiological to neurochemical approaches, use of cannabis and psychostimulants has been repeatedly linked to psychotic symptoms and syndromes, mainly schizophrenia. For instance, moderate exposure to cannabis is associated with an increased risk to develop schizophrenia in certain genotypes ${ }^{35,36}$. In addition, administration of cannabis and psychostimulants can exacerbate positive symptoms in patients with schizophrenia ${ }^{33,37}$ and produce transient psychosis-like symptoms in healthy individuals ${ }^{33,37}$ or even give rise to a temporary drug-induced psychosis sufficiently serious to lead to hospitalization on suspicion of schizophrenia ${ }^{33,38}$. Little research connecting cannabis and dopamine has been conducted specifically within the field of bipolar disorder.

\section{Findings on movement disorders}

One specific chapter was devoted to tardive movement disorders within the context of bipolar disorder (Chapter 6), a topic that received little attention in current literature. The mean incidence rate for tardive movement disorders (combination of tardive dystonia and tardive dyskinesia; TDD) was high at $4.1 \%$ over a period of 2 years. An interesting pattern arose from our analyses: the occurrence of TDD was independently associated with the occurrence of various proximity measures for dopamine anomalies within the brain, such as more severe bipolar symptoms, other extrapyramidal symptoms and prolactin-related adverse effects. Similar findings were reported for a patient population diagnosed with schizophrenia, demonstrating associations between tardive movement disorders on the one hand and more severe psychotic symptoms ${ }^{39,40}$ and sexual dysfunction $^{41}$ on the other. Due to the epidemiological character of our research, our findings provide circumstantial support for the notion of generalized dopamine dysregulation in bipolar disorder, which will be discussed more extensively in the next section.

\section{Current literature: Movement disorders and dopamine}

Movement disorders are generally regarded as a side effect of antipsychotic treatment and, in contrast to schizophrenia, are rarely investigated within bipolar disorder populations. The dominant hypothesis on the underlying mechanism of movement disorders, the 'dopamine hypersensitivity theory', involves 
dysfunctional dopamine transmission in the nigrostriatal tract ${ }^{2,42}$. The receptor system within this tract is assumed to develop increased sensitivity to dopamine as a consequence of chronic dopamine receptor blockade induced by neuroleptics ${ }^{42}$. Generally, it is assumed that movement disorders, and tardive dyskinesia (TD) in particular, are associated with low dopamine transmission in the nigrostriatal dopamine tract. This notion is underlined by the relatively high TD incidence rates associated with antipsychotics that function as strong dopamine antagonists ${ }^{2}$. Although extensive research does not provide consistent evidence for a primary causal role for dopamine in movement disorders, specifically $\mathrm{TD}$, at least a secondary or modulatory role is convincingly demonstrated. Thus far, no direct evidence of any specific pathophysiological process has been identified ${ }^{42}$.

In contrast to the general consensus, recent studies suggest that movement disorders may not simply and solely be a consequence of dopamine dysfunction triggered by medication use. Although antipsychotics are the most frequent cause of drug-induced movement disorders, a recent meta-analysis revealed that movement disorders not only emerge in treatment naïve patients with schizophrenia, but they are also more frequent in first-degree non-ill relatives. Thus, next to the well-known associations with antipsychotics, movement disorders are found to be associated to a certain degree with the illness itself, and additionally may also be related to a certain (genetic) risk of developing the disease ${ }^{43}$.

\section{Towards a broader model of dopamine dysfunction?}

Recently, a Dopamine Dysfunction model for bipolar disorder was postulated by Berk and co-workers ${ }^{1}$, based on a review which comprised data from very diverge domains, including preclinical, genetic, neuroimaging, pharmacological and clinical research. The model proposes that bipolar disorder is associated with a cyclical dysregulation in quantitative dopamine transmission. The manic phase is suggested to be associated with an increase in dopamine transmission. Secondary down regulation of certain key elements and pre- as well as post-synaptic receptors may subsequently decrease dopamine transmission, dampening the cycle. A substantial reduction in dopamine transmission is hypothesized to characterize the depressive phase, which may be alleviated by secondary upregulation of the same key elements. Up and down regulation is suggested to be mediated by endogenous homeostatic mechanisms. Individual vulnerabilities 
exist to the hyper- and hypodopaminergic state, explaining the large interindividual variability in illness course ${ }^{1}$.

The current model mainly covers abnormalities within the mesolimbic dopamine tract in the brain, by focusing on mania and depression symptoms. Due to a gap in scientific research to date, most research substantiating the model relied on indirect measurements of dopamine function in the context of bipolar disorder. By employing epidemiological research methods, our results are also limited to providing indications of dysfunction, suggesting that dopamine dysfunction might be more widespread than suggested by the Dopamine Dysfunction model by Berk and colleagues ${ }^{1}$.

In the past decades, technological advances have enabled scientists to explore and map biological bases of normal and abnormal psychology, from cognitive processes to the role of the human genome. With our proposal for an extension to the existent biological model, we certainly do not intent to disregard the importance of factors outside the scope of neuroscience. In agreement with Bullmore and colleagues ${ }^{44}$, we aspire to contribute to the understanding of neurobiological mechanisms underlying the onset and course of bipolar disorder, as to help physicians explain to their patients why they have become ill, reliably predict their expected outcome and treat them according to a personalized rationale $^{44}$. In our opinion, it is the complex combination of neurobiological, emotional, cognitive and environmental factors that provide the complete picture of the cause and course of the illness for individual patients. Therefore, although evidence is often circumstantial and occasionally originating from adjoining disease states, we developed an extension to the existent biological model as to guide future research taking into account biological as well as non-biological factors.

\section{New evidence for dopamine dysfunction in bipolar disorder?}

As hypotheses about alterations in dopamine function in severe mental illness are difficult to examine directly, it has been suggested that these abnormalities may be explored using clinical assessments that serve as proximity measures (i.e., indirect measures) for dopamine neurotransmission in different dopamine tracts $^{22,40,41}$. This way, evidence from epidemiological studies may provide leads for further development of scientific models. 


\section{Extending the dopamine model: psychotic symptoms}

The limited consensus on the exact mechanism of dopamine dysfunction in relation to the core symptom clusters of bipolar disorder (i.e., mania, depression and psychosis) hampers the development of a clear multifactorial model. However, based on our findings as well as direct and indirect evidence from divergent research lines concerning bipolar and adjacent populations of psychiatric patients, our attempt is presented in Figure 2. In this model, the original proposal by Berk and colleagues ${ }^{1}$ is indicated by the shaded background. Available evidence on the association between dopamine dysregulation and psychotic symptoms, including higher striatal D2 receptor density ${ }^{9}$, more dopamine release after amphetamine challenge ${ }^{11,12}$ and higher HVA levels ${ }^{15}$, led to the modest extension in the right column. Through this addition, the extended dopamine model now includes the 3 core symptom clusters of the disease (Figure 2).

\section{Extending the dopamine model: co-occurrence of symptoms and syndromes}

Next to adding a core symptom into the model, we would like to propose that a more generalized dopamine dysfunction is present in certain bipolar patients, that is, a disturbance in dopamine activity in multiple dopamine tracts. Particularly our results reported in Chapter 6 provided interesting hints for such a hypothesis. With tardive movement disorders (TDD, assumed to represent the nigrostriatal dopamine tract) as a starting point, a strong association was demonstrated with high bipolar disorder symptom severity scores (assumed to represent abnormalities in the mesolimbic dopamine tract) as well as the presence of sexual dysfunction and amenorrhea (assumed to represent abnormalities in the tuberoinfundibular dopamine tract). The use of proxy measures limits the interpretation of our findings, but it gives an interesting starting point for theories on generalized dopamine dysfunction in bipolar disorder.

Measures of sexual dysfunction and amenorrhea are suggested to be associated with relatively low dopamine transmission in the tuberoinfundibular $\operatorname{tract}^{2,45}$. Dopamine functions as a brake on prolactin release within this dopamine tract, therefore, low dopamine transmission can result in increased prolactin levels, potentially translating into problematic sexual functioning ${ }^{2}$. However, although there is reason to assume that sexual dysfunction and amenorrhea are prolactin 
Figure 2. Extension of Berk's model for core bipolar symptoms

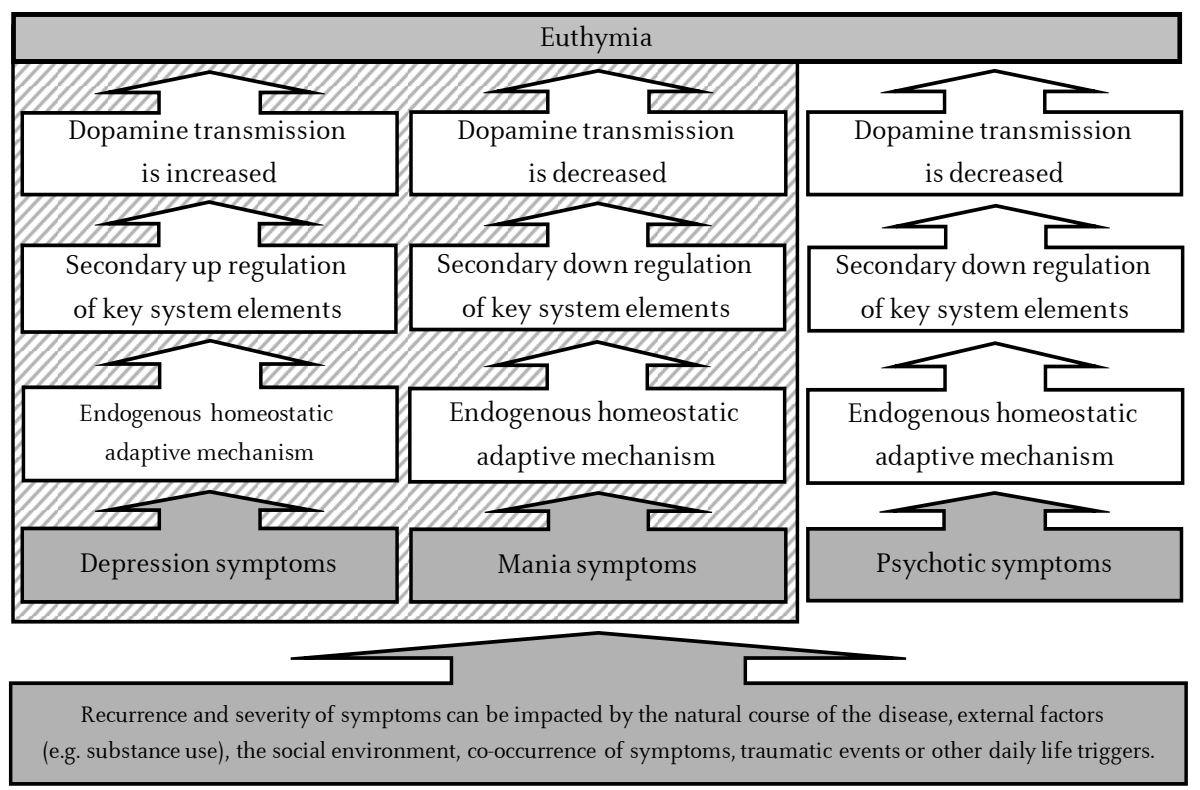

related to at least some degree, many relevant factors apart from prolactin may impact on these variables. For instance, antipsychotic-induced effects (e.g., histaminergic, noradrenergic and anticholinergic) potentially influence sexual behavior, next to potential effects of concomitant medication ${ }^{45}$. Clinical evidence pleading in favor of at least a certain degree of dopamine involvement includes: i) higher prolactin levels in patients reporting sexual dysfunction; ii) the fact that treatment-emergent sexual adverse events have been reported during treatment with antipsychotics known to elevate prolactin levels relatively specifically ${ }^{41}$.

In previous sections, the potential involvement of dopamine in mania, depression and psychotic symptoms as well as movement disorders has been described. Together with sexual dysfunction and amenorrhea, these symptoms and syndromes are suggested to represent anomalies in at least three different dopamine tracts; the mesolimbic, nigrostriatal and tuberoinfundibular tracts. Our finding of co-occurrence of these symptoms and syndromes led us to speculate on a generalized dopamine dysfunctional state associated with bipolar disorder. This is in line with a similar theory in the schizophrenia realm, where several research groups recently reported on associations between abnormalities in proximity measures of multiple dopamine tracts; more severe psychotic symptoms were found to be associated with movement disorders ${ }^{39,40}$ and sexual dysfunction ${ }^{41}$. 
Extending the dopamine model: The role of external factors

Our findings on associations between external factors and worse disease course and outcome may serve as indirect evidence for the involvement of dopamine in bipolar disorder. We hypothesize that factors such as substance use and social adversity exert their influence to a certain extent through an effect on dopamine activity associated with the symptom clusters, mainly in the mesolimbic tract. This hypothesis is based on the following aspects: i) the (varying weight of) evidence in current literature for the involvement of dopamine in individual bipolar disorder symptom clusters ${ }^{1,3,4,9,11,12,15,22,23}$ combined with ii) our own findings on the negative effect of co-occurrence of bipolar symptoms on disease course and symptom severity (Chapters 2, 3 and 6) confirming findings reported in current literature (e.g., ${ }^{46,47}$ ); and iii) current literature reporting elevated dopamine activity following substance use (e.g., ${ }^{25,30,31}$ ) combined with iv) our own findings related to the negative impact of substance use on disease course and symptom severity (Chapters 4 and 5) confirming findings reported in current literature (e.g., ${ }^{48,49}$ ).

Although very interesting, associations between higher illness severity and worse social circumstances from our research are important to reflect on within the context of a dopamine model. Speculations on interactions between dopamine dysregulation and social adversity are difficult to substantiate with our own findings, but form a methodological and ethically complicated challenge for future research.

\section{Concluding remarks and suggestions for further research}

Berk and colleagues ${ }^{1}$ recently lay an inspiring basis with their proposed model on dopamine dysfunction within a bipolar patient population. Even though our evidence is circumstantial, and epidemiological research investigates mere associations, results from our research are compatible with a notion of broad dysfunction in the dopamine system. In our opinion, our findings provided modest hints that give rise to new hypotheses. The concept of interrelated deviations in multiple dopamine tracts has previously been reported for a patient population with schizophrenia ${ }^{39-41}$, and it constitutes an interesting line of approach for research in bipolar disorder as well.

Besides the methodological issues that restrict the conclusions that can be drawn from our findings, some remarks need to be taken into account when evaluating the model and the proposed extension. Obviously, the model is highly 
abstract, as the various brain areas discussed cannot be thought of as distinct, since they function as a highly overlapping and interacting circuit ${ }^{25}$. Also, dopamine transmission is certainly not the sole underlying factor for neural dysfunction in bipolar disorder, and it is plausible that the primary abnormality does not lie within the dopamine trajectory, but upstream in other structures and systems ${ }^{1}$. For instance, research suggests that anomalies in the dopamine system of patients with psychotic disorder is a consequence of primary prefrontal cortex dysfunction, and dopamine dysregulation is mainly regarded as a final common pathway to psychosis ${ }^{50,51}$. This possibility is underlined by multiple findings reported in current literature, such as the fact that $\Delta^{9} \mathrm{TCH}$ and other cannabinoids exert effects on the release of various neurotransmitters apart from dopamine (e.g., L-glutamate, GABA, noradrenaline, $5 \mathrm{HT}$ and acetylcholine ${ }^{38}$ ), as well as the fact that a substantial proportion of patients with schizophrenia are treatment resistant to dopamine blocking neuroleptics ${ }^{52}$. Also, the influence of glutamate dysregulation is not yet clear, but a substantial role of this neurotransmitter has been suggested, in interaction with dopamine dysfunction ${ }^{52}$.

Reviewing our results and the proposed extensions to the dopamine model yielded many hypotheses, due to the limited research conducted in this field and the early stage of the proposed model. As repeatedly stated, our epidemiological designs were not appropriate for making a substantiated contribution to the development of a disease model, so suggestions for further research could be extensive. However, we would like to restrict our suggestions to two relevant but challenging ideas.

First, neuroimaging studies could shed light on the type and extend of any dopamine dysfunction in patients with bipolar disorder. The limited brain imaging research that is available from bipolar patient populations usually involves small samples sizes and needs replication ${ }^{1}$. One interesting design would be to investigate patients with bipolar disorder, their unaffected monozygotic and dizygotic twins and healthy monozygotic and dizygotic twins without any psychiatric history serving as control group. Using PET imaging, subjects should perform neuropsychological tests that are representative of frontal lobe functioning. Among multiple measures of interest are the dopamine synaptic availability and dopamine binding activity. By including unaffected twins and a healthy control group, one could additionally gain insight into genetic risk. In case abnormalities are found for patients with bipolar disorder, it would be valuable to 
study whether these abnormalities vary with fluctuations in symptom presence during the course of their illness.

Second, salience attribution is a new and promising line of approach in research of various psychiatric illnesses. In Chapter 2 we suggested that affective dysregulation within a general population cohort may contribute causally to the persistence and clinical relevance of psychotic symptoms, potentially by facilitating a mechanism of aberrant salience attribution. Unfortunately, no direct measures of neurological and cognitive processes were included in this study. The second suggestion for further research would therefore involve the interplay between the three core symptoms of bipolar disorder (mania, depression and psychosis) and cognition on both neuronal and behavioral level.

The elegant study design employed by Murray and colleagues ${ }^{53}$ should $^{2}$ serve as a model; they demonstrated an abnormal physiological response in the midbrain and striatum, measured through fMRI, associated with increased difficulty to discriminate between motivationally salient and neutral stimuli in first episode psychotic patients compared to healthy controls ${ }^{53}$. This way, a disturbance in salience attribution was linked to disturbed activity in brain structures that are essential in learning stimulus-outcome associations. Although the involvement of dopamine was speculated upon ${ }^{53}$, as salience attribution is suggested to be mediated by dopamine activity ${ }^{54}$, no direct measurement of dopamine activity was included in this design.

Future research should employ a similar reward conditioning experiment, combining both fMRI measurement and PET imaging to additionally gain insight into dopamine activity in midbrain and striatum regions associated with psychotic symptoms. Of special interest would be the effect of co-occurring affective dysregulation on these behavioral and physiological abnormalities as well as dopamine activity. An important assumption in this design would be that the effects of psychotic symptoms on dopamine level are roughly similar regardless of the clinical diagnosis of a patient, as the origin of these specific symptoms are likely to have followed the same developmental path of symptom formation. Therefore, the ideal sample under investigation should be: i) patients with non-affective psychotic disorder; ii) bipolar patients with current mania symptoms in the absence of psychotic symptoms; iii) bipolar patients with cooccurring (current) mania and psychotic symptoms and iv) a matched healthy control group. This research design could potentially answer multiple research questions such as: i) is the association between behavioral and physiological 


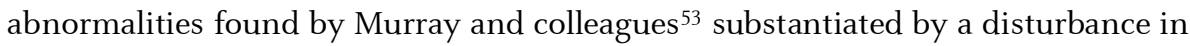
dopamine activity in the specified brain regions?; ii) is this finding specific for first episode psychotic patients, or generally linked to psychosis regardless of the clinical diagnosis?; iii) does co-occurring affective dysregulation influence the disturbance on behavioral, physiological and neurotransmitter level?; iv) as an association was found between the severity of mania symptoms and emotional salience attribution ${ }^{55}$, are these patients similarly affected on a behavioral, physiological and neurotransmitter level in the absence of psychotic symptoms?

In conclusion, we investigated the nature of co-existent clinical and subclinical symptoms, illness characteristics and factors influencing the short-term and longterm course of bipolar illness. With the results presented in this thesis as well as the proposed model and suggestions for further research, we are confident that a useful contribution to scientific research in the field of bipolar disorder is made. 


\section{References}

1. Berk M, Dodd S, Kauer-Sant'anna M (2007). Dopamine dysregulation syndrome: implications for a dopamine hypothesis of bipolar disorder. Acta Psychiatr Scand, 434(suppl):41-9

2. Stahl SM: Stahl's essential psychopharmacology. Cambridge: Cambridge University Press; 2008.

3. Yatham LN, Liddle PF, Lam RW, Shiah I-S, Lane C, Stoessl J, Sossi V, Ruth TJ (2002). PET study of the effects of valproate on dopamine D2 receptors in neuroleptic- and mood stabilizer naïve patients with nonpsychotic mania. Am J Psychiatry, 159:1718-23 Yatham LN, Liddle PF, Shiah I-S, Lam RW, Ngan E, Scarrow G, Imperial M, Stoessl J, Sossi $\mathrm{V}$, Ruth TJ (2002). PET study of $\left[{ }^{18} \mathrm{~F}\right] 6$-Fluoro-L-Dopa uptake in neuroleptic- and mood stabilizer naïve first episode nonpsychotic mania: effects of treatment with divalproex sodium. Am J Psychiatry, 159:768-74

Anand A, Verhoeff P, Seneca N, Zoghbi SS, Seibyl JP, Charney DS, Innis RB (2000). Brain SPECT imaging of amphetamine-induced dopamine release in euthymic bipolar disorder patients. Am J Psychiatry, 157(7):1108-14

Scarna A, Gijsman HJ, McTavish SFB, Harmer CJ, Cowen PJ, Goodwin GM (2003). Effects of a branched-chain amino acid drink in mania. Br J Psychiatry, 182:2 10-3

McTavish SFB, McPherson MH, Harmer CJ, Clark L, Sharp T, GM Goodwin, Cowen PJ (2001). Antidopaminergic effects of dietary tyrosine depletion in healthy subjects and patients with manic illness. Br J Psychiatry, 179:356-60

Joyce PR, Fergusson DM, Woollard G, Abbott RM, Horwood LJ, Upton J (1995). Urinary catecholamines and plasma hormones predict mood state in rapid cycling bipolar affective disorder. J Affect Disorders, 33:233-43

Laruelle M (1998). Imaging dopamine transmission in schizophrenia. A review and metaanalysis. Q J Nucl Med, 42(3):211-21

Pearlson GD, Wong DF, Tune LE, Ross CA, Chase GA, Links JM, Dannals RF, Wilson AA, Ravert HT, Wagner HN (1995). In vivo D2 dopamine receptor density in psychotic and nonpsychotic patients with bipolar disorder. Arch Gen Psych, 52(6):471-7

1. Howes OD, Montgomery AJ, Asselin M-C, Murray RM, Grasby P, McGuire P (2007). Molecular imaging studies of the striatal dopaminergic system in psychosis and predictions for the prodromal phase of psychosis. Br J Psychiatry, 51(suppl):s13-8

Howes OD, Montgomery AJ, Asselin M-C, Murray RM, Valli I, Tabraham P, Bramon-Bosch E, Valmaggia L, Johns L, Broome M, McGuire P, Grasby P (2009). Elevated striatal dopamine function linked to prodromal signs of schizophrenia. Arch Gen Psychiatry, 66(1):13-20

3. Hirvonen J, van Erp TG, Huttunen J, Aalto S, Nagren K, Huttunen M, Lonnqvist J, Kaprio J, Hietala J, Cannon TD (2005). Increased caudate dopamine D2 receptor availability as a genetic marker for schizophrenia. Arch Gen Psychiatry, 62:371-8

Seeman P, Kapur S (2000). Schizophrenia: more dopamine, more D2 receptors. PNAS, 97(14):7673-5

5. Maas JW, Bowden CL, Miller AL, Javors MA, Funderburg LG, Berman N, Weintraub ST (1997). Schizophrenia, psychosis, and cerebral spinal fluid homovanillic acid concentrations. Schiz Bull, 23(1):147-54

6. Chouinard G, Annable L, Ross-Chouinard A (1986). Supersensitivity psychosis and tardive dyskinesia: a survey in schizophrenic outpatients. Psychopharmacol Bull, 22(3):891-6 
17. Moncrieff J (2006). Does antipsychotic withdrawal provoke psychosis? Review of the literature on rapid onset psychosis (supersensitivity psychosis) and withdrawal-related relapse. Acta Psychiatr Scand, 114:3-13

18. Kirkpatrick B, Alphs L, Buchanan RW (1992). The concept of supersensitivity psychosis. J Nerv Ment Dis, 180(4):265-70

19. Steiner W, Laporta M, Chouinard G (1990). Neuroleptic-induced supersensitivity psychosis in patients with bipolar affective disorder. Acta Psychiatr Scand, 81(5):437-40 Strakowski SM, DelBello MP, Fleck DE, Adler CM, Anthenelli RM, Keck PE, Arnold LM, Amicome J (2007). Effects of co-occuring cannabis use disorders on the course of bipolar disorder after a first hospitalization for mania. Arch Gen Psychiatry, 64:57-64

21. Cabib S, Puglisi-Allegra S (1996). Stress, depression and the mesolimbic dopamine system. Psychopharmacology, 128:331-42

22. Dunlop BW, Nemeroff CB (2007). The role of dopamine in the pathophysiology of depression. Arch Gen Psychiatry, 64:327-37

23. Gershon AA, Vishne T, Grunhaus L (2007). Dopamine D2-like receptors and the antidepressant response. Biol Psychiatry 2007, 61:145-53

24. Kapur S, Mann JJ (1992). Role of the dopaminergic system in depression. Biol Psychiatry, 32:1-17

25. Nestler EJ, Carlezon WA (2006). The mesolimbic dopamine reward circuit in depression. Biol Psychiatry, 59:1151-9

26. Martin-Soelch C (2009). Is depression associated with dysfunction of the central reward system? Biochemical Society Transactions, 37(1):313-7

27. Adell A, Artigas F (2004). The somatodendritic release of dopamine in the ventral tegmental area and its regulation by afferent transmitter systems. Neurosci Biobehav Rev, 28:415-31

28. Yatham LN, Goldstein JM, Vieta E, Bowden CL, Grunze H, Post RM, Suppes T, Calabrese JR (2005). Atypical antipsychotics in bipolar depression: potential mechanisms of action. J Clin Psychiatry, 66(suppl 5):40-8

29. Fergusson DM, Boden JM, Horwood LJ (2006) Cannabis and other illicit drug use: testing the cannabis gateway hypothesis. Addiction, 101:556-69

30. Cheer JF, Wassum KM, Heien MLAV, Phillips PEM, Wightman M (2004). Cannabiniods enhance subsecond dopamine release in the nucleus accumbens of awake rats. J Neurosc, 24(18):4393-400

31. Voruganti LNP, Slomka P, Zabel P, Mattar A, Awad AG (2001). Cannabis induced dopamine release: an in-vivo SPECT study. Psychiatr Res, 107:173-7

32. Alex KD, Pehek EA (2007). Pharmacologic mechanisms of serotonergic regulation of dopamine neurotransmission. Pharmacol Ther, 113(2):296-320

33. Lieberman JA, Kinon BJ, Loebel AD (1990). Dopaminergic mechanisms in idiopathic and drug-induced psychosis. Schiz Bull, 16(1):97-110

34. Feltenstein MW, See RE (2008). The neurocircuitry of addiction: an overview. Br J Pharmacology, 154:261-74

35. Andreasson S, Allebeck P, Engstrom A, Rydberg U (1988). Cannabis and schizophrenia. Lancet I: 1000-1

36. Van Os J, Bak M, Hanssen M, Bijl RV, de Graaf R, Verdoux H (2002). Cannabis use and psychosis: a longitudinal population-based study. Am J Epidemiology, 156:319-29 

Gueorguieva R, Cooper TB, Krystal JH (2005). Delta-9-tetrahydrocannabinol effects in schizophrenia: implications for cognition, psychosis and addiction. Biol Psych, 57:594-608

38. Iversen L (2003). Cannabis and the brain. Brain, 126:1252-70

39. Mittal VA, Neumann C, Saczawa M, Walker EF (2008). Longitudinal progression of movement abnormalities in relation to psychotic symptoms in adolescents at high risk of schizophrenia. Arch Gen Psychiatry, 65(2):165-71

Tenback DE, van Harten PN, Slooff CJ, van Os J; SOHO Study Group (2007) Worsening of psychosis in schizophrenia is longitudinally associated with tardive dyskinesia in the European Schizophrenia Outpatients Health Outcomes study. Compr Psychiatry, 48:436-40 Tenback DE, van Harten PN, Slooff CJ, van Os J; SOHO Study Group (2006). Tardive dyskinesia in schizophrenia is associated with prolactin-related sexual disturbances. Neuropsychopharm, 31:1832-7

42. Casey DE (2000). Tardive dyskinesia: pathophysiology and animal models. J Clin Psychiatry, 61(suppl 4):5-9

43. Koning JPF, Tenback DE, Van Os J, Aleman A, Kahn RS, Van Harten PN (2008). Dyskinesia and parkinsonism in antipsychotic-naive patients with schizophrenia, first-degree relatives and healthy controls: a meta-analysis. Schizophr Bull, epub ahead of print, doi:10.1093/schbul/sbn146

44. Bullmore E, Fletcher P, Jones PB (2009). Why psychiatrists can't afford to be neurophobic. Br J Psychiatry, 194:293-5

45. Knegtering H, van der Moolen AE, Castelein S, Kluiter H, van den Bosch RJ (2003). What are the effects of antipsychotics on sexual dysfunctions and endocrine functioning? Psychoneuroendocrinology, 28:109-23

46. Calabrese JR, Woyshville MJ, Kimmel SE, Rapport DJ (1993). Predictors of valproate response in bipolar rapid cycling. J Clin Psychopharm, 13:280-3

47. Dilsaver SC, Swann AC, Shoaib AM, Bowers TC, Halle MT (1993). Depressive Mania Associated with Nonresponse to Antimanic Agents. Am J Psychiatry, 150:1548-51

48. Goldberg JF, Garno JL, Leon AC, Kocsis JH, Portera L (1999). A History of Substance Abuse Complicates Remission From Acute Mania in Bipolar Disorder. J Clin Psychiatry, 60:733-40

49. Cassidy F, Ahearn EP, Carroll BJ (2001). Substance abuse in bipolar disorder. Bipolar Disord, 3:181-8

50. Di Forti M, Lappin JM, Murray RM (2007). Risk factors for schizophrenia - all roads lead to dopamine. Eur Psychopharmacology, 17:S101-7

51. Selten JP, Cantor-Graae E (2007). Hypothesis: social defeat is a risk factor for schizophrenia? Br J Psychiatry, 191(suppl):s9-12

52. Stone JM, Morrison PD, Pilowsky LS (2007). Glutamate and dopamine dysregulation in schizophrenia - a synthesis and selective review. J Psychopharm, $21(4): 440-52$

53. Murray GK, Corlett PR, Clark L, Pessiglione M, Blackwell AD, Honey G, Jones PB, Bullmore ET, Robbins TW, Fletcher PC (2008). Substantia nigra/ventral tegmental reward prediction error disruption in psychosis. Mol Psychiatry, 13:267-76

54. Kapur S, Mizrahi R, Li M (2005). From dopamine to salience to psychosis - linking biology, pharmacology and phenomenology of psychosis. Schiz Res, 79:59-68

55. Tai S, Haddock G, Bentall R (2004). The effects of emotional salience on thought disorder in patients with bipolar affective disorder. Psychol Med, 34:803-9 
No

ก

甯 
$8 a$

Summary 
Bipolar disorder (BD), also known as manic depressive illness, is a chronic disease, associated with episodic extremes in mood, with a prevalence rate of about 1$1.5 \%$. The term BD covers a spectrum of disorders of diverging severity with a highly variable course. The most frequently studied subtype is BD type I, usually characterized by an alternation of manic and depressive episodes. Psychotic symptoms are frequently experienced by patients with $\mathrm{BD}$, usually during the manic phase. BD may have devastating effects on many aspects of the patient's life including but not limited to social and cognitive functioning, with high lifetime suicide rates. The course of the illness is influenced by a large range of internal and external factors, some of them related to the illness itself. Observational cohort studies are useful tools to provide valuable information on the effect of naturalistic variations in exposure to a large range of factors on the individual symptoms and the overall course of the illness.

The main objective of this thesis was to investigate the nature of BDrelated symptoms on two levels; i) on a subclinical level, we wished to investigate the effect of affective dysregulation on the presence, course and impact of reality distortion; ii) on a clinical level, we wished to investigate illness characteristics and factors influencing the short-term and long-term course of bipolar illness. To this end, data from two unique European observational studies were employed.

The European Mania in Bipolar Longitudinal Evaluation of Medication (EMBLEM) study, provides up to 2 years follow-up in 3549 patients with BD type I. Patients were included when initiating a new treatment for an acute manic or mixed episode, at the discretion of the investigator. Ths study design resulted in a heterogeneous sample of patients, treated in naturalistic settings, in which reallife outcome measures such as relapse, (re)hospitalization, social functioning and quality of life were studied. In contrast, the Early Developmental Stages of Psychopathology (EDSP) study was conducted within the general population. A representative population sample of adolescents and young adults (aged 14-24 years at baseline) living in the Munich area (Germany) was randomly drawn from population registers. Subjects were followed up to 10.6 years. Such an observational study may provide insight into the distribution of symptoms related to psychiatric disorders in the general population, as well as the mechanisms that either protect from or facilitate transition to clinical syndromes. 


\section{Our findings}

The unique EDSP dataset was employed in analyses described in Chapter 2, in which associations were investigated between levels of affective dysregulation (symptoms of depression and (hypo)mania) and incident psychotic experiences within the general population. We found that most psychotic experiences occurred in a context of affective dysregulation, and that persistence of psychotic experiences was progressively more likely to occur with greater level of (hypo)manic symptoms as well as depressive symptoms. Similarly, psychotic experiences of clinical relevance were progressively more likely to occur with greater level of affective dysregulation. The findings suggested that correlated genetic liabilities underlying affective and non-affective psychotic syndromes may be expressed as correlated dimensions in the general population. In addition, affective dysregulation may contribute causally to the persistence and clinical relevance of psychotic experiences, possibly by facilitating a mechanism of aberrant salience attribution.

The EMBLEM dataset was employed for the analyses described in Chapters 3 through 6. Chapter 3 investigates factors that may moderate the speed of symptom improvement in acute manic, psychotic and depressive symptoms. Although much research has been directed towards clinical and demographic predictors at baseline for treatment outcome after 3 months, these studies do not take into account the fact that symptom improvement takes place over time. Indeed, multiple variables derived from the social and psychopathological context were found to moderate the rate of response for manic symptoms, such as greater illness severity in the past year, lower age of onset, rapid cycling and social adversity. The rate of response of psychotic symptoms was moderated by mania and depression scores at baseline, whereas the rate of reduction in depression symptoms was not conditional on baseline psychopathology.

Chapter 4 describes analyses directed towards the stability over time of 3 distinct classes of mania, as well as their treatment outcomes. These classes were previously extracted from factor analysis; 'Typical Mania' (59\% of the sample), 'Psychotic Mania' (28\%) and 'Dual Mania' (13\%). A worrisome finding, as eligibility criteria applied in randomized controlled trials excludes patients from the Dual Mania class (referring to misuse of substances), which may create a gap in our knowledge on treatment effectiveness. We found that the 3 classes showed substantial stability in the 12 weeks post-baseline in the pattern of associations with class-characteristic variables, such as psychosis comorbidity, symptom 
severity measures, and alcohol as well as substance abuse. Worse social outcomes were observed for both Dual and Psychotic Mania. Thus, the identified distinct classes are stable and associated with differential treatment outcome. Overall, Dual and Psychotic Mania show less favorable outcomes compared to Typical Mania.

A deleterious effect of cannabis use on treatment outcome has been consistently demonstrated for patients with schizophrenia. Despite of the high rates of cannabis use in patients with $\mathrm{BD}$, we were one of the first research groups to focus on this topic. The analyses described in the fifth chapter focus on the influence of cannabis exposure on clinical and social treatment outcome measures over the course of 1 year, as well as the effects on these associations of third, mediating, variables. Cannabis users were found to be less compliant, with higher levels of overall illness severity, mania and psychosis compared to non-users. Additionally, cannabis users experienced less satisfaction with life and had a lower probability of having a relationship compared to non-users. There was little evidence that cannabis-outcome associations were mediated by third variables. Overall, an independent impact of cannabis use on psychopathological outcomes in patients with BP was apparent, whereas the impact on social outcomes was only modest.

Movement disorders, in particular tardive dyskinesia, have been extensively studied within the context of schizophrenia. Chapter 6 examines movement disorders within a bipolar population, another topic that has received little attention up till now, even though literature suggests that patients with bipolar illness may be more vulnerable for movement disorders compared to patients with schizophrenia. Next to the need to gain insight into prevalence and incidence rates of tardive movement disorders (i.e., tardive dyskinesia and tardive dystonia) within a bipolar population, this topic caught our attention due to its suggested association with dopamine activity. Recently, it has been suggested that dopamine dysfunction may play a role in BD. Therefore, we conducted an indirect examination of this issue, by focusing on associations between dopamine-related clinical traits such as bipolar symptoms and prolactin-related adverse effects, using tardive movement syndromes as dopamine proxy measure of reference. The incidence rate of tardive syndromes was $4.1 \%$ over a 2 year follow-up period. Incident TDD was independently associated with more severe bipolar symptoms, other extrapyramidal symptoms and prolactin-related adverse effects of 
medication. These findings indirectly support the notion of generalized dopamine dysregulation in BD.

\section{Our conclusions}

The broad definition of the general aim of this thesis resulted in diverge hypotheses and findings on topics that had not received much attention in current literature, providing new insights on course and outcome of bipolar symptoms on a subclinical as well as a clinical level. Findings are of practical relevance, as they i) identify potential ways to influence course and outcome of the illness, given that some factors impacting course and outcome could be influenced within the treatment setting (e.g. substance use, social circumstances) or ii) at least help create insight into the illness status of individual patients and consequently define realistic treatment expectations (e.g. effects of co-morbid complexities).

Aside from the findings from the individual analyses, an unforeseen higher-level pattern was noticed within the results; circumspect evidence on a potential role of dopamine in the onset and course of bipolar disorder accumulated during the course of this research. In Chapter 7 , next to providing an overview of our results, an attempt is made to interpret our findings within a recently postulated dopamine dysfunction model of bipolar disorder, which proposes that bipolar disorder is associated with a cyclical dysregulation in quantitative dopamine transmission ${ }^{1}$. Our research provided indirect hints towards a more widespread dopamine dysfunction within BD than was originally proposed by Berk and colleagues ${ }^{1}$. First, we propose an extension to the existent model with psychotic symptoms, probably through a similar mechanism on dopamine level as was proposed for mania symptoms. This extension was based on current literature on the association between psychotic symptoms and dopamine dysfunction.

Next, we hypothesize that BD would be associated with a more general dopamine dysfunction. This hypothesis was based on the associations we found between various proxy measures of dysfunctional dopamine activity; bipolar symptoms, movement disorders and sexual dysfunction. These factors are suggested to represent multiple dopamine tracts. Demonstrated associations between higher symptom severity and various external factors (i.e., cannabis use and social adversity) may provide an indirect confirmation of our hypotheses; it has been speculated that these external factors may affect dopamine activity 
within the same structures that were linked to bipolar symptoms. In conclusion, our finding of co-occurrence of various BD related symptoms and adverse effects led us to speculate on a generalized dopamine dysfunctional state. This is in line with a similar theory in schizophrenia research, where several reports recently demonstrated associations between abnormalities in proximity measures of multiple dopamine tracts ${ }^{2,3}$. However, our hypotheses on dopamine dysfunction in BD should be interpreted with caution; all findings in this thesis were indirect indicators and generated within the context of epidemiological research. Proposals for further research with suitable designs are described in Chapter 7.

\section{References}

1. Berk M, Dodd S, Kauer-Sant'anna M (2007). Dopamine dysregulation syndrome: implications for a dopamine hypothesis of bipolar disorder. Acta Psychiatr Scand, 434(suppl):41-9

2. Mittal VA, Neumann C, Saczawa M, Walker EF (2008). Longitudinal progression of movement abnormalities in relation to psychotic symptoms in adolescents at high risk of schizophrenia. Arch Gen Psychiatry, 65(2):165-71 Tenback DE, van Harten PN, Slooff CJ, van Os J; SOHO Study Group (2006). Tardive dyskinesia in schizophrenia is associated with prolactin-related sexual disturbances. Neuropsychopharm, 31:1832-7 
$8 b$

Samenvatting 
De bipolaire stoornis, beter bekend als manisch-depressieve stoornis, is een chronische ziekte die gekenmerkt wordt door extreme stemmingen. Ongeveer één op de honderd mensen ontwikkelt een bipolaire stoornis gedurende het leven. De term bipolaire stoornis verwijst naar een verzameling ziektebeelden die verschillen in ernst en een uiteenlopend ziektebeloop hebben. Het meeste bekende type bipolaire stoornis, ook wel type 1 genoemd, wordt gekenmerkt door een afwisseling van manische en depressieve periodes, al dan niet met psychotische symptomen. Tijdens een manische periode heeft een persoon vaak een overvloed aan energie, weinig behoefte aan slaap, moeite met concentreren en de behoefte om zeer veel te praten, vaak van de hak op de tak. Het gedrag wordt tijdens een manische fase vaak omschreven als 'ontremd'. Daarentegen kan iemand tijdens een depressieve periode een sombere stemming ervaren, moeilijk genieten van activiteiten waar iemand gewoonlijk wel plezier in heeft, moeite hebben om zich ergens toe te zetten en kan men te maken krijgen met schuldgevoelens en soms zelfs (ideeën over) zelfdoding. Naast manische en depressieve symptomen kan iemand psychotische symptomen ervaren, zoals stemmen horen, dingen zien die er niet zijn, het gevoel hebben achtergevolgd te worden of dat gedachten worden gelezen door anderen. Psychotische symptomen vinden meestal plaats tijdens manische periodes.

Een bipolaire stoornis kan een negatieve invloed hebben op verschillende aspecten van het leven van patiënten; iemand kan minder of niet meer in staat zijn om te werken, de kwaliteit van leven kan sterk verminderen, en het sociaal en cognitief functioneren kan aanzienlijk achteruit gaan. De bipolaire stoornis wordt geassocieerd met een zeer hoog percentage zelfdoding, dat bijna 28 maal hoger ligt dan in de algemene bevolking.

Middels de onderzoeken in dit proefschrift wilden we symptomen van de bipolaire stoornis op 2 nivo's bestuderen. Ten eerste, op een 'subklinisch' nivo, dat wil zeggen binnen de algemene bevolking. Binnen de algemene bevolking komen manische, depressieve en psychotische symptomen voor, zonder dat iemand hoeft te voldoen aan alle criteria van een diagnose bipolaire stoornis of een gerelateerd ziektebeeld. Binnen deze context wilden we onderzoeken wat het effect is van 
manische en/of depressieve symptomen op de aanwezigheid en persistentie van psychotische symptomen, en daarnaast op de impact die psychotische symptomen hebben op het dagelijks functioneren en mate waarin men hulp zoekt. Ten tweede, op een 'klinisch' nivo, dat wil zeggen binnen een populatie van patiënten die gediagnosticeerd is met een bipolaire stoornis. Binnen deze groep wilden we ziektekenmerken en factoren bestuderen die het beloop van het ziektebeeld op korte en lange termijn beïnvloeden.

Men kan veel over het ontstaan van een ziekte, het ziektebeloop en de factoren die deze beïnvloeden, te weten komen door grote groepen mensen gedurende een lange tijd te volgen. Wanneer hierbij geen interventie wordt gepleegd, zoals bijvoorbeeld het geven van nieuwe medicatie, wordt dit een observationeel onderzoek genoemd; er worden enkel gegevens verzameld gedurende een lange periode. Om onze onderzoeksvragen te beantwoorden konden we beschikken over de gegevens die waren verzameld binnen het kader van twee grote Europese observationele studies. In de EMBLEM studie (European Mania in Bipolar Longitudinal Evaluation of Medication) zijn 3549 patiënten met een bipolaire stoornis tot 2 jaar lang gevolgd, nadat zij nieuwe medicatie voorgeschreven hadden gekregen voor de behandeling van een acute manische periode. Hierdoor ontstond een zeer gevarieerde groep patiënten met uiteenlopende bijkomende stoornissen, zoals verslaving of angststoornissen, en grote verschillen in het ziektebeloop. Binnen deze groep werd onder andere informatie verzameld over het eventuele terugkeren van symptomen, ziekenhuisopnames, sociaal functioneren en de kwaliteit van leven.

De andere grote Europese studie, de EDSP (Early Developmental Stages of Psychopathology) is uitgevoerd in de algemene bevolking. De onderzoeksgroep was een representatieve steekproef van adolescenten en jongvolwassenen, van 14 tot 24 jaar bij start van de studie, wonend in München en omstreken. Deze groep werd tot 10.6 jaar gevolgd. Een observationele studie in de algemene bevolking kan inzicht geven in het bestaan van symptomen die gerelateerd zijn aan psychiatrische ziektebeelden, alsook de mechanismen die mensen beschermen of juist kwetsbaar maken voor het ontwikkelen van een psychiatrische stoornis. 


\section{Onze bevindingen}

De EDSP studie is gebruikt voor de analyses in hoofdstuk 2, waarbij associaties zijn onderzocht tussen de mate van manische en/of depressieve symptomen en psychotische symptomen die binnen de algemene bevolking voorkwamen. We vonden dat de meeste psychotische symptomen voorkwamen in de aanwezigheid van manische en/of depressieve symptomen. Daarnaast vonden we dat de persistentie en de impact van psychotische symptomen groter waren naarmate er meer manische en/of depressieve symptomen aanwezig waren. Deze bevindingen suggereren dat psychotische, manische en depressieve symptomen mogelijk een genetische vatbaarheid delen, ook binnen de algemene bevolking. Daarnaast is het mogelijk dat de aanwezigheid van manische en/of depressieve symptomen de oorzaak zijn van de persistentie en impact van psychotische symptomen, bijvoorbeeld middels een afwijkende manier van toekennen van emotionele relevantie aan gebeurtenissen.

Voor de analyses in hoofdstukken 3 tot en met 6 is de EMBLEM studie gebruikt. Het derde hoofdstuk onderzoekt factoren die de snelheid van symptoomverbetering kunnen beïnvloeden. Tot op heden is er veel onderzoek gedaan naar voorspellende factoren van symptoomverbetering na 3 maanden behandeling, maar deze studies negeren wat er tussen start- en eindpunt gebeurt. Verschillende factoren binnen de sociale en psychopathologische context bleken de snelheid van het verbeteren van manische symptomen negatief te beïnvloeden, zoals een algemeen ernstiger ziektebeeld in het voorgaande jaar, het ontstaan van de ziekte op jongere leeftijd, ongunstige sociale omstandigheden en een 'rapid cycling' patroon (hierbij ervaart een patiënt minstens 4 periodes van manie of depressie per jaar). De snelheid waarmee psychotische symptomen verbeterden werd beïnvloed door de ernst van manische en depressieve symptomen op baseline, terwijl de snelheid waarmee depressieve symptomen verbeterde niet beïnvloed werd door de ernst van manische en psychotische symptomen op baseline. 
In hoofdstuk 4 worden 3 separate groepen van manische patiënten onderzocht, die in eerder onderzoek werden onderscheiden op basis van factor analyse op baseline (hierbij worden groepen onderscheiden die sterk worden gekenmerkt door een klein aantal individuele symptomen of factoren). Eén van deze groepen werd gekenmerkt door het gebruik van verslavende middelen zoals alcohol, cannabis en andere drugs. Deze groep wordt doorgaans uitgesloten van onderzoek naar nieuwe geneesmiddelen, waardoor het interessant is om te testen of het onderscheid tussen deze groepen na 12 weken nog steeds bestaat, en of de groepen verschillen in behandelresponse laten zien. Het onderscheid tussen de groepen bleek inderdaad stabiel gedurende 12 weken behandeling. Daarbij reageerden 2 groepen significant slechter op de behandeling ten opzichte van de derde groep, waardoor deze bevinding relevant is binnen de dagelijkse behandelpraktijk.

Het is al langere tijd bekend dat het gebruik van cannabis een negatief effect heeft op het ziektebeloop van schizofrenie, een ziektebeeld dat op verschillende aspecten overlapt met de bipolaire stoornis. Ondanks dat cannabis frequent wordt gebruikt door patiënten met een bipolaire stoornis, is er weinig onderzoek gedaan naar een eventueel effect. In hoofdstuk 5 wordt getest wat de invloed is van cannabisgebruik op de klinische behandeluitkomst en sociale omstandigheden 1 jaar na de start van behandeling van een manische periode. Manische en psychotische symptomen waren ernstiger bij cannabisgebruikers, en zij bleken minder therapietrouw dan patiënten die geen cannabis gebruikten. Cannabisgebruikers waren daarnaast minder tevreden met hun leven en hadden minder vaak een relatie. Deze effecten van cannabisgebruik waren onafhankelijk van andere aspecten zoals leeftijd of gebruik van alcohol en andere drugs. Kortom, we vonden een onafhankelijk effect van cannabisgebruik op psychopathologie terwijl het effect op de sociale omstandigheden beperkt was.

Bewegingsstoornissen kunnen als bijwerking van antipsychotica optreden, welke worden voorgeschreven ter behandeling van schizofrenie en de bipolaire stoornis. Bij patiënten met schizofrenie zijn deze stoornissen uitgebreid onderzocht. Ondanks dat patiënten met een bipolaire stoornis mogelijk gevoeliger 
zijn voor deze stoornissen is er weinig onderzoek naar dit onderwerp gedaan. Uit onze analyse, beschreven in hoofdstuk 6, bleek dat de frequentie inderdaad hoog is: 1 op de 25 patiënten ontwikkelden gedurende 2 jaar specifieke bewegingsstoornissen, namelijk tardive dyskinesie en tardive dystonie. Ook waren we geïnteresseerd in welke mate deze bewegingsstoornissen geassocieerd waren met zowel symptomen van de bipolaire stoornis als specifieke ongewenste bijwerkingen zoals seksueel disfunctioneren. Dit wilden we onderzoeken in het kader van een recent gepubliceerd model dat stelt dat dopamine disfunctie op specifieke locaties in het brein ten grondslag ligt aan de manische en depressieve symptomen van de bipolaire stoornis ${ }^{1}$. Ook bewegingsstoornissen en seksuele functiestoornissen worden geassocieerd met dopamine disfunctie, in twee andere dopaminebanen in de hersenen. Associaties tussen bewegingsstoornissen enerzijds en symptomen van de bipolaire stoornis en ongewenste bijwerkingen anderzijds zou een indicatie kunnen zijn van een brede dopamine disfunctie, waarbij meerdere dopaminebanen betrokken zijn. Onze bevindingen bevestigen inderdaad deze hypothese; het ontwikkelen van bewegingsstoornissen bleek geassocieerd met ernstigere manische, psychotische en depressieve symptomen en seksuele functiestoornissen.

\section{Onze conclusies}

De brede definitie van de doelstelling van dit proefschrift resulteerde in uiteenlopende hypotheses en bevindingen op onderwerpen die tot op heden weinig aandacht hebben genoten in de wetenschappelijke literatuur. De bevindingen hebben nieuwe inzichten gegeven in het beloop van bipolaire symptomen, zowel op klinisch als subklinisch nivo. Onze resultaten zijn praktisch relevant, aangezien ze 1) potentiële manieren aanreiken om het ziektebeloop en de behandeluitkomsten te beïnvloeden, aangezien sommige factoren die impact hebben op het beloop en de uitkomst beïnvloedbaar kunnen zijn binnen de behandeling, zoals sociale omstandigheden of drugsgebruik; 2) in ieder geval helpen bij het creëren van inzicht in de status van individuele patiënten en het 
definiëren van realistische behandeldoelen, door bijvoorbeeld rekening te houden met complicerende factoren als cannabisgebruik.

Naast de resultaten uit de individuele analyses, viel ons een onverwacht patroon op in de bevindingen; de resultaten leken indirect te wijzen op een mogelijke rol van dopamine bij het ontstaan en het beloop van bipolaire symptomen. In hoofdstuk 7 wordt, naast een overzicht van onze resultaten, een poging ondernomen om onze bevindingen te interpreteren binnen de eerder genoemde dopamine theorie voor de bipolaire stoornis ${ }^{1}$. Ten eerste stelden we een uitbreiding voor van de bestaande dopamine theorie door psychotische symptomen toe te voegen. Hierbij lijkt het aannemelijk dat er een soortgelijk mechanisme op dopamine nivo ten grondslag ligt aan het ontstaan van psychotische symptomen zoals beschreven is voor manische symptomen ${ }^{1}$, gezien de bestaande literatuur over de rol van dopamine bij psychotische symptomen.

Zoals eerder beschreven, waren we geïnteresseerd in het concept van een brede dopamine disfunctie geassocieerd met de bipolaire stoornis. Inderdaad vonden we associaties tussen verschillende symptomen en bijwerkingen waarvan wordt aangenomen dat ze een zekere mate van dopamine disfunctie representeren in verschillende dopaminebanen in de hersenen. Daarnaast vonden we, met name in de analyses van hoofdstuk 3 en 5 , associaties tussen een hogere ernst van symptomen en een aantal externe factoren zoals cannabisgebruik en sociale omstandigheden. Van deze externe factoren is ook in de wetenschappelijke literatuur gesuggereerd dan wel gedemonstreerd dat ze een specifieke invloed kunnen hebben op dopamine activiteit in het brein. Een dergelijke theorie over een brede dopamine disfunctie is gesuggereerd met betrekking tot schizofrenie; verschillende onderzoeksgroepen rapporteerden associaties tussen bewegingsstoornissen enerzijds en psychotische symptomen en seksueel disfunctioneren anderzijds ${ }^{2,3}$. Echter, gezien het feit dat alle bevindingen in dit proefschrift wat betreft de rol van dopamine disfunctie in de ontwikkeling en het beloop van bipolaire symptomen van indirecte aard zijn, dienen deze hypothesen met de nodige kanttekeningen geïnterpreteerd te worden. Suggesties voor 
geschikte studiedesigns en hypotheses om dit onderwerp op de juiste wijze te onderzoeken worden beschreven in hoofdstuk 7 .

\section{Referenties}

1. Berk M, Dodd S, Kauer-Sant'anna M (2007). Dopamine dysregulation syndrome: implications for a dopamine hypothesis of bipolar disorder. Acta Psychiatr Scand, 434(suppl):41-9

2. Mittal VA, Neumann C, Saczawa M, Walker EF (2008). Longitudinal progression of movement abnormalities in relation to psychotic symptoms in adolescents at high risk of schizophrenia. Arch Gen Psychiatry, 65(2):165-71

0
0
0
0
0
0

3. Tenback DE, van Harten PN, Slooff CJ, van Os J; SOHO Study Group (2006). Tardive dyskinesia in schizophrenia is associated with prolactin-related sexual disturbances. Neuropsychopharm, 31:1832-7 


\section{Dankwoord}

Aan het einde van de rit hoort er nog even teruggeblikt te worden.

Jim, allereerst en in het bijzonder wil ik jou bedanken voor het initiëren van dit promotietraject en je enorme betrokkenheid onderweg. De vrijheid die je gaf in het ontwikkelen van ideeën, gecombineerd met een (altijd enthousiast) duwtje in de goede richting en uitstekende feedback, gaven de inspiratie en motivatie om papers op een zo hoog mogelijk niveau te tillen. Ik heb dankbaar gebruik gemaakt van je bodemloze wetenschappelijke en statistische kennis.

Diederik, het was duidelijk dat de combinatie bewegingsstoornissen en dopamine je na aan je hart lag. Ondanks je subtiele pogingen om verschillende analyses richting jouw aandachtsgebied te coachen, vielen de uiteenlopende puzzelstukjes pas in een late fase binnen een dopamine theorie op zijn plek. Het lijkt me geweldig om dit verder uit te bouwen! Dank voor je begeleiding, en ik vond het mooi om te zien hoeveel geluk en energie je uit je werk en je gezin haalt.

Maarten, je vond het een sport om me te challengen op de eerste 3 papers, waarbij je betrokken was. Gestart als copromotor in spe, maar je carrière in het bedrijfsleven kreeg voorrang. Vanaf de zijlijn heb je altijd nog interesse getoond, en was je nooit te beroerd voor een lesje diplomatiek handelen (helaas nog steeds- niet aan mij besteed). Leuk dat we elkaar privé niet uit het oog zijn verloren!

Rudolf van Olden \& Rob Kroes, dank voor het faciliteren van dit promotietraject bij Lilly. En Rudolf, je grijnzende opmerking 'Geen promotieonderzoek zonder frustratie, dit is geweldig!' wanneer er weer eens een paper was afgewezen bij een tijdschrift, sloeg de spijker op z'n kop en bleek een belangrijk leermoment...

Wanneer je enkel werkt met een enorme dataset en zelf geen patiënten behandelt, loop je het risico je blind te staren op gegevens en resultaten, waardoor je soms vergeet dat het om levensechte patiënten gaat en de resultaten daadwerkelijk meerwaarde kunnen hebben voor individuen. Elise Knoppert, ik heb veel bewondering en respect voor de manier waarop jij leeft voor je patiënten. Jouw passie voor het ziektebeeld heeft me geholpen de context en relevantie van dit proefschrift te blijven zien. 
Eduard Vieta y Josep Maria Haro: ¡muchas gracias por vuestra crítica constructiva y vuestro entusiasmo! Catherine Reed and Iris Goetz, thank you for reviewing and facilitating the EMBLEM papers. Mari-de-Gracia Dominguez, our collaboration was short but very successful!

(Ex-)Lilly mensen, bedankt voor de getoonde interesse en gezelligheid! In het bijzonder natuurlijk Monique en Emily. Monique, je bent een enorm sterke vrouw, ik heb veel respect voor hoe jij in het leven staat. Ik hoop dat het geluk je toe zal lachen, dat heb je inmiddels meer dan verdiend! Emily (wortel), onze cynische humor matcht ook heel goed zonder Irish Coffee. Goed om te zien dat je je draai de afgelopen jaren echt hebt gevonden! Meiden, bedankt voor de steun en gezelligheid!

Sabien, die squashballen hebben het zwaar te voorduren gehad in de afgelopen jaren, deze onveilige traditie moet zeker weer worden opgepakt zodra de zwangere buiken en naweeën achter de rug zijn. Ondanks dat onze vriendschap gedurende 10 jaar verschillende intensiteiten heeft gekend, zullen we elkaar nooit uit het oog verliezen.

Bas, Marleen, Jasja \& Silvia; de vaste gezelligheidsfactor in ons leven. Drie trouwerijen, 2 promoties, vele diploma's, 1 kindje, 2 vogels, 3 katten, 4 honden, 9 huizen, van tequila's in Mexico tot krodillenstaart in Kenia, van gekneusde billen in Oostenrijk tot de consequenties van een kipspiesje in de Turkse zon, eindeloos veel weekendjes met veel te veel honden, we hebben het allemaal meegemaakt. Bas, we hebben er inmiddels ruim 17 jaar vriendschap op zitten, echt die sok. Top dat je wilt paranimfen!

Diana, Erik, Kaylee \& Josephine, dank voor de afleiding, gezelligheid en natuurlijk het heerlijke eten! Ik kan iedereen die van lekker eten houdt oprecht aanraden een Indonesische familie in te trouwen :-) Fijn dat jullie mijn Mediterrane compensatiepogingen dapper doorstaan (en vervolgens rijst met hete kip klaarmaken).

Pap, mam \& Leon, met erg rommelige jaren achter de rug hoop ik dat jullie wat meer rust zullen vinden. Jullie plaatsvervangende stress van dit proefschrift valt gelukkig bij deze weg, zodat jullie je volledig kunnen storten op de nieuwe rollen als opa, oma en suikeroom, en gewoon lekker genieten! Lee, goed om je als paranimf naast me te hebben!

Boaz \& Peer, jullie hypomane afleidingtechnieken waren nuttig om het hoofd met regelmaat leeg te maken, maar bleken niet succesvol gezien dit 
eindresultaat. Milo en Odin...., tja, als jullie niet genoemd worden krijg ik ruzie met jullie baas.

Lieve Lise, iedere dag ben ik er opnieuw van overtuigd dat het niet leuker kan worden dan dit, en elke volgende dag bewijs je me weer het tegendeel. Ik zal ontzettend van jou en jouw ontwikkelingen blijven genieten, en hoop dat je trots zal zijn op het leven dat je zal leiden en de keuzes die je maakt.

Ferry, de laatste woorden zijn voor jou. Jij hebt me laten realiseren hoe belangrijk het is om bepaalde doelen in het leven zo hoog mogelijk te stellen en hier volledig voor te gaan. Ik betwijfel of ik dezelfde keuzes had gemaakt zonder jou aan mijn zij. Je eeuwige geduld is eindelijk beloond, vooral in de vorm van Lise. $\mathrm{Nu}$ we beiden onze 'eigen' projecten hebben afgerond, kunnen we ons volledig storten op onze fantastische gezamenlijke creatie. Ik geniet van ons leven samen, dikke beso. 
$\stackrel{ }{7}$

$\underset{\infty}{\infty}$ 


\section{Curriculum Vitae}

Inge van Rossum is geboren op 6 mei 1978 in IJsselstein. Van 1996 tot 2000 heeft zij Psychologie gestudeerd aan de Universiteit Utrecht, met als specialisatie Biologische Psychologie. Zij studeerde af bij de vakgroepen Kinderpsychiatrie (bij prof. dr. Herman van Engeland) en Volwassenenpsychiatrie (bij prof. dr. René Kahn) van het Universitair Medisch Centrum Utrecht. Hierna is zij gaan werken bij Lilly Nederland als Clinical Research Associate, en sinds 2007 in de rol als Medical Liaison met focus op de bipolaire stoornis en schizofrenie. In september 2005 begon zij haar promotie-onderzoek aan de vakgroep Psychiatrie en Neuropsychologie aan de Universiteit Maastricht. 
$\stackrel{N}{N}$

疍 


\section{Publications and presentations}

\section{Publications}

Winter-Van Rossum I, Boomsma M, Tenback D, Reed C, Van Os J. De invloed van cannabis op het ziektebeloop van de bipolaire stoornis: een longitudinale analyse. Accepted in Tijdschrift voor Psychiatrie

Miquel L, Usall J, Haro JM, Vieta E, Gonzalez-Pinto A, Van Rossum I, Nolen W. Gender differences in bipolar disorder outcomes: 12 month follow-up study. Submitted to Bipolar Disorders

Van Rossum I, Dominguez MG, Lieb R, Wittchen HU, Van Os J (2009). Affective dysregulation and reality distortion: A 10-year prospective study of their association and clinical relevance. Schizophr Bull, in press. Epub ahead of print, PMID: 19793794

Van Rossum I, Tenback D, Van Os J, the EMBLEM Advisory Board (2009). Bipolar disorder and dopamine function: an indirect approach focusing on tardive dyskinesia and dystonia. BMC Psychiatry, 28;9-16

Van Rossum I, Boomsma M, Tenback D, Reed C, Van Os J, the EMBLEM Advisory Board (2009). Does cannabis use impact on treatment outcome in bipolar illness? A longitudinal analysis. J Nerv Ment Disease, 197(1):35-40

Van Rossum I, Haro JM, Tenback D, Boomsma M, Goetz I, Vieta E, Van Os J, the EMBLEM Advisory Board (2008). Treatment outcome in distinct classes of mania. Eur Psychiatry, 23(5):360-7

Van Os J, Van Rossum I, Boomsma M, Vieta E, Goetz I, Reed C, Haro JM, the EMBLEM Advisory Board (2007). The social, psychopathological and consumer context of rate of symptom improvement in acute mania. Soc Psychiatry Psychiatr Epidemiol, 42(8):631-8

Van Goozen SH, Snoek H, Matthys W, Van Rossum I, Van Engeland H (2004). Evidence of fearlessness in behaviourally disordered children: a study on startle reflex modulation. J Child Psychol Psychiatry, 45(4):884-92 


\section{Oral presentations}

Social and Psychopathological Context of Rate of Symptom Improvement in Acute Mania. Stanley Conference on Bipolar Disorder, Barcelona, Spain, 2006 (plenary)

Sociale en psychopathologische context van de snelheid van symptoomverbetering in acute manie. Voorjaarscongres NVvP, Maastricht, 2007

Does cannabis use impact on treatment outcome in bipolar illness? A longitudinal analysis. International Conference of Bipolar Illness, Pittsburgh, United States of America, 7-9 June 2007

\section{Poster presentations}

Does cannabis use impact on treatment outcome in bipolar illness? A longitudinal analysis. Voorjaarscongres NVvP, Amsterdam, 2008

Social and Psychopathological Context of Rate of Treatment Outcome in Acute Mania. Winterworkshop Schizophrenia, Davos, Switzerland, 2006

Social and Psychopathological Context of Rate of Symptom Improvement in Acute Mania. Stanley Conference on Bipolar Disorder, Barcelona, Spain, 2006

Treatment Outcome in Distinct Classes of Mania in the EMBLEM study. Stanley Conference on Bipolar Disorder, Barcelona, Spain, 2006 